University of Redlands

\title{
Identifying Annual Brome Within Joshua Tree National Park
}

A Major Individual Project submitted in partial satisfaction of the requirements for the degree of Master of Science in Geographic Information Systems

by

Laura Elizabeth Horner

Mark Kumler, Ph.D., Committee Chair

Douglas Flewelling, Ph.D.

Sean Murphy, M.S.

April 2010 
Identifying Annual Brome Within Joshua Tree National Park

Copyright $(92010$

by

Laura Elizabeth Horner 
The report of Laura Elizabeth Horner is approved.
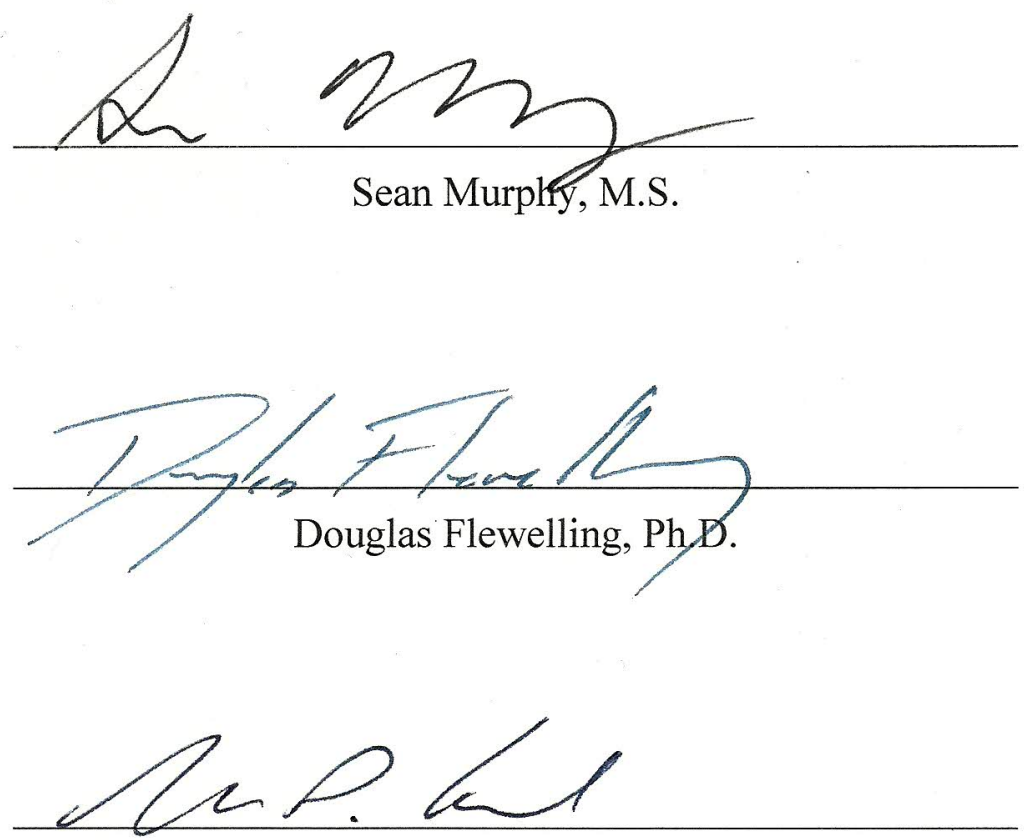

Mark Kumler, Ph.D., Committee Chair

April 2010 



\section{Acknowledgements}

It is important that I acknowledge all of the wonderful folks who helped me finish this project and this program. First, thank you to Dr. Philip Munger and the BASF Corporation for providing support and funding to the project. Next, thank you to Lori Weingartner, Biological Technician from Joshua Tree National Park, for providing the brome data that allowed me to complete the analysis. A giant thank you goes to Sean Murphy for providing data, advice, and encouragement throughout the project. Next, I cannot thank the faculty at the MS GIS program enough for helping me through this experience. Thank you Doug for introducing me to GIS (literally, in undergrad). Thank you Max for getting me started. Thank you Mark for getting me finished. Thank you Ruben for being my technology hero. Thank you Debbie for EVERYTHING! The students of the MS GIS program also deserve a thank you. To the members of the notorious Cohort 14, thanks for the memories my friends. A ginormous amount of gratitude goes out to my family: Mom, Dan, Jen, Josh for being a constant source of support and encouragement, a sounding board, a shoulder to cry on, an ear to talk off, and sometimes a big kick in the butt. 



\author{
Abstract \\ Identifying Annual Brome Within Joshua Tree National Park \\ by \\ Laura Elizabeth Horner
}

\begin{abstract}
Non-native invasive grass species such as bromus tectorum and bromus rubens (annual brome) negatively impact the native ecosystems of the Mojave Desert. Not only do these grasses prevent the growth of native plant species, they also serve as highly flammable fuels that increase the frequency and scale of devastating wildfire. Using remote-sensed Landsat data, locations of known annual brome presence, areas of human disturbance, and historic fire boundaries, this project serves to accurately identify and map the current extent of annual brome within Joshua Tree National Park in order to support land management and fire mitigation efforts.
\end{abstract}





\section{Table of Contents}

Chapter 1 - Introduction ............................................................................... 1

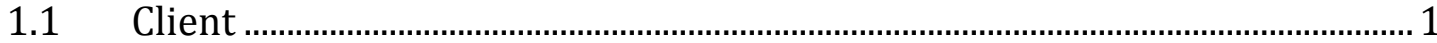

$1.2 \quad$ Problem Statement ................................................................................................ 2

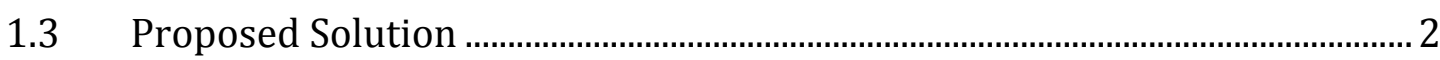

1.3.1 Goals and Objectives ........................................................................................

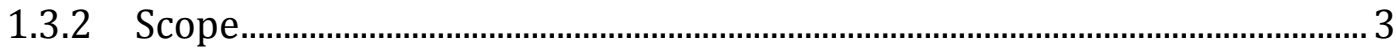

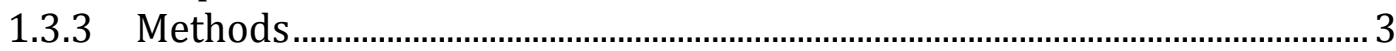

$1.4 \quad$ Audience ..................................................................................................................... 4

1.5 Overview of the Rest of this Report...................................................................... 4

Chapter 2 - Background and Literature Review..................................................... 5

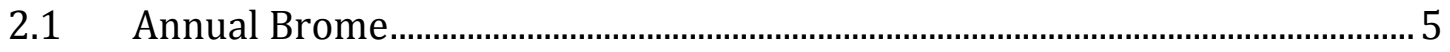

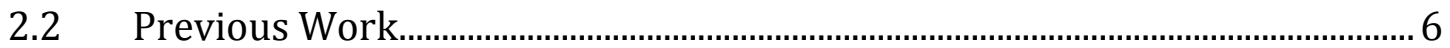

2.2.1 The Wildland/Urban Interface................................................................6

2.2.2 Annual Brome (Bromus tectorum) Wildfire Fuel Breaks..............................

2.2.3 Integrating an Agent-based Model ..................................................................

2.3 Joshua Tree National Park and Annual Brome ................................................... 8

2.4 Use of Plateau in National Parks .......................................................................

2.5 Modeling Annual Brome Extent ...........................................................................

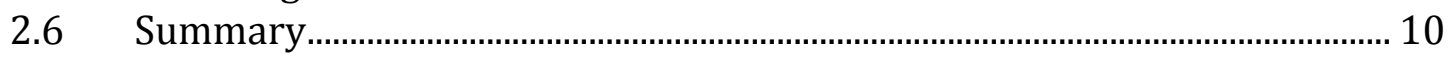

Chapter 3 - Database Design ......................................................................11

3.1 Conceptual Data Model............................................................................................. 11

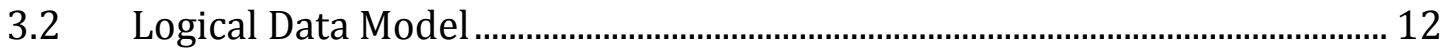

3.2.1 Fire Dataset............................................................................................. 12

3.2.2 Disturbance Dataset..................................................................................... 12

3.2.3 Other Feature Classes........................................................................................ 12

3.2.4 Raster Data ....................................................................................................... 13

3.3 Data Sources.......................................................................................................... 13

3.4 Data Collection Methods .................................................................................. 14

3.5 Data Scrubbing and Loading ........................................................................... 16

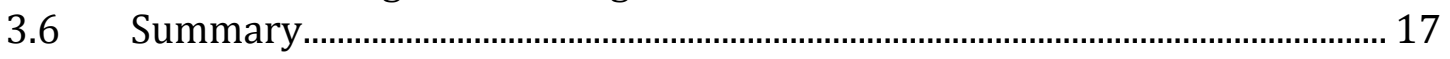

Chapter 4 - Image Processing and Analysis …….............................................19

4.1 Preparing Landsat TM Imagery for Vegetation Index Calculation.............. 19

4.1.1 Converting Raw Imagery Data to At-Sensor Spectral Radiance .............. 19

4.1.2 Converting Spectral Radiance to Top-Of-Atmosphere Reflectance...... 20

$4.2 \quad$ Vegetation Index Calculation ........................................................................... 21

4.2.1 Normalized Difference Vegetation Index.................................................... 21

4.2.2 Soil Adjusted Vegetation Index...................................................................... 23 
4.3 Difference in Vegetation Index Calculation......................................................25

4.3.1 Normalized Difference Vegetation Index ……………………………….....25

4.3.2 Soil Adjusted Vegetation Index …………………………………………....2

$4.4 \quad$ Summary ……………………………………………………………………...28

Chapter 5 - Map Interface Development ..........................................................29

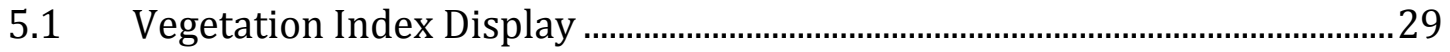

5.2 Annual Brome Presence ........................................................................................32

$5.3 \quad$ Historic Fire Classification and Display ………………………………………..32

5.4 Symbolizing Human Disturbance.......................................................................34

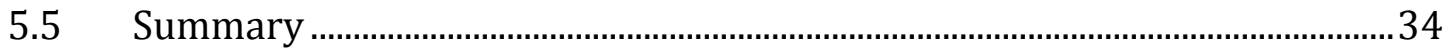

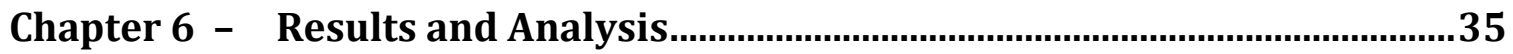

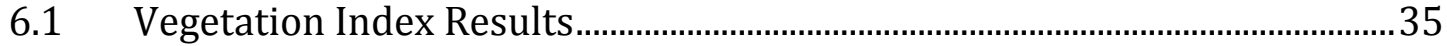

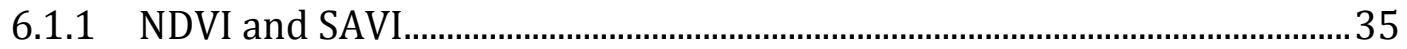

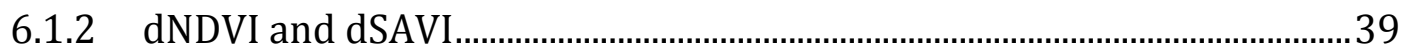

6.2 Determining Annual Brome Presence ………………………………………...42

6.2.1 Using Vegetation Indices...............................................................................4

6.2.2 Using Known Locations of Brome................................................................4

6.2.3 Using Historic Fire Boundaries .....................................................................4

6.2.4 Using Areas of Human Disturbance .............................................................51

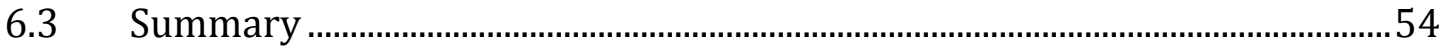

Chapter 7 - Conclusions and Future Work …….................................................55

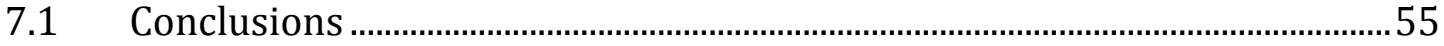

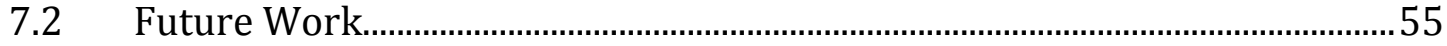

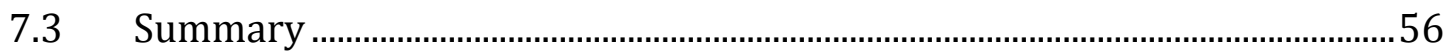

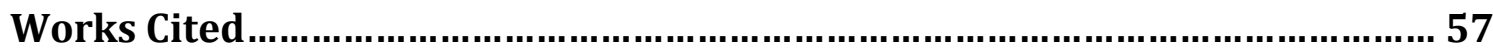

Appendix A. Calculation of Wet/Dry Years ……...........................................59

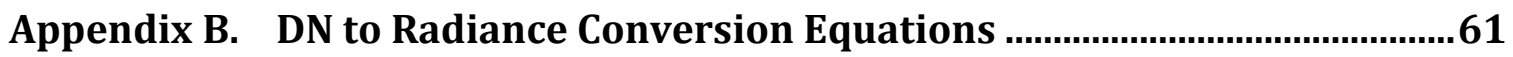

Appendix C. Radiance to Reflectance Conversion Equations .............................62 


\section{Table of Figures}

Figure 3-1: Organization of the Geodatabase

Figure 3-2: Excerpt from BoulderPlots_Bro_pres_abs_Attribute Table .................. 13

Figure 3-3: USGS Earth Explorer Dataset Selection .............................................. 15

Figure 3-4: USGS Earth Explorer Search Criteria................................................... 16

Figure 3-5: Definition Query Used to Create Campgrounds Feature Class ............... 17

Figure 4-1: Example of DN to radiance conversion equation ..................................20

Figure 4-2: Example of radiance to reflectance conversion equation.......................21

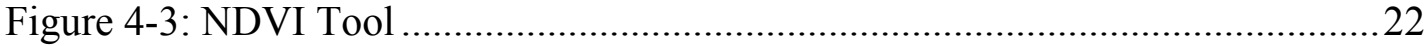

Figure 4-4: Example of NDVI Tool Parameters .......................................................2 22

Figure 4-5: SAVI Tool............................................................................................ 24

Figure 4-6: Example of SAVI Tool Parameters ........................................................25

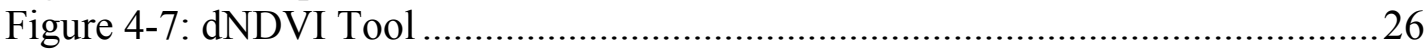

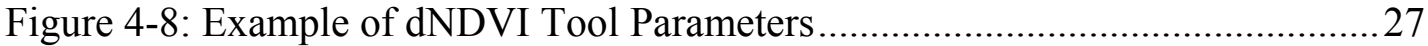

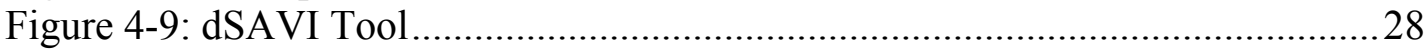

Figure 4-10: Example of dSAVI Tool Parameters .................................................. 28

Figure 5-1: Vegetation Index Classification Values ................................................. 30

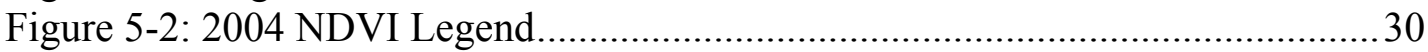

Figure 5-3: Difference in Vegetation Index Classification Values........................... 31

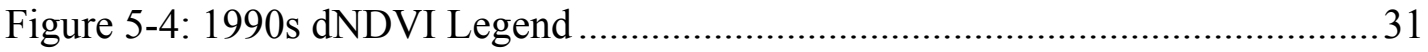

Figure 5-5: Wildfire Point Data Legend ................................................................... 32

Figure 5-6: Wildfire Polygon Data Legend, Custom Fill Symbol............................. 33

Figure 5-7: Symbolization of Fire Dataset in Map Interface......................................33

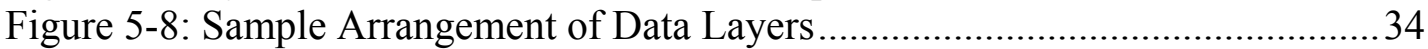

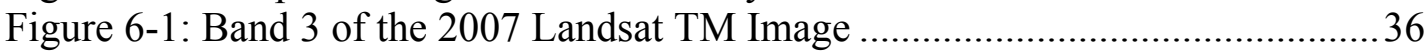

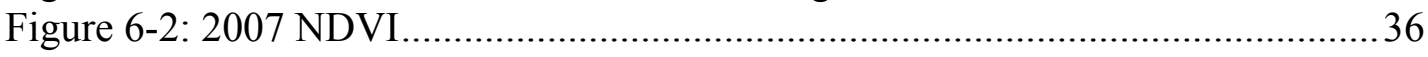

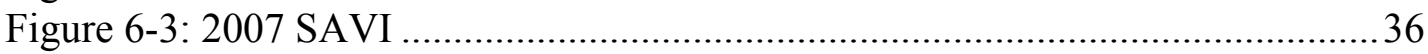

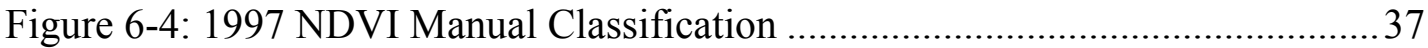

Figure 6-5: 1997 SAVI Manual Classification ........................................................ 37

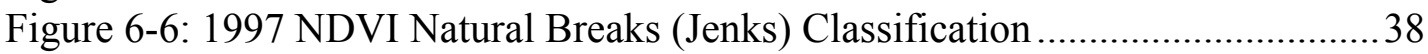

Figure 6-7: 1997 SAVI Natural Breaks (Jenks) Classification................................. 38

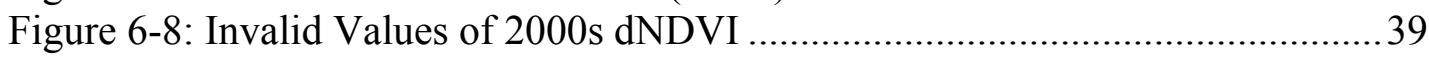

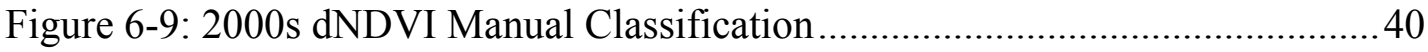

Figure 6-10: 2000s dSAVI Manual Classification............................................... 40

Figure 6-11: Improved 2000s dNDVI Manual Classification .................................. 41

Figure 6-12: Improved 2000s dSAVI Manual Classification ................................... 42

Figure 6-13: Areas Excluded from Visual Analysis ............................................... 43

Figure 6-14: Legend used to analyze Figures 15 - 17 ......................................43

Figure 6-15: 1980s dNDVI and dSAVI Showing Possible Brome Infestation .........44

Figure 6-16: 1990s dNDVI and dSAVI Showing Possible Brome Infestation .........45

Figure 6-17: 2000s dNDVI and dSAVI Showing Possible Brome Infestation .........46

Figure 6-18: 2000s dNDVI and dSAVI with Annual Brome Presence Points .......... 48

Figure 6-19: 1990s Fire and 2000s dNDVI and dSAVI .........................................50

Figure 6-20: 2000s dNDVI and dSAVI, Roads, and Trails ....................................52 
Figure 6-21: 2000s dSAVI, Human Disturbance, Brome Presence Points ............... 53

Figure 6-22: 2000s dSAVI and Human Disturbance ............................................. 54 


\section{List of Tables}

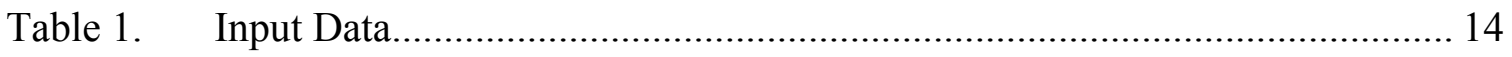

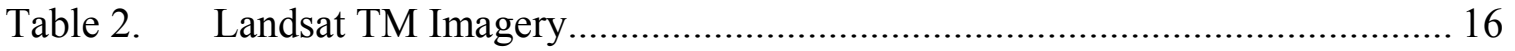

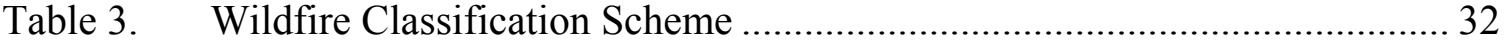

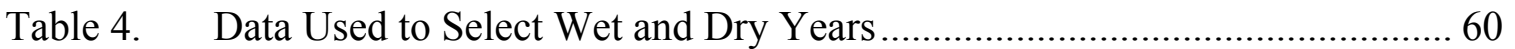





\section{List of Acronyms and Definitions}

$\begin{array}{ll}\text { ABMS } & \text { Agent-based Modeling and Simulation } \\ \text { AVHRR } & \text { Advanced Very High Resolution Radiometer } \\ \text { DN } & \text { Digital Number } \\ \text { dNDVI } & \text { Difference in Normalized Difference Vegetation Index } \\ \text { dSAVI } & \text { Difference in Soil Adjusted Vegetation Index } \\ \text { GIS } & \text { Geographic Information System } \\ \text { JTNP } & \text { Joshua Tree National Park } \\ \text { NDVI } & \text { Normalized Difference Vegetation Index } \\ \text { NPS } & \text { National Park Service } \\ \text { SAVI } & \text { Soil Adjusted Vegetation Index } \\ \text { USFS } & \text { United States Forest Service } \\ \text { USGS } & \text { United States Geological Survey } \\ \text { WUI } & \text { Wildland Urban Interface }\end{array}$





\section{Chapter 1 - Introduction}

Annual brome, including the species Bromus tectorum and Bromus rubens, is a group of non-native grasses that increases the frequency and severity of wildfires in the western United States (Murphy, 2008). Annual brome matures earlier than native species, becoming a highly flammable dry fuel causing wildfires to burn large areas of vegetation quickly (Bossard, Randall, \& Hoshovsky, 2000). By shortening the fire cycle and increasing the frequency of wildfires, annual brome causes the destruction of native habitat and enables its own dominance of the landscape (Bossard, Randall, \& Hoshovsky, 2000). Land managers have sought to curtail this destruction by controlling the spread of these invasive grasses. Appropriately placed fire breaks are one way to fight the effects of annual brome on an area's fire cycle. The National Park Service and its land managers need to know where annual brome intensifies fire danger in order to mitigate wildfire with effective fire breaks. Joshua Tree National Park is an example of a native habitat suffering from a shortened fire cycle and in need of annual brome control, specifically control of bromus tectorum and bromus rubens. A geographic information system (GIS) could empower land managers to solve the problem of annual brome. The purpose of this project's GIS is to create an accurate mapping of the grasses' extent that, when paired with a model of the occurrence of fire danger, would give land managers the information necessary to identify appropriate areas for fire breaks.

This chapter describes the remote sensing project that was completed to support fire management in Joshua Tree National Park. The project's client is introduced and the client's role in the project is described. The problem of annual brome in the west and in Joshua Tree National Park is defined, as well as the solution for supporting the management of fire danger. The goals and objectives for the project are outlined, along with the project's scope. Lastly, the methodology of the solution is revealed.

\subsection{Client}

The project's primary client is the BASF Corporation. BASF has also been the client for three annual brome projects completed previously at the University of Redlands. BASF, the world's leading multinational chemical corporation, offers "high-quality products" and "intelligent system solutions" (BASF, 2009a). One of these solutions is the herbicide Plateau (Imazapic). Its product profile states that Plateau is used in "selective weeding and seedhead suppression applications, and in creating fire breaks and safety zones" (BASF, 2009b). The herbicide is able to prevent growth of specific species and does not affect native plants or animals. Plateau can be used as a fire management solution because it is able to prevent annual brome from growing, thus creating fire breaks.

The contact at BASF is Dr. Philip Munger, a Senior Biology Area Manager. The client requested continuation and incorporation of the three previous annual brome projects. These previous projects were completed with the goal of creating a GIS that suggested fuel break locations to land managers in order to give them the opportunity to build more effective fire breaks with BASF's product Plateau.

The secondary client, and consequently the study area for the project, is Joshua Tree National Park (JTNP). JTNP's plant and wildlife communities became protected when 
the area first achieved National Monument status in 1936 (JTNP, 2009a). The monument was elevated to National Park status in 1994 and today encompasses over 792,000 acres of land, with over 591,000 acres designated as wilderness (JTNP, 2009a). The park consists of high and low desert habitats (JTNP, 2006a). The low desert, the Colorado Desert, lies in the south end of the park and is characterized by its arid landscape and creosote bush (JTNP, 2006a). The high desert, the Mojave Desert, lies in the northwest end of the park and contains its namesake Joshua tree (JTNP, 2006a). The Mojave Desert is cooler and wetter than the Colorado (JTNP, 2006a). These elements, combined with the Mojave's higher elevation, makes it vulnerable to annual brome infestation. The National Park Service recognizes cheatgrass (bromus tectorum) and red brome (bromus rubens) as two of the main factors in shortening the natural fire cycle in the Mojave from 100 years to between 5 and 30 years (JTNP, 2006b). The project's study area is in this north-western Mojave Desert area within Joshua Tree National Park due to its vulnerability to annual brome.

The contact at Joshua Tree National Park is Sean Murphy, a GIS Specialist, who completed one of the previous projects for BASF (Murphy, 2008). This project builds upon his work and two previous projects that will be summarized in the following chapter. Murphy provided data and expert guidance to the project.

\subsection{Problem Statement}

Joshua Tree National Park has an annual brome problem and BASF is willing to provide a solution. If BASF can provide a tool to its Plateau users that will show where annual brome exists and where it is likely to spread, land managers can use this information to build fire breaks and potentially mitigate fire danger. Before this type of tool could be developed for JTNP, the extent of annual brome within the park needed to be accurately identified and mapped. This project focused on delivering valuable information to both parties concerning annual brome location.

\subsection{Proposed Solution}

The proposed solution to BASF's information problem was an ArcGIS desktop application (geodatabase viewed within an ArcMap document) that would clearly display analysis results to land managers in order to support their fire mitigation efforts. The system was designed to give managers at Joshua Tree National Park an accurate representation of annual brome within the park, thus empowering them to better manage the park's annual brome problem. Biologists at Joshua Tree National Park already knew they had an annual brome problem; this map application would tell them where they had an annual brome problem. Equipped with annual brome extent information, land managers would have the tools they needed to apply BASF's fire management solution, Plateau. The proposed system included remotely sensed data to show the past and current extent of annual brome in relation to historic fire disturbances and areas of human disturbance. 


\subsubsection{Goals and Objectives}

The goals of this project were to build upon previous annual brome studies and to create a tool to protect national park land from devastating wildfires. The objectives of the project were: to provide a current extent of annual brome within Joshua Tree National Park, to map past annual brome extents to be used to analyze annual brome spread, and to map areas of human disturbance and historic fire disturbance to be used to analyze the effects these disturbances have on annual brome growth within the park.

\subsubsection{Scope}

What began as a systems development project quickly became an applied research project as the literature review will explain in Chapter 2. This project serves as a case study for this type of fire management in national parks. Analysis was limited to the study area, located in the northwest section of Joshua Tree National Park. Analysis did not include field verification of remote sensed results. The GIS was designed to be the first step in the development of an annual brome management decision support system the park could create in order to utilize Plateau. The scope of the project included delivery of a geodatabase containing analysis results, a map document displaying the results, and a project report. The project was completed on a Dell Precision M4300 laptop computer using ArcGIS version 9.3.1 software. The client understood that this was a case study, and a prototype solution was not ready to be implemented.

\subsubsection{Methods}

The first step to completing this project was to determine the best method for modeling the existence and spread of annual brome. Given the data available, it was decided that Bradley and Mustard's (2005) methods of using Landsat data to calculate the difference in vegetation indices would be best. The reasoning behind this decision can be found in Chapter 2.

Once the remote sensing technique was chosen, the data was collected and loaded into a file geodatabase according to the database design discussed in Chapter 3. Vector data was collected from Joshua Tree National Park and Landsat TM imagery was obtained from the United States Geological Survey (USGS).

Spatial Analyst, ESRI's extension to ArcGIS, was used to convert the Landsat raster values to radiance and then to reflectance in order to compute the Normalized Difference Vegetation Index (NDVI) and the Soil Adjusted Vegetation Index (SAVI). Spatial

Analyst was also used to calculate the differences in the NDVI and the SAVI over a 30year period to predict the current presence of annual brome. With the differences in NDVI and SAVI calculated, the presence of annual brome could be determined. A visual analysis of historic fire boundaries, areas of human disturbance, and past and current extents of annual brome could then be undertaken to determine relationships between disturbances and annual brome growth in JTNP. 


\subsection{Audience}

This project was designed to provide valuable information to the primary client, the BASF Corporation, and the secondary client, Joshua Tree National Park. The findings of this report may also benefit other land/resource managers or scientists interested in modeling the existence and spread of annual brome using remote sensing techniques. The reader is not expected to have an extensive knowledge of geographic information systems (GIS).

\subsection{Overview of the Rest of this Report}

Chapter 1 introduced the problem addressed in the project and the proposed solution. Chapter 2 reviews the literature researched to complete the project and provides important background to the problem. Chapter 3 introduces the data used in the project and discusses the design of the project database, how the data were collected, and how they were loaded into the final database. Chapter 4 and 5 describe the implementation of the proposed solution to the project problem. Chapter 4 outlines the calculation of the vegetation indices used in the analysis of the project while Chapter 5 describes the map interface that was developed. Chapter 6 provides the results of the vegetation index calculation and the analysis of those results. Chapter 7 concludes the report, discusses the success of the project, and provides suggestions for future work. 


\section{Chapter 2 - Background and Literature Review}

With the problem clearly stated, the solution proposed, and the methodology introduced, it is important to understand the background of the problem and the literature researched to support the choice of methodology. This chapter reviews the literature researched in order to answer the important questions associated with the project: What is annual brome and why is it problematic? Why is Joshua Tree National Park concerned about annual brome? Will Joshua Tree National Park consider Plateau as a land management solution? How will annual brome be identified and modeled in Joshua Tree National Park?

\subsection{Annual Brome}

In this paper, the invasive plant species bromus tectorum and bromus rubens are referred to collectively as annual brome. Both species are present in the project's study area.

Bromus tectorum, Latin for "brome of the roofs," was named for its original straw habitat in the thatched roofs of the Mediterranean region (Skinner, Ogle, St. John, Briggs, $\&$ Neese, 2008). The grass grows between 1 and 24 inches high, changing color as it matures from bright green, to reddish, to tan (Young, 2000). In addition to the Mediterranean, the grass is native to northern Africa and southwestern Asia, growing at elevations from sea level to 5,000 feet and in areas with average precipitation from 6 to 22 inches. Its sharp, hairy seeds are carried by wind, transported in grain seed or hay, or caught in animal fur or human clothing, spreading the invasive species to new habitats. Bromus tectorum, also known as cheatgrass, has spread through Europe, southern Russia, west central Asia, North America, Japan, South Africa, Australia, New Zealand, Iceland, and Greenland (Young, 2000). The grass spread from the eastern United States to the western United States in as little as 40 years in the late 1800's, and is now found in 46 of the 50 states.

Cheatgrass is able to dominate an area quickly and completely because of its flexible germination, extensive seed production, and rapid growth rate. It can germinate in fall or spring, depending on precipitation, in varied temperatures, and with little to no soil coverage (Young, 2000). Each plant, large or small, has the potential to produce at least 300 seeds per season. If a seed does not germinate and produce a plant, it can lie dormant and viable in the ground for up to three years, even in high temperatures and after wildfires. Cheatgrass seedbanks can hold up to twice as many potential plants as there are established plants, thus supporting continuous germination. Once germination occurs, each seedling grows quickly, producing shoots in the spring until moisture is depleted, then growing roots deeply and laterally in the fall and winter. These lateral roots allow cheatgrass to conquer competing vegetation because they have the "capability to reduce soil moisture to the permanent wilting point to a depth of 28 inches" (Young, 2000, "How Does It Grow and Reproduce?," para. 4). Cheatgrass is a highly invasive species because of its impressive seed production, ability to establish viable seedbanks, and its ability to establish plants and roots before native vegetation.

Bromus rubens, also known as red brome, is similar to bromus tectorum in several aspects. Red brome grows up to 16 inches in height, changing in color from bright green, to purplish, to tan as it matures (Brooks, 2000). The grass is native to northern Africa, 
southern Europe, and southwestern Asia, growing in elevations from sea level to 4,260 feet, and preferring "stony or sandy soils of cultivated fields and rangelands in arid to mesic scrub and steppe regions" (Brooks, 2000, "Where Did It Come From and How is It Spread?," para. 1). Like cheatgrass, red brome seeds are spread locally by wind, and carried longer distances in animal fur or human clothing. The grass was established in California in 1848 and was common in the Mojave Desert by 1950.

Red brome growth is not as flexible as cheatgrass growth, but the species is considered to be a winter annual, germinating in the fall and growing in the spring until it exhausts the moisture in the soil. The red brome seedbank is comparable to the cheatgrass seedbank in that seeds are able to lie dormant for up to three years in the soil. The plant itself can survive up to a year if it is located near anthropogenic sources of water, but even in desert regions, dead stems can remain rooted in the ground for up to three years.

Annual brome is a detriment to native habitat for several reasons. Both cheatgrass and red brome dominate native vegetation and convert the desert landscape to non-native annual grassland (Young, 2000; Brooks, 2000). Once established in a region, annual brome negatively affects the "frequency, extent, and timing of wildfires" (Young, 2000, "What Problems Does It Cause?," para. 2). The highly flammable grasses increase the likelihood of fire in an area, as well as increase the rate at which these devastating wildfires will spread. Fueled by annual brome, wildfires destroy native vegetation, allowing the early-maturing grasses to repopulate an area before native vegetation has a chance to re-grow and re-establish in the region. In addition to native vegetation, native reptile species like the threatened desert tortoise get caught in these fast-burning fires (Brooks, 2000). As Peterson (2003) observes, annual brome and fire together form a positive feedback loop that destroys native ecosystems and the species within those ecosystems. It is clear that annual brome is an effective and destructive invader. Complete annual brome dominance is dangerous to natural habitats and effective annual brome control is needed.

\subsection{Previous Work}

This project is a continuation of three previous projects conducted at the University of Redlands. Each project will be summarized to show how this project incorporates the previous three.

\subsubsection{The Wildland/Urban Interface: Cheatgrass, Fire Danger, and Fuel Breaks}

Esh's objective was to create and combine models of cheatgrass habitat and high-fire danger zones in order to locate possible fuel breaks within her case study area of the Wildland Urban Interface (WUI) in Big Bear, California. She built a modeling template application with a user's manual designed to "provide the BASF Corporation, land managers, city planners, and insurance companies with a GIS tool for decision support on protecting urban communities and surrounding wildlands" (Esh, 2006, p. vii).

Esh combined elements of J. Gillham's (2001) dissertation and expert advice from ESRI staff to create her Cheatgrass Habitat Model that included aspect, elevation, fire history, fuel reduction zones, roads, and urban areas as habitat suitability parameters. She used the United States Forest Service (USFS) 13 Fire Fuel Models to develop her 
Fire Danger Model that reclassified vegetation into areas of high and null fire danger. Citing the lack of clear fuel break criteria, Esh described her third model, the Fuel Break Model, as an analytical tool that added the results of the Cheatgrass Habitat Model and the Fire Danger Model and displayed possible fuel break locations.

\subsubsection{Annual Brome (Bromus tectorum) Wildfire Fuel Breaks: Web-enabled GIS Wildfire Model Decision Support System}

Armstrong's objective was to identify areas to build fuel breaks, like Esh (2006), but also to incorporate Web functionality. He included a model for both cheatgrass habitat suitability and wildfire danger, but also utilized Web services to contribute additional GIS data (Armstrong, 2007). Armstrong built a Web-enabled GIS decision support system, a Web service, and user interface that made fuel break analysis and installation information available to users via the Web.

Armstrong designed his project with a specific use case in mind. He wanted a user to be able to answer six questions with his Web service: Where is my property? Where is annual brome likely to occur? Where is wildfire danger likely to occur? Which areas are in the Wildfire Urban Interface (WUI)? Where are potential good locations for firebreaks for annual brome wildfire danger? How do I install a firebreak?

To answer the question of where annual brome is likely to occur, Armstrong chose to deviate from the cheatgrass model parameters used by Esh and base his model on the work of Bradley and Mustard (2006). Bradley and Mustard (2006) exclusively researched predictive parameters for cheatgrass, while J. Gillham (2001) focused on five invasive species not including cheatgrass. For this reason, Armstrong used the model parameters developed particularly for cheatgrass: aspect, elevation, roads, hydrologic channels, cultivation, power lines, and existing cheatgrass extent. Bradley and Mustard (2006) identified these parameters by remote sensing Landsat data for areas of Nevada. They had also used remote sensing to detect the extent of cheatgrass in an earlier study (Bradley \& Mustard, 2005), following the work of Peterson (2003) who had mapped cheatgrass across a large portion of Nevada and had published his GIS data. Armstrong chose Nevada as his study area to utilize Peterson's existing cheatgrass data as a parameter in his annual brome predictive model. He noted that expanding the predictive model beyond areas with a mapped cheatgrass presence would require a replication of the type of analysis completed by Bradley and Mustard (2005) or Peterson (2003) (Armstrong, 2007).

Armstrong used external Web map services to answer his use-case questions about WUI locations and areas of wildfire danger. To suggest potential locations for firebreaks, he combined the outputs of his annual brome predictive model, the WUI map service, and the wildfire danger model. Finally, he provided links to fuel break installation information in the user interface, including links to mechanical and herbicidal solutions.

\subsubsection{Integrating an Agent-based Model into a Web-enabled Annual Brome Land Management System}

Murphy's objective was not only to identify fuel breaks, like Esh (2006), and to build a Web-enabled decision support system, like Armstrong (2007), but to enhance the system by incorporating Agent-based Modeling and Simulation (ABMS) to simulate future 
annual brome extents (Murphy, 2008). Murphy built an agent-based model using Agent Analyst, an interface between ABMS software Repast and ArcGIS, and integrated the model into Armstrong's existing Web application. This integration was designed to give users the ability to visualize and compare current and future areas of annual brome infestation. In keeping with his decision to enhance the work of Armstrong (2007), Murphy chose Nevada as his study area.

Murphy's agent-based model simulated cheatgrass seed migration and successful germination. He developed a set of rules to dictate the behavior of the agents - the seeds - in the simulation. The first rule determined that a seed's primary means of movement is the wind. The second rule recognized the influence of vegetation density on primary seed movement, stating that wind could move seeds further through less densely vegetated areas. The third rule identified automobiles as the secondary means of seed movement, stating that seeds get caught in tire treads and passing cars generate enough wind to displace seeds. The fourth rule established germination probability. Murphy used Armstrong's habitat suitability model developed from the predictive parameters discovered by Bradley and Mustard (2006) to obtain probabilities of germination which then were used as variables in the germination simulation.

\subsection{Joshua Tree National Park and Annual Brome}

Officials at Joshua Tree National Park identify the establishment of annual brome as a cause for an increase in frequency and severity of wildfire within the park in its Fire Management Plan Environmental Assessment (Mangi Environmental Group, 2005). Before the infestation of annual brome, desert wildfires were a rare occurrence, usually caused by lightning, and burned less than an acre of land given the sparse vegetation (Mangi Environmental Group, 2005). Annual brome fills in the gaps between vegetation, especially in years where precipitation is above average, thus allowing fire to devastate larger areas of land (Brooks \& Matchett, 2006). While several native desert species are intolerant to fires, there is evidence that fires actually strengthen annual brome dominance because of increased availability of soil nutrients after a burn (Mangi Environmental Group, 2005). There is also some evidence that an invasive plant/fire regime cycle may be establishing in the region (Brooks \& Matchett, 2006). Since 1965, JTNP has suffered larger and more frequent wildfires (Mangi Environmental Group, 2005). The Quail Mountain fire burned 6,000 acres in 1979, the Covington fire burned 5,158 acres in 1995, and in 1999, the Juniper Complex fire burned the most acres of slow-growing habitat in the park's history, 13,894 acres (JTNP, 2009b).

\subsection{Use of Plateau in National Parks}

Joshua Tree National Park has not experimented with the application of herbicides to limit the spread of wildfires, but Plateau would help the park meet many of the objectives outlined in its fire management plan. Currently, the park's fire management plan calls for full suppression of all fires, whether they are ignited naturally or by humans (JTNP, 2009b). This plan aligns with the fire management objectives identified by the National Park Service (NPS) and the park itself (Mangi Environmental Group, 2005). Some of these objectives are: "Protect human life and property both within and adjacent to park areas, ... perpetuate, restore, replace, or replicate natural processes to the greatest extent 
practicable, ... protect natural and cultural resources and intrinsic values from unacceptable impacts attributed to fire and fire management activities, ... and ... manage land and wilderness to preserve them unimpaired for future generations" (Mangi Environmental Group, 2005, pp. 1-5, 1-6).

There is a precedent for using Plateau within another national park. Biologists at Zion National Park decided to apply Plateau within park boundaries after the cheatgrassfueled Kolob Fire in June, 2006 (Fuhrmann, Weber, \& Decker, 2009). This was the largest fire in the park's history, burning 10,524 acres of native vegetation within the park and 7,107 acres in areas surrounding the park. The Kolob Fire was similar in size to the Juniper Complex fire, the largest wildfire in JTNP's history, which was also fueled by annual brome.

Zion National Park staff recognized that the Kolob Fire left the native plants and historic fire regimes vulnerable to cheatgrass invasion (Fuhrmann, Weber, \& Decker, 2009). Following the recommendations of a USGS/NPS Zion Canyon vegetation research project, park managers decided Plateau would be the most effective solution for suppressing non-native annual grass growth after a fire disturbance like the Kolob Fire. These recommendations were based on the fact that Plateau specifically targets annual brome, is nontoxic to a large array of animals because of its lack of bioaccumulation, and has shown limited lateral movement in soil. The Zion Canyon study also determined that Plateau had "little or no negative effect on perennial natives" but in fact promoted their growth because of decreased cheatgrass competition (Fuhrmann, Weber, \& Decker, 2009, p. 132).

After application in 2006, Zion biologists found that Plateau had reduced the cheatgrass invasion, but because of "uncontrollable environmental conditions at the time of the original aerial spraying," native plant species had not taken complete control over the burned areas (Eaker \& Decker, 2009, para. 3). As a result, Zion National Park officials decided to spray the affected areas again when the effective time period of the first spraying ended in September of 2009. The park managers noted Plateau's success in reducing cheatgrass and again decided re-application would be the best treatment for the burned wildland to completely eradicate cheatgrass.

\subsection{Modeling Annual Brome Extent}

This project intends to expand the work of Armstrong (2007) and Murphy (2008) outside of Nevada and into a different annual brome impacted environment. Inspired by the success of Plateau in Zion National Park, this project aims to provide Joshua Tree National Park the necessary information to effectively manage its annual brome infestation. Following the observations of Armstrong (2007), in order to expand the predictive model into the unmapped annual brome territory of JTNP, this project would have to perform analysis similar to Peterson's (2003) or Bradley and Mustard's (2005).

Peterson $(2003,2005)$ used Landsat 7 ETM+ satellite data to derive variables for a statistical model of cheatgrass cover over a large area of Nevada. He obtained satellite data for early and late-season dates, calculated the Normalized Difference Vegetation Index (NDVI) for each time period and used the difference in NDVI to measure the area's phenology. Peterson (2003) compared this measure to training plots to test the accuracy of the results. He used Tobit Regression to develop the mapping model and used other remote-sensing techniques to eliminate errors in the model's results. 
Bradley and Mustard (2005) used cheatgrass' amplified response to rainfall to map its extent in Nevada. They collected Landsat and Advanced Very High Resolution Radiometer (AVHRR) data for years of relatively high and low precipitation and performed a time series analysis of the difference in NDVI for each set of high and low precipitation images. The difference in NDVI was an effective measure of the response of cheatgrass to rainfall. Large differences in NDVI indicated a larger amount of healthy vegetation in years of high precipitation, thus indicating the presence of cheatgrass. They then compared the data with field observations to assess the accuracy of the cheatgrass distribution maps created with the results. Bradley and Mustard used these results to develop their criteria for cheatgrass invasion (Bradley \& Mustard, 2006).

Given the study area and availability of data, this project changed from a systems development project to an applied research project and follows the analysis methods of Bradley and Mustard (2005), excluding analysis of AVHRR data. In addition to NDVI, the Soil Adjusted Vegetation Index (SAVI) is calculated for each Landsat image. The SAVI was developed to minimize soil background noise in areas of sparse vegetation (Huete, Liu, Batchily, \& van Leeuwen, 1997). The SAVI should provide a better measure of vegetation health than the NDVI in the arid environment of JTNP. Historic burn sites and areas of human disturbance will also be considered in identifying areas of present cheatgrass extent.

\subsection{Summary}

Research shows that annual brome is adversely affecting the natural habitat and fire regime of Joshua Tree National Park. Because of its ability to inform fire management decisions and suggest fuel break locations, park managers would benefit from the decision support system designed by Esh (2006), Armstrong (2007), and Murphy (2008). Before that kind of predictive analysis can be done, the extent of annual brome within the park must be accurately identified and mapped. This project strives to complete that task

using the methodology of Bradley and Mustard (2005). This project provides insight into remote sensing of annual brome extent and serves as an example of what can be done to accurately determine annual brome presence. The next few chapters describe this process in detail. 


\section{Chapter 3 - Database Design}

This chapter describes how the database design was chosen, how the data were obtained, and how they were prepared for analysis. The chapter first outlines the conceptual data model, providing an overall idea of the database design and the relationships within the database. The logical data model is then described and information about the specific data used in the project is given. Next, the data sources are revealed and data collection methods are explained. Finally, the chapter discusses data scrubbing completed in the project and the methods for loading the data into the database.

\subsection{Conceptual Data Model}

Because of the nature of this project, the conceptual data model is best described by the equations used in analysis. The equations explicitly describe the relationships within the data in the database. These equations are described in detail in Chapter 4.

The project geodatabase contains both the vector and raster data necessary for analysis. The vector data include a feature dataset containing historic fire data, a feature dataset containing areas considered to be human disturbance within the park, and three feature classes containing the extent of the study area, the boundary for Joshua Tree National Park, and points of annual brome presence. The raster data include imagery used to perform the analysis and vegetation indices produced by the analysis. Figure 3-1 helps to visualize the organization of data.

Figure 3-1: Organization of the Geodatabase 


\subsection{Logical Data Model}

Based on the data obtained for analysis, it was decided that the final deliverable geodatabase would be an ArcGIS File Geodatabase. Both vector and raster data can be loaded and stored in the file geodatabase format with ample space available for any further analysis or additional data. The next three subsections describe the data loaded into the geodatabase.

\subsubsection{Fire Dataset}

The FireData dataset contains two feature classes: bf_poly and classab. Both are vector data: one consists of polygons and the other contains points. The bf_poly feature class contains historic class $\mathrm{C}$ and above fire boundaries as polygons within Joshua Tree National Park from 1967 to 2006. The classab feature class contains points representing locations of class A and B fires within the park from 1942 to 2004. The FireData dataset was directly loaded into the geodatabase and required no alteration or data cleanup.

\subsubsection{Disturbance Dataset}

The Disturbance dataset contains four feature classes: campgrounds, rds pub2, Social_Trails_20090306, and trails. All are vector data: one contains polygon data and the rest consist of line data. The campgrounds feature class contains the boundaries of campgrounds within Joshua Tree National Park, as well as the boundaries of picnic areas and parking lots, as polygons. Picnic areas and parking areas were included in the campgrounds feature class because campers park their vehicles in the parking areas and also picnic within the picnic areas; thus, these areas were important aspects of camping and of human disturbance in the park. This feature class was acquired from a larger dataset; the creation of this feature class is discussed later in this chapter. The rds_pub2 feature class contains line data representing the paved and dirt roads within JTNP. The Social_Trails_20090306 feature class contains line data representing trails that visitors have created within the park. These trails are not recognized by park officials and are not maintained by park staff. The trails feature class contains the official trails recognized by the park. The Disturbance dataset was directly loaded into the geodatabase and required no alteration or data cleanup.

\subsubsection{Other Feature Classes}

The JTNP_Boundary polygon feature class and the BoulderPlots_Bro_pres_abs_point feature class were also directly loaded into the geodatabase without any alteration. The ExtentRectangle polygon feature class was created to obtain the coordinates of the study area in order to clip the Landsat imagery used for analysis. Neither the JTNP_Boundary nor the ExtentRectangle feature classes were used for analysis, but both were useful in mapping the analysis results.

The BoulderPlots_Bro_pres_abs_point feature class represents 82 10x10 meter vegetation plots near boulders within Joshua Tree National Park. The feature class contains attributes for bromus tectorum and bromus rubens presence within each plot. A 
$\mathrm{Y}$ in the BroTec field indicates cheatgrass presence and a $\mathrm{Y}$ in the BroRub field indicates red brome presence (see Figure 3-2).

\begin{tabular}{|l|l|}
\hline \multicolumn{1}{|c|}{ BroTec } & \multicolumn{2}{c|}{ BroRub } \\
\hline$N$ & $Y$ \\
\hline$Y$ & $Y$ \\
\hline$N$ & $Y$ \\
\hline$Y$ & $Y$ \\
\hline$Y$ & $Y$ \\
\hline$Y$ & $Y$ \\
\hline$Y$ & $Y$ \\
\hline$Y$ & $Y$ \\
\hline
\end{tabular}

Figure 3-2: Excerpt from BoulderPlots_Bro_pres_abs_Attribute Table

\subsubsection{Raster Data}

The Landsat TM imagery was clipped to the study area before it was loaded into the final geodatabase. Since the red and near infrared bands were needed to calculate the NDVI and the SAVI, these were the only bands loaded into the geodatabase. Each band was loaded individually and saved as its own raster dataset.

The analysis results - the vegetation indices in raster format - were loaded as the analysis was completed. The geodatabase was the workspace for all analysis to keep results saved in one location. The analysis rasters were created with the same extent as the clipped Landsat TM imagery and with the same 30 meter resolution.

\subsection{Data Sources}

Input data were obtained from two main sources (see Table 1). Joshua Tree National Park provided the necessary vector data, while all imagery data was downloaded from the United States Geological Survey Earth Explorer website (http://edcsns17.cr.usgs.gov/EarthExplorer/). 
Table 1. Input Data

\begin{tabular}{|l|l|l|l|}
\hline \multicolumn{2}{|c}{ Name } & Description & \multicolumn{1}{c|}{ Tource } \\
\hline bf_poly & Historical fire data & JTNP & Vector - Poly \\
\hline BoulderPlots_Bro_pres_abs & Annual brome presence & JTNP & Vector - Point \\
\hline Campgrounds & camp, picnic, parking areas & JTNP & Vector - Poly \\
\hline Classab & Historical fire data & JTNP & Vector - Point \\
\hline JTNP_Boundary & Park boundary & JTNP & Vector - Poly \\
\hline rds_pub2 & Roads & JTNP & Vector - Line \\
\hline Social_Trails_20090306 & Unofficial, social trails & JTNP & Vector - Line \\
\hline Trails & Official park trails & JTNP & Vector - Line \\
\hline TM5061984_B3 & Landsat TM imagery & USGS & Raster \\
\hline TM5061984_B4 & Landsat TM imagery & USGS & Raster \\
\hline TM5062007_B3 & Landsat TM imagery & USGS & Raster \\
\hline TM5062007_B4 & Landsat TM imagery & USGS & Raster \\
\hline TM5101997_B3 & Landsat TM imagery & USGS & Raster \\
\hline TM5101997_B4 & Landsat TM imagery & USGS & Raster \\
\hline TM5132004_B3 & Landsat TM imagery & USGS & Raster \\
\hline TM5132004_B4 & Landsat TM imagery & USGS & Raster \\
\hline TM5161999_B3 & Landsat TM imagery & USGS & Raster \\
\hline TM5161999_B4 & Landsat TM imagery & USGS & Raster \\
\hline TM5311987_B3 & Landsat TM imagery & USGS & Raster \\
\hline TM5311987_B4 & Landsat TM imagery & USGS & Raster \\
\hline & & & \\
\hline
\end{tabular}

\subsection{Data Collection Methods}

In order to follow the methodology of Bradley and Mustard (2005), it was necessary to acquire imagery data captured mid-May in years of relatively high and low annual rainfall. To determine these wet and dry years, the past 40 years of historical monthly precipitation totals (inches) for Twentynine Palms were downloaded from the California Data Exchange Center on the Department of Water Resources website (http://cdec.water.ca.gov/snow_rain.html). Data from Twentynine Palms were used because complete Joshua Tree National Park data were not available and Twentynine Palms was the closest weather station to the project's study area. While there are weather stations within the study area, the data provided for these stations were not as complete as the data obtained from the California Data Exchange Center for Twentynine Palms. Yearly precipitation totals were calculated from the monthly totals and the mean precipitation for the time period was determined from those yearly totals. The difference between each yearly precipitation total and the mean precipitation was taken and these differences determined the relatively wet and dry years for the study area. Years with no precipitation data were excluded (see Appendix A).

The USGS Earth Explorer website (http://edcsns17.cr.usgs.gov/EarthExplorer/) provides the complete Landsat archive to users to download free of charge. The website 
allows the user to search for imagery based on satellite, area of interest, and date (see Figure 3-3 and Figure 3-4).

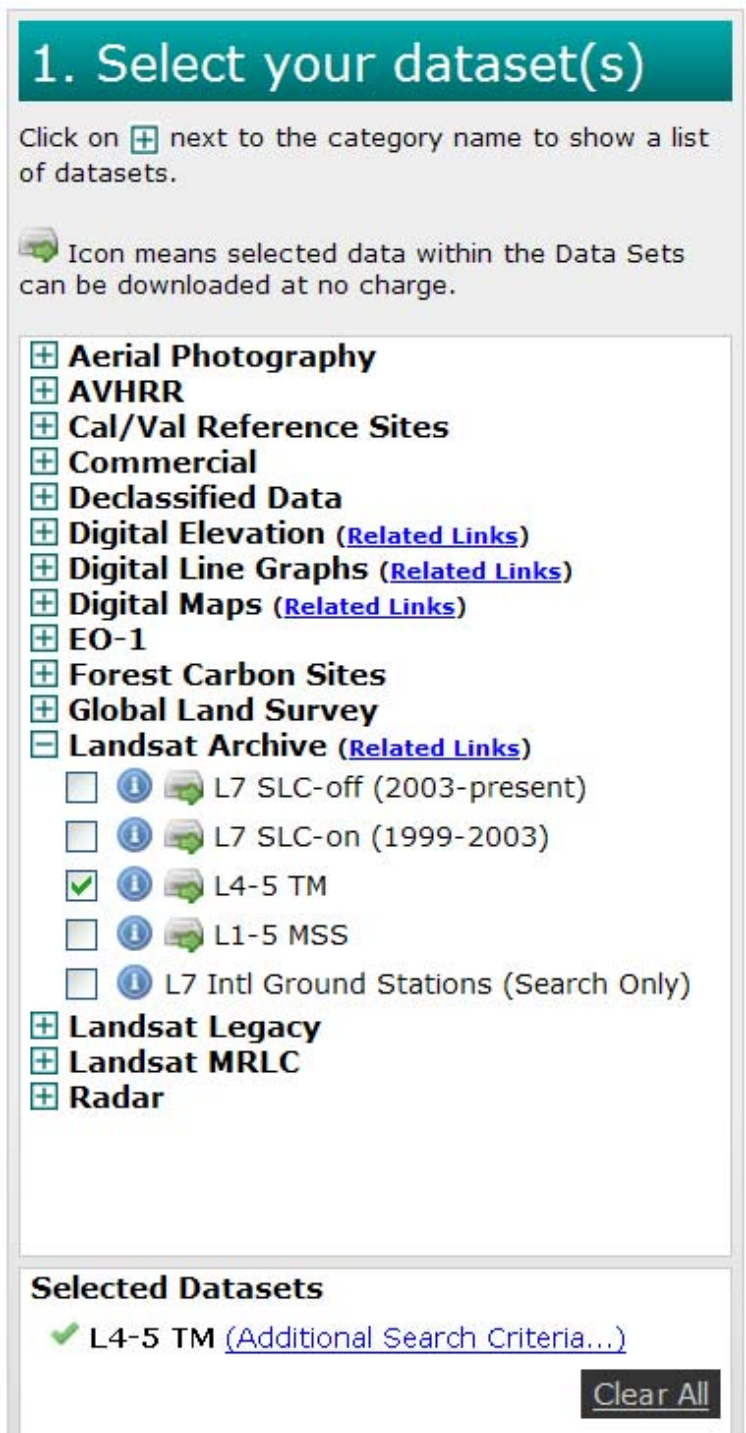

Figure 3-3: USGS Earth Explorer Dataset Selection 


\section{Enter your search criteria}

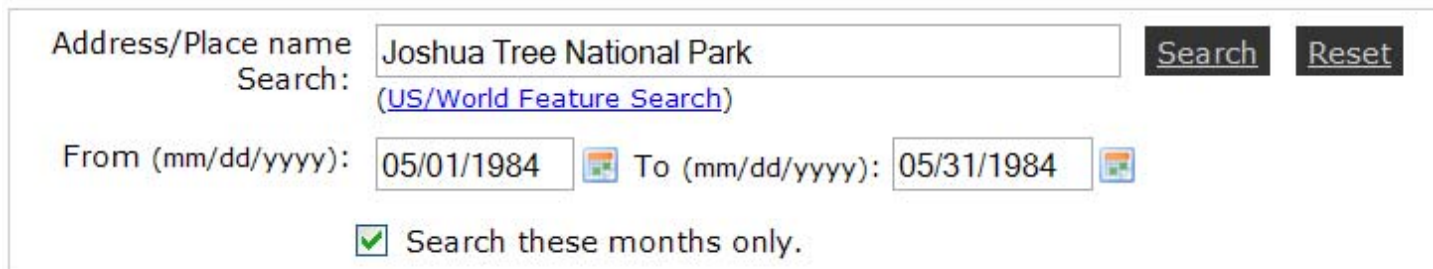

Figure 3-4: USGS Earth Explorer Search Criteria

These search capabilities allowed for the download of one wet and one dry mid-May image from each decade from the 1970s to the 2000s. Images were chosen by date captured (closest to 5/15), image quality, and percentage of cloud cover ( $0 \%$ preferred). Because of poor image quality, the 1970s images were excluded from analysis. Six Landsat TM images were downloaded from the website, clipped to the study area, and loaded into the geodatabase. The image date and band were used to name each raster dataset in the geodatabase (see Table 2).

Table 2. Landsat TM Imagery

\begin{tabular}{|l|l|l|l|}
\hline \multicolumn{1}{|c}{ Name } & \multicolumn{1}{l|}{ Date of Image } & \multicolumn{1}{c|}{ Band } & \multicolumn{1}{c|}{ Type } \\
\hline TM5061984_B3 & $5 / 6 / 1984$ & Red & Wet \\
\hline TM5061984_B4 & $5 / 6 / 1984$ & NIR & Wet \\
\hline TM5311987_B3 & $5 / 31 / 1987$ & Red & Dry \\
\hline TM5311987_B4 & $5 / 31 / 1987$ & NIR & Dry \\
\hline TM5101997_B3 & $5 / 10 / 1997$ & Red & Wet \\
\hline TM5101997_B4 & $5 / 10 / 1997$ & NIR & Wet \\
\hline TM5161999_B3 & $5 / 16 / 1999$ & Red & Dry \\
\hline TM5161999_B4 & $5 / 16 / 1999$ & NIR & Dry \\
\hline TM5132004_B3 & $5 / 13 / 2004$ & Red & Wet \\
\hline TM5132004_B4 & $5 / 13 / 2004$ & NIR & Wet \\
\hline TM5062007_B3 & $5 / 6 / 2007$ & Red & Dry \\
\hline TM5062007_B4 & $5 / 6 / 2007$ & NIR & Dry \\
\hline
\end{tabular}

\subsection{Data Scrubbing and Loading}

The majority of the data received from Joshua Tree National Park were completely ready to be loaded into the final geodatabase. Each dataset was simply imported into MIP.gdb. The campgrounds polygons were obtained from the JOTR_AISVegLayer personal geodatabase provided by JTNP. In addition to cataloging the vegetation found within each polygon, this vegetation layer provides attribute data for each polygon's land use and land type. A definition query was performed on the dataset to select polygons of campgrounds, parking areas, or picnic areas land type (see Figure 3-5). 


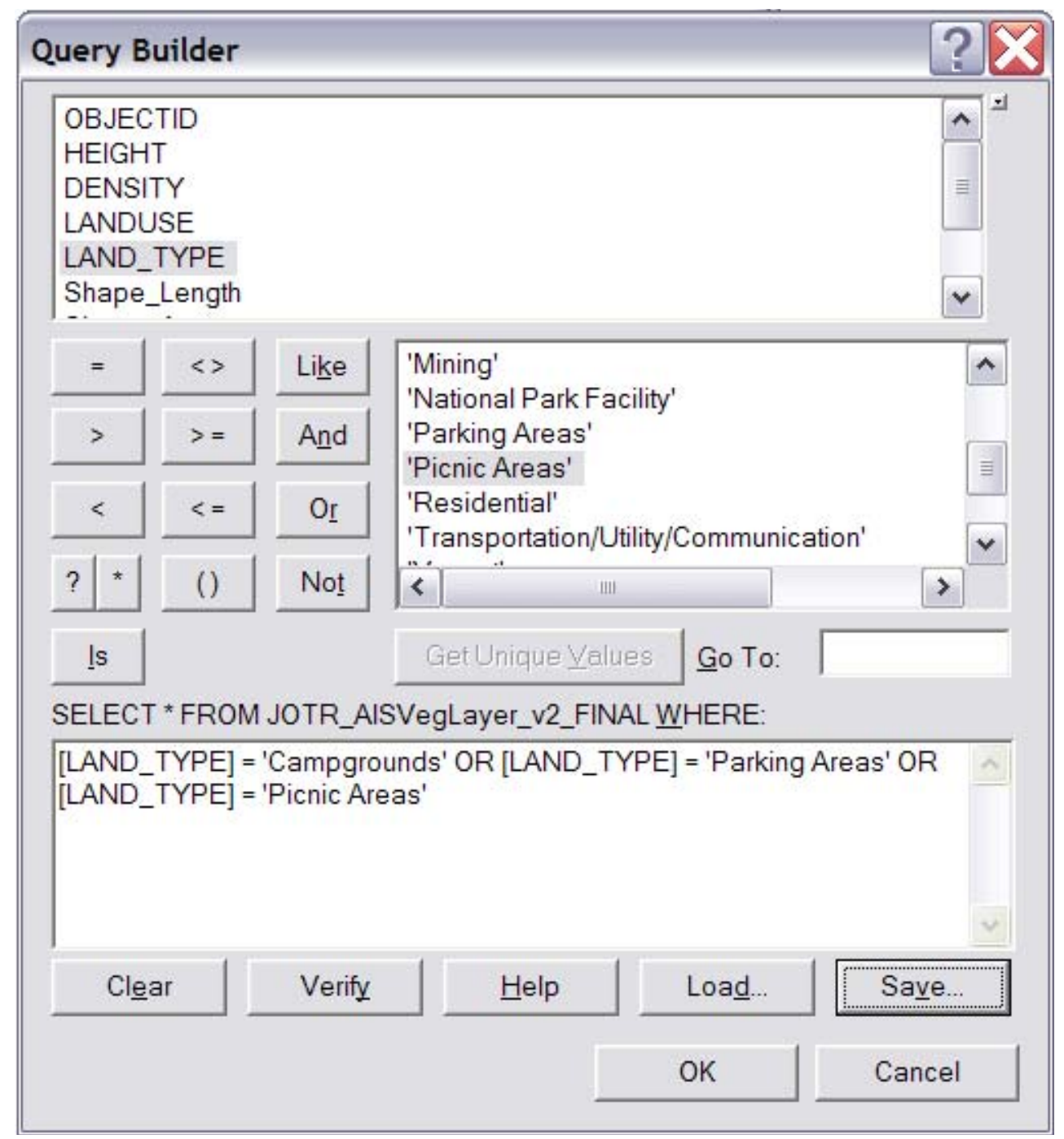

Figure 3-5: Definition Query Used to Create Campgrounds Feature Class

The data obtained from the definition query were then exported into a new feature class and imported into the Disturbance dataset. The Landsat imagery obtained from USGS was clipped to the study area extent using the Raster Clip tool in the Data Management Tools provided by ArcGIS. The clipped imagery was then imported into MIP.gdb.

\subsection{Summary}

Overall, the data design for this project was simple. An ArcGIS File Geodatabase provided the logical data model and the majority of data obtained were able to be directly loaded into the geodatabase. The project required very little data collection and most of the data provided by the client was ready to use. 



\section{Chapter 4 - Image Processing and Analysis}

This chapter describes the project's implementation, including the steps taken to process the Landsat images and to perform the analysis. Following the methodology of Bradley and Mustard (2005), the raw Landsat TM imagery obtained from the USGS was converted to reflectance values in order to calculate vegetation indices for each image. For each decade, the difference in vegetation indices of the wet and dry image was calculated. These difference rasters were used in the map interface to determine annual brome presence and its relationship to historic fire and human disturbance.

\subsection{Preparing Landsat TM Imagery for Vegetation Index Calculation}

The Landsat TM imagery provided by the USGS Earth Explorer website contains the "calibrated digital numbers" that have been rescaled from the "raw digital numbers transmitted from the satellite" (Chander, Markham, \& Helder, 2009). In order to calculate the Normalized Difference Vegetation Index (NDVI) and the Soil Adjusted Vegetation Index (SAVI), these Digital Numbers (DN) had to be converted to reflectance values.

\subsubsection{Converting Raw Imagery Data to At-Sensor Spectral Radiance}

The first step in this process was to convert the DN to spectral radiance values. The equation used for this conversion was:

$$
L_{\lambda}=G_{\text {rescale }} \times Q_{\text {cal }}+B_{\text {rescale }}
$$

Where:

$$
\begin{array}{ll}
L_{\lambda}= & \text { Spectral radiance } \\
G_{\text {rescale }}= & \text { Band-specific rescaling gain factor } \\
Q_{\text {cal }}= & \text { DN } \\
B_{\text {rescale }}= & \text { Band-specific rescaling bias factor }
\end{array}
$$

The ArcGIS extension Spatial Analyst was used to perform the image calculations. Specifically, the Single Output Map Algebra Tool was used to compute the spectral radiance for each band of each image and create a raster from each calculation (see Figure 4-1). The gain factor and the bias factor values were obtained from the paper "Summary of current radiometric calibration coefficients for Landsat MSS, TM, ETM+, and EO-1 ALI sensors" and also from the metadata provided with the Landsat TM imagery (see Appendix B) (Chander, Markham, \& Helder, 2009). The Snap Raster setting in the Environments Settings was set to the input raster to insure the output rasters' pixels would line up correctly. The resulting radiance rasters were not stored in the final geodatabase because they were considered intermediate data. With spectral 
radiance calculated for each band of each image, the next step in conversion to reflectance could be taken.

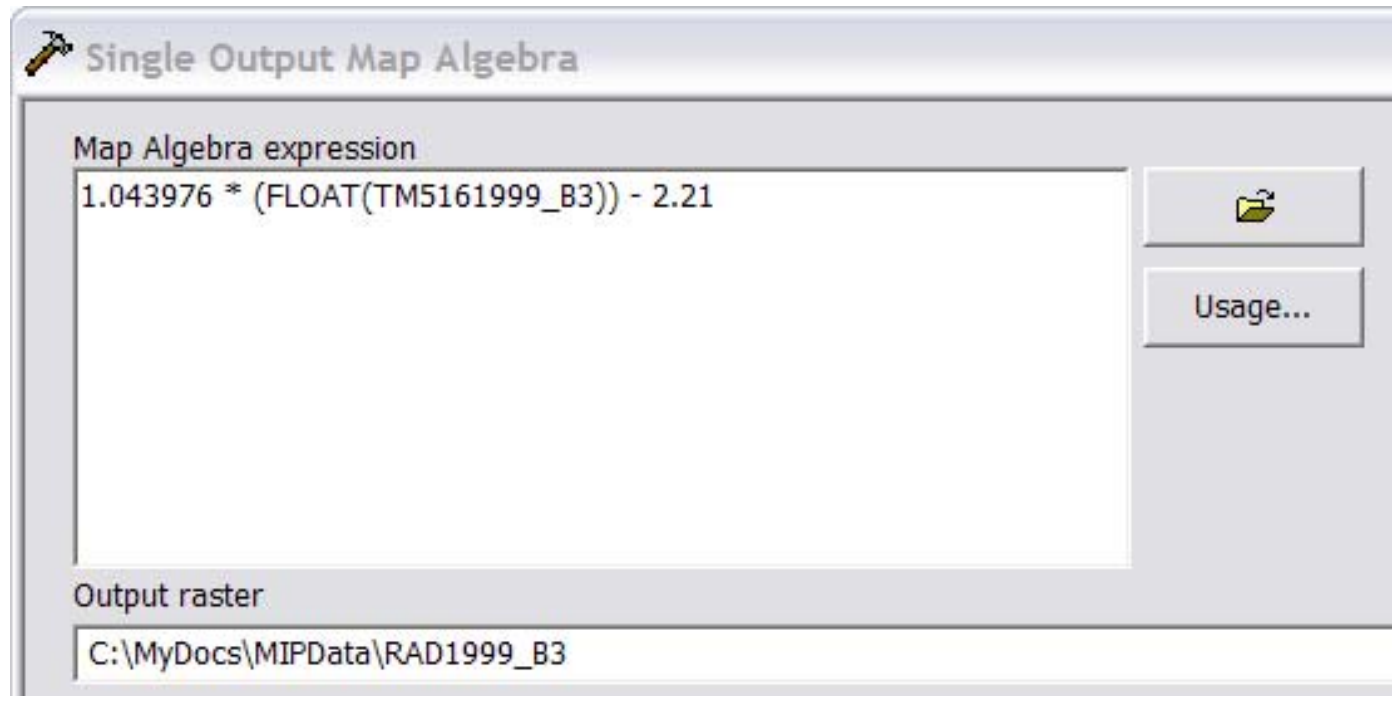

Figure 4-1: Example of DN to radiance conversion equation

\subsubsection{Converting Spectral Radiance to Top-Of-Atmosphere Reflectance}

The next step in the image processing was to convert the spectral radiance values to reflectance values. Following the information provided by Chander, Markham, \& Helder (2009), the equation used for this conversion was:

$$
\rho_{\lambda}=\frac{\pi \cdot L_{\lambda} \cdot d^{2}}{E S U N_{\lambda} \cdot \sin \theta_{s}}
$$

Where:

$$
\begin{array}{ll}
\rho_{\lambda}= & \text { Planetary TOA reflectance } \\
\pi= & \text { Pi } \sim 3.14159 \\
L_{\lambda}= & \text { Spectral radiance } \\
d= & \text { Earth-Sun distance (AU) } \\
E S U N_{\lambda}= & \text { Mean exoatmospheric solar irradiance } \\
\theta_{S}= & \text { Solar elevation angle }
\end{array}
$$

Again, the Single Output Map Algebra Tool was used to compute the reflectance values for each band of each image and to create a raster from each calculation (see Figure 4-2). The values for the Earth-Sun distance, mean exoatmospheric solar irradiance, and the solar elevation angle were obtained from Chander, Markham, \& Helder (2009) and from the metadata provided with the Landsat TM imagery (see Appendix C). The solar elevation angle was given in degrees and was converted to radians. The Snap Raster 
setting in the Environments Settings was again set to the input raster in order to insure the accuracy of the output rasters' extents. The reflectance rasters created by this calculation were not stored in the final geodatabase because, like the radiance rasters, they were considered intermediate data. With reflectance calculated for each band of each image, the vegetation indices could be calculated.

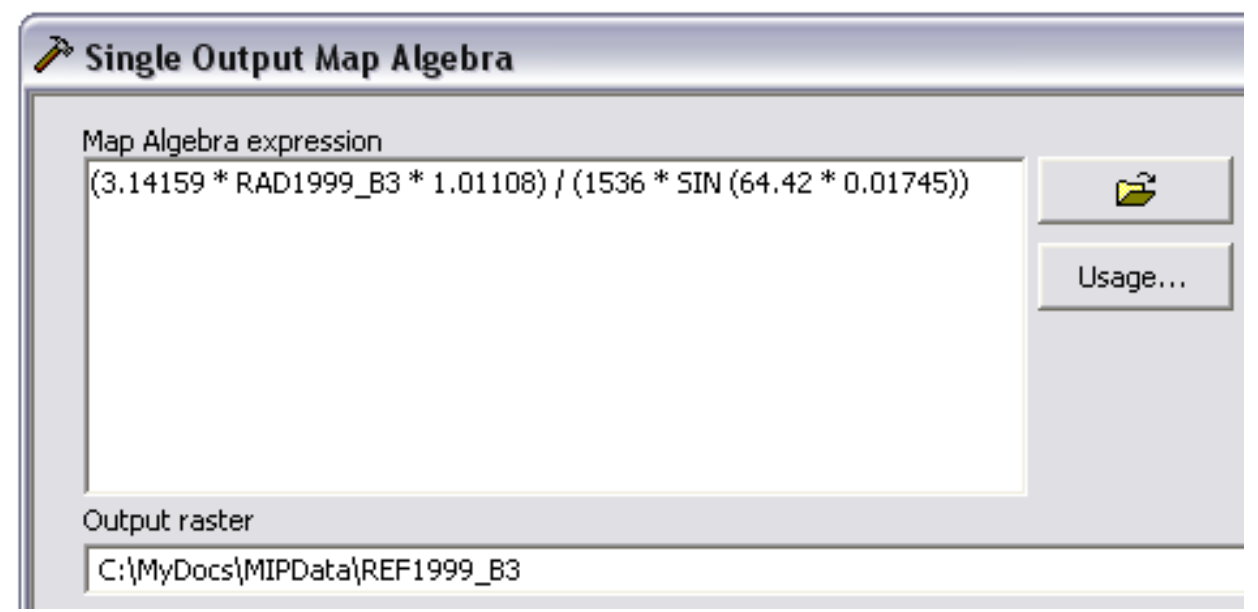

Figure 4-2: Example of radiance to reflectance conversion equation

\subsection{Vegetation Index Calculation}

As discussed in Chapter 2, Bradley and Mustard (2005) used the Normalized Difference Vegetation Index (NDVI) to determine the existence of annual brome in Nevada. Following their methodology, the NDVI for the study area was calculated for each Landsat image. In addition, the Soil Adjusted Vegetation Index (SAVI) was also calculated for each image. As explained in Chapter 2, the SAVI was developed to minimize background noise from soil in areas of sparse vegetation, like the desert habitat in Joshua Tree National Park (Huete, Liu, Batchily, \& van Leeuwen, 1997). The next two sub-sections describe the steps taken to calculate each index.

\subsubsection{Normalized Difference Vegetation Index}

The equation used to calculate the NDVI was:

$$
N D V I=\frac{N I R-R}{N I R+R}
$$

Where:

$$
\begin{array}{ll}
N I R= & \text { Landsat TM near infrared band, band } 4 \\
R= & \text { Landsat TM red band, band } 3
\end{array}
$$


A tool was built to streamline the NDVI computation process (see Figure 4-3). The input $\mathrm{R}$ and NIR rasters and the output NDVI raster were set as parameters of the tool, allowing the user to choose the appropriate input data, the output name, and the output location. The user can also set the Snap Raster in order to match the output raster extent to the input rasters. For each year of Landsat TM data, the third and fourth bands converted to reflectance values were used as the R and NIR inputs respectively. With these inputs, the tool was run to calculate each year's NDVI (see Figure 4-4). The resulting rasters were named for the year they represented and saved in the final geodatabase.

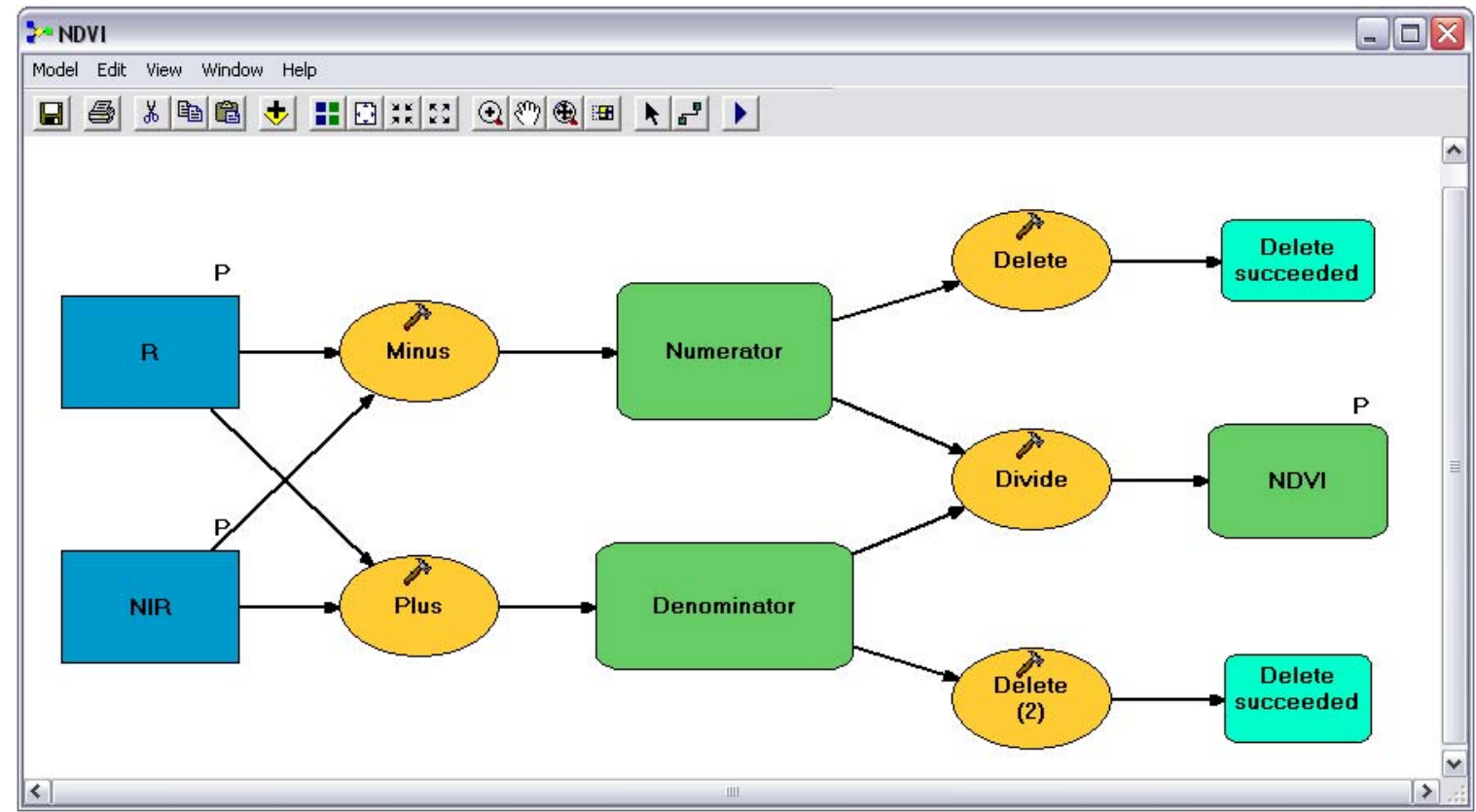

Figure 4-3: NDVI Tool

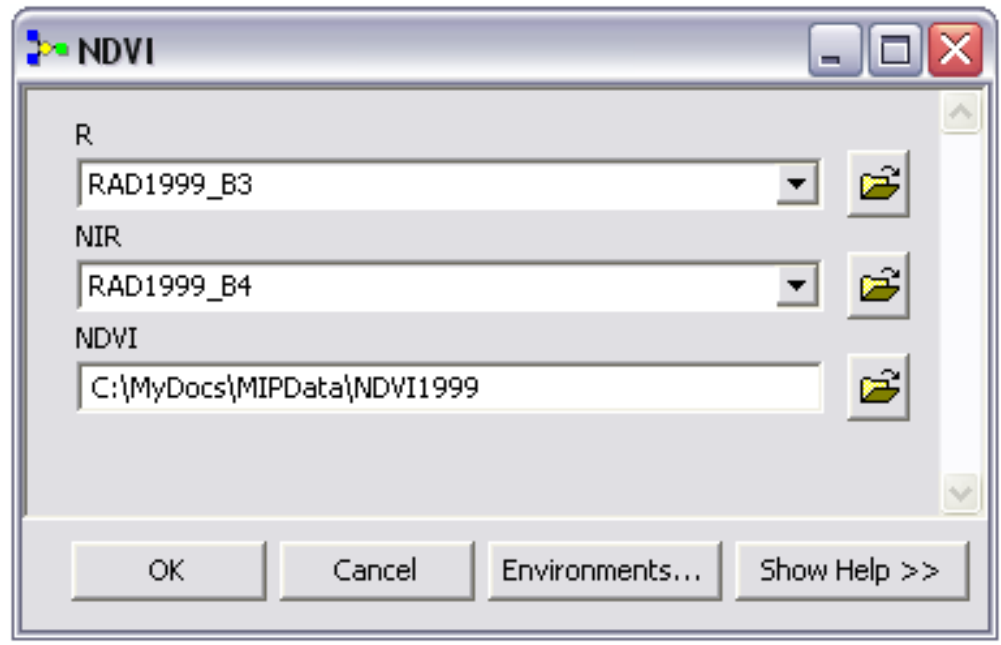

Figure 4-4: Example of NDVI Tool Parameters 


\subsubsection{Soil Adjusted Vegetation Index}

The equation used to calculate the SAVI was:

$$
S A V I=\frac{(1+L)(N I R-R)}{N I R+R+L}
$$

Where:

$$
\begin{array}{ll}
N I R= & \text { Landsat TM near infrared band, band } 4 \\
R= & \text { Landsat TM red band, band } 3 \\
L= & \text { Soil background correction factor }
\end{array}
$$

The correction factor $L$ differentiates the NDVI and the SAVI. This correction factor reduces background noise from the soil in areas of sparse vegetation and allows for improved vegetation detection (Huete, Liu, Batchily, \& van Leeuwen, 1997). Without this factor, reflectance from the soil has the potential to "mask-out" the reflectance from the vegetation (Lee, 2009). Values for $L$ range from 0 , for high vegetation cover, to 1 , for low vegetation cover (Lee, 2009). Lee (2009) chose the value 0.8 to calculate a SAVI for JTNP in her study, Monitoring Trails and Disturbance in Joshua Tree National Park. Because of the similar area of interest, this project used 0.8 to calculate the SAVI for each Landsat image.

A tool was built to streamline the SAVI computation process (see Figure 4-5). The input R and NIR rasters and the output SAVI raster were set as parameters of the tool, allowing the user to choose the appropriate input data, to name the output data, and to choose the output location. The user should also set the Snap Raster in order to maintain the correct extent of the output raster. For each Landsat image converted to reflectance values, the third and fourth bands were used as the R and NIR inputs respectively. With these inputs, and $L$ equal to 0.8 , the tool was run to calculate each year's SAVI (see Figure 4-6). The output rasters produced by the tool were named for the year they represented and saved in the final geodatabase. Intermediate data produced by the tool were automatically deleted using the delete tool. 


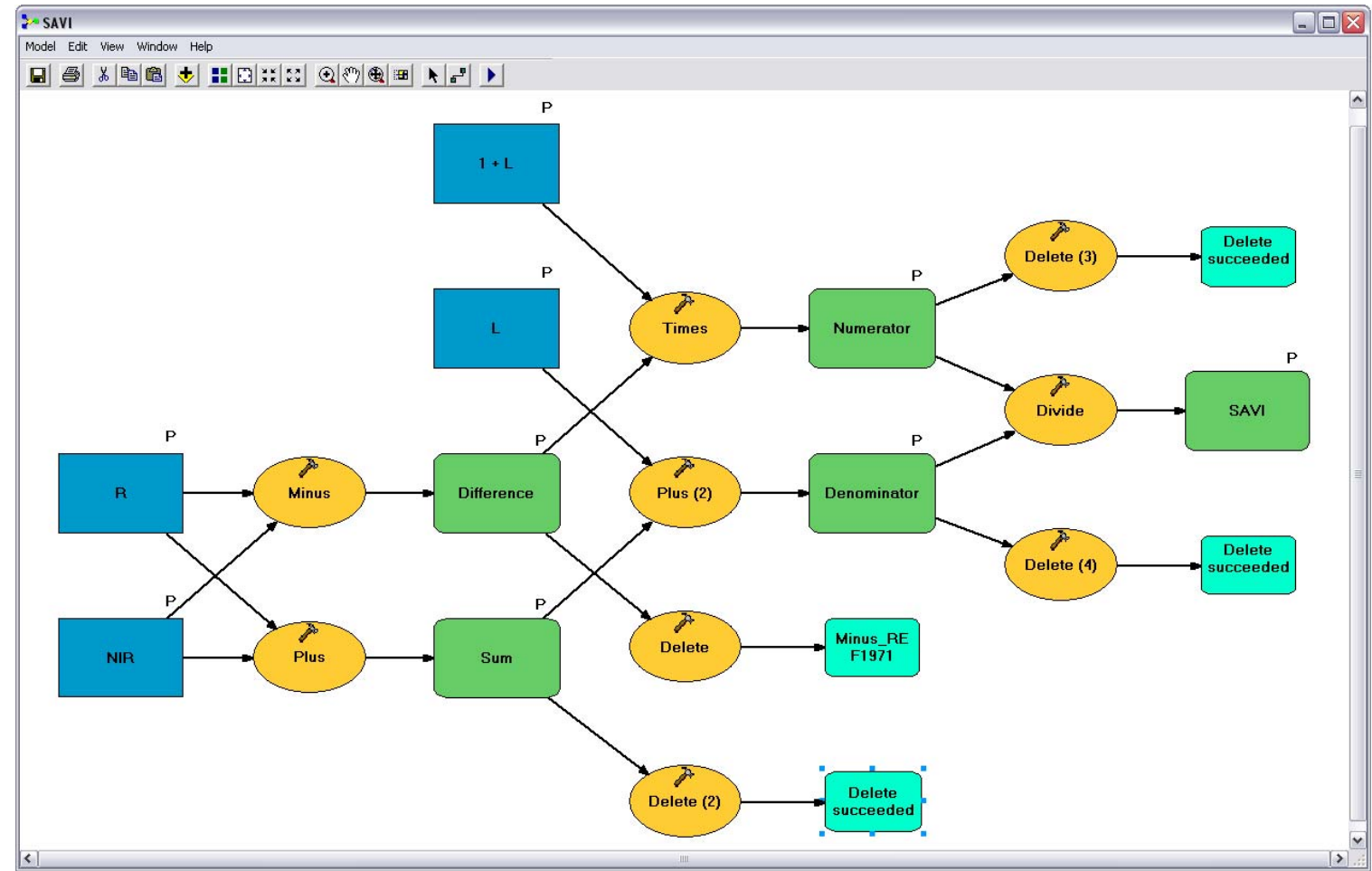

Figure 4-5: SAVI Tool 


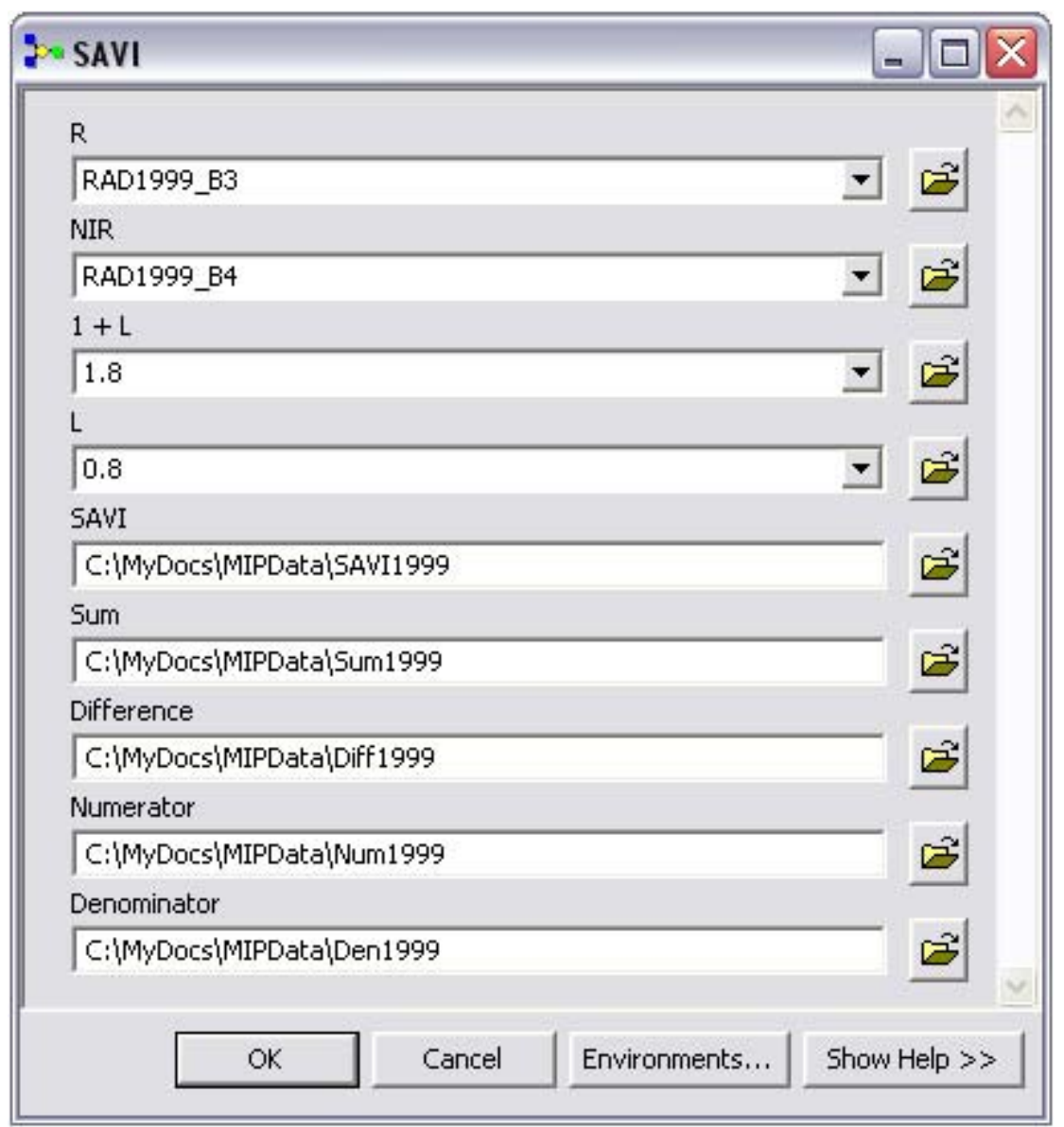

Figure 4-6: Example of SAVI Tool Parameters

\subsection{Difference in Vegetation Index Calculation}

With the NDVI and SAVI calculated for each Landsat TM image, the next step in Bradley and Mustard's (2005) methodology could be taken. Bradley and Mustard (2005) used the difference in vegetation index values between relatively wet and dry years of precipitation to model the amplified response of annual brome to rainfall. A large difference in vegetation index in an area indicated healthier vegetation in the wet year. Bradley and Mustard (2005) concluded that this healthier vegetation was actually annual brome infestation. This project calculated the difference in NDVI and in SAVI between a wet year and a dry year in the 1980s, 1990s, and 2000s. The process to select these wet and dry years was explained in Chapter 3 and Appendix A.

\subsubsection{Normalized Difference Vegetation Index}

The dNDVI Tool was built to calculate the difference between each decade's wet NDVI and its dry NDVI (see Figure 4-7). The tool performed the following function: 


$$
d N D V I=N D V I_{w e t}-N D V I_{d r y}
$$

Where:

$$
\begin{array}{ll}
d N D V I= & \text { Difference in NDVI } \\
N D V I_{\text {wet }}= & \text { NDVI image from wet year } \\
N D V I_{d r y}= & \text { NDVI image from dry year }
\end{array}
$$

The input NDVI and the output difference in NDVI were set as parameters of the tool (see Figure 4-8). The user can choose the appropriate input data as well as decide where the output is saved. As with the previous tools, the user should set the Snap Raster in the Environment Settings to maintain the correct output extent. The dNDVI Tool was used to create a dNDVI raster for the 1980s, the 1990s, and the 2000s. Each raster was named for the year it represented and saved in the final geodatabase.

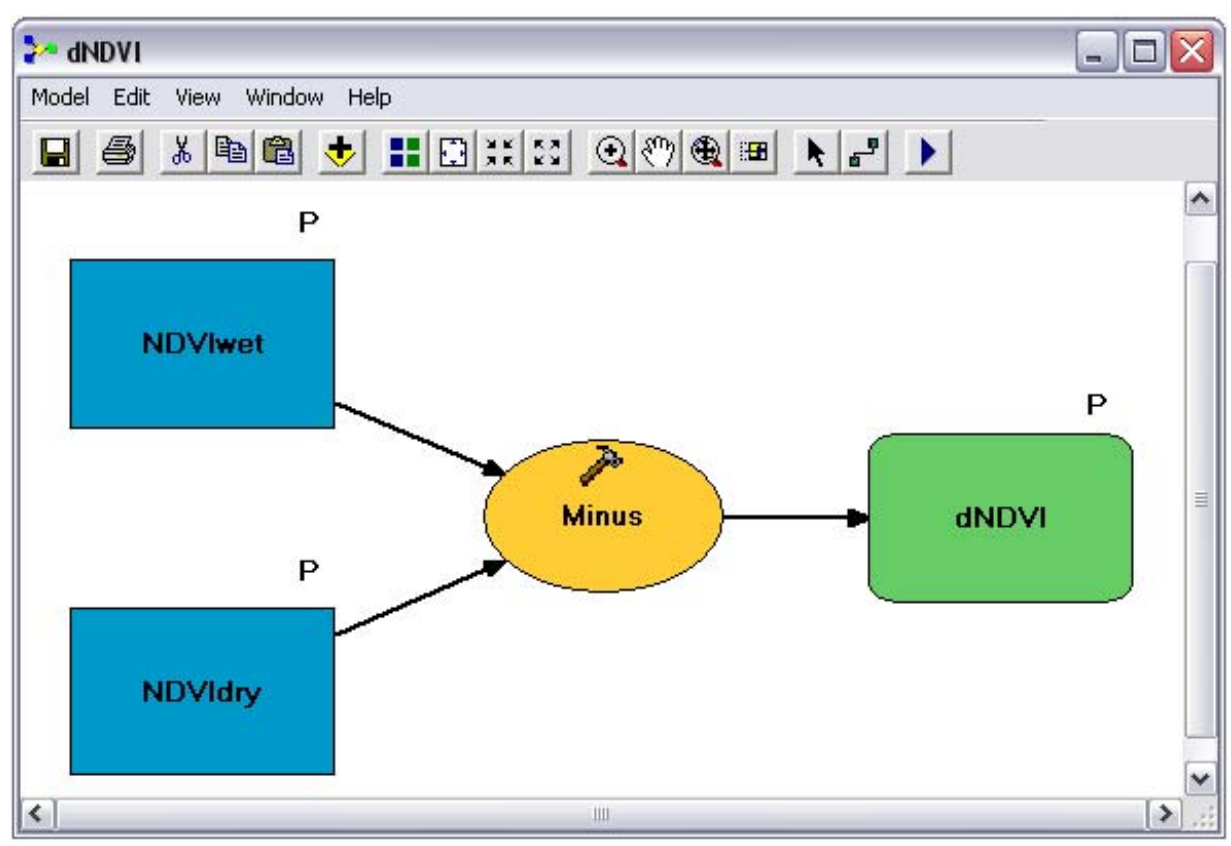

Figure 4-7: dNDVI Tool 


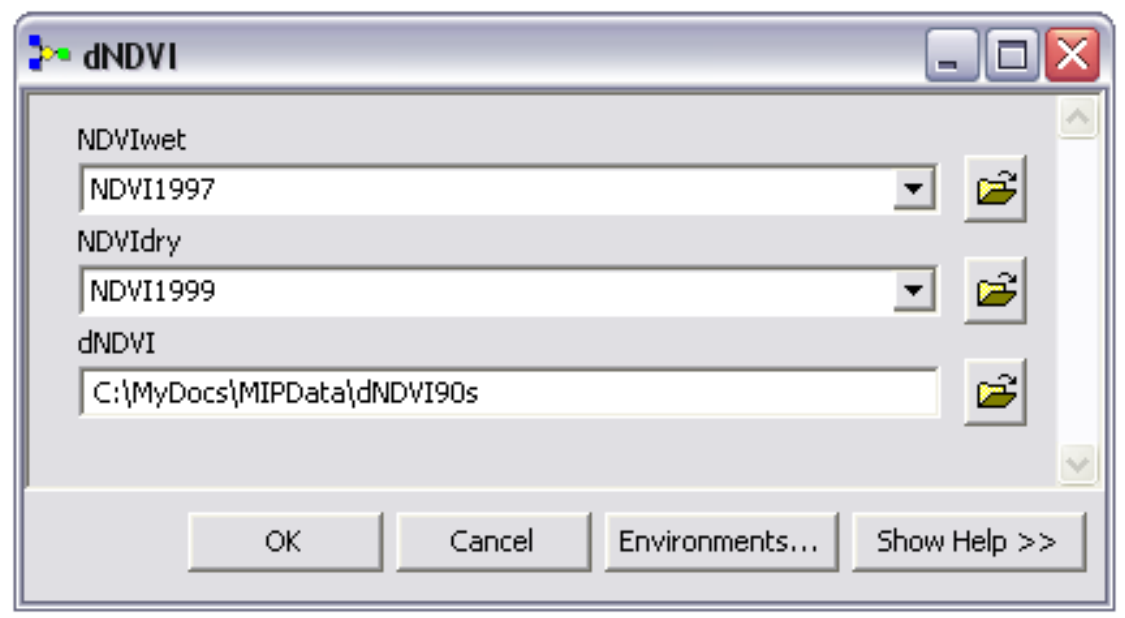

Figure 4-8: Example of dNDVI Tool Parameters

\subsubsection{Soil Adjusted Vegetation Index}

The dSAVI Tool was built to calculate the difference between each decade's wet SAVI and its dry SAVI (see Figure 4-9). The tool performed the following function:

$$
d S A V I=S A V I_{w e t}-S A V I_{d r y}
$$

Where:

$$
\begin{array}{ll}
d S A V I= & \text { Difference in SAVI } \\
S A V I_{\text {wet }}= & \text { SAVI image from wet year } \\
S A V I_{d r y}= & \text { SAVI image from dry year }
\end{array}
$$

The input SAVI and the output difference in SAVI were set as parameters of the tool (see Figure 4-10). The user can choose the appropriate input data as well as decide where the output is saved. As with the previous tools, the user should set the Snap Raster in the Environment Settings to maintain the correct output extent. The dSAVI Tool was used to create a dSAVI raster for the 1980s, the 1990s, and the 2000s. Each raster was named for the year it represented and saved in the final geodatabase. 


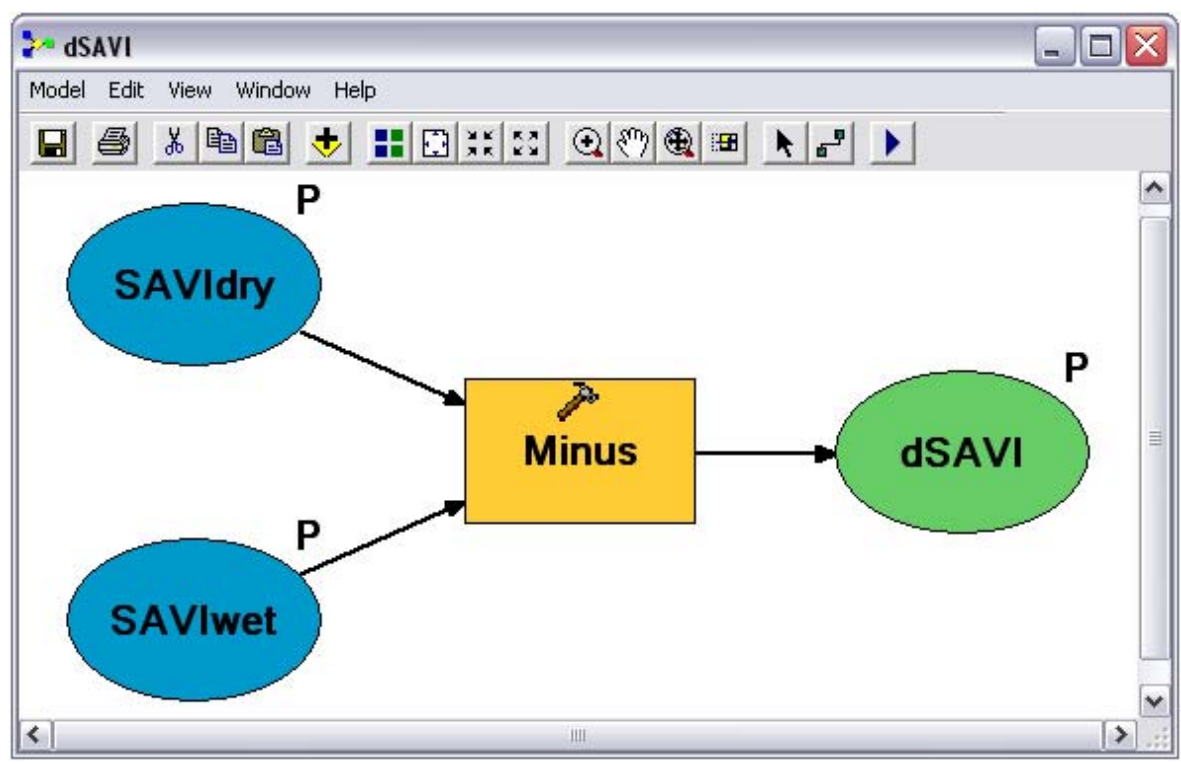

Figure 4-9: dSAVI Tool

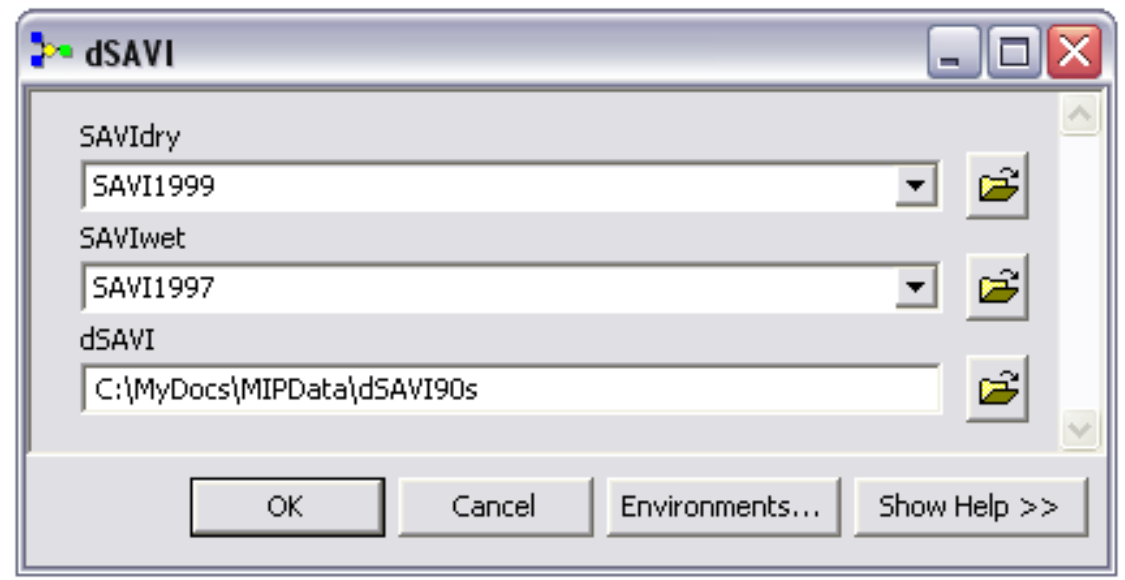

Figure 4-10: Example of dSAVI Tool Parameters

\subsection{Summary}

Implementing the proposed solution required image processing, raster calculation, and tool development. Using tools from the Spatial Analyst Toolset, vegetation indices and differences in vegetation indices were calculated and saved in the final geodatabase.

These rasters were displayed in an ArcMap interface. The development of this interface is explained in the following chapter. 


\section{Chapter 5 - Map Interface Development}

This chapter describes the design and development of the project's map interface. The purpose of the interface was to display the analysis results so that the client could explore and understand the data. The interface is organized by decade, allowing the user to move through time, looking at park conditions during different time periods. Included in the interface are the vegetation indices and the vegetation indices differences, the annual brome presence data provided by JTNP, historic fire boundaries, and areas of human disturbance. The following subsections describe how each dataset was added to the deliverable product.

\subsection{Vegetation Index Display}

Both the NDVI and the SAVI are raster datasets with cell values ranging from -1, indicating no presence of healthy vegetation, to 1 , indicating the presence of healthy vegetation. The index results were classified using the results of Bradley and Mustard (2005) as a guide. Bradley and Mustard (2005) found that the average NDVI value for cheatgrass in their study fell between 0.15 and 0.36 (see Figure 5-1). This range of values was used as the healthy range of vegetation for this project. The NDVI and SAVI were classified using the Natural Breaks (Jenks) classification with seven classes and a brown to green color ramp (see Figure 5-2). In some cases, values below -1 or above 1 were excluded from the classification because these values were invalid. The invalid values were a result of invalid Landsat imagery DNs (Digital Numbers). 


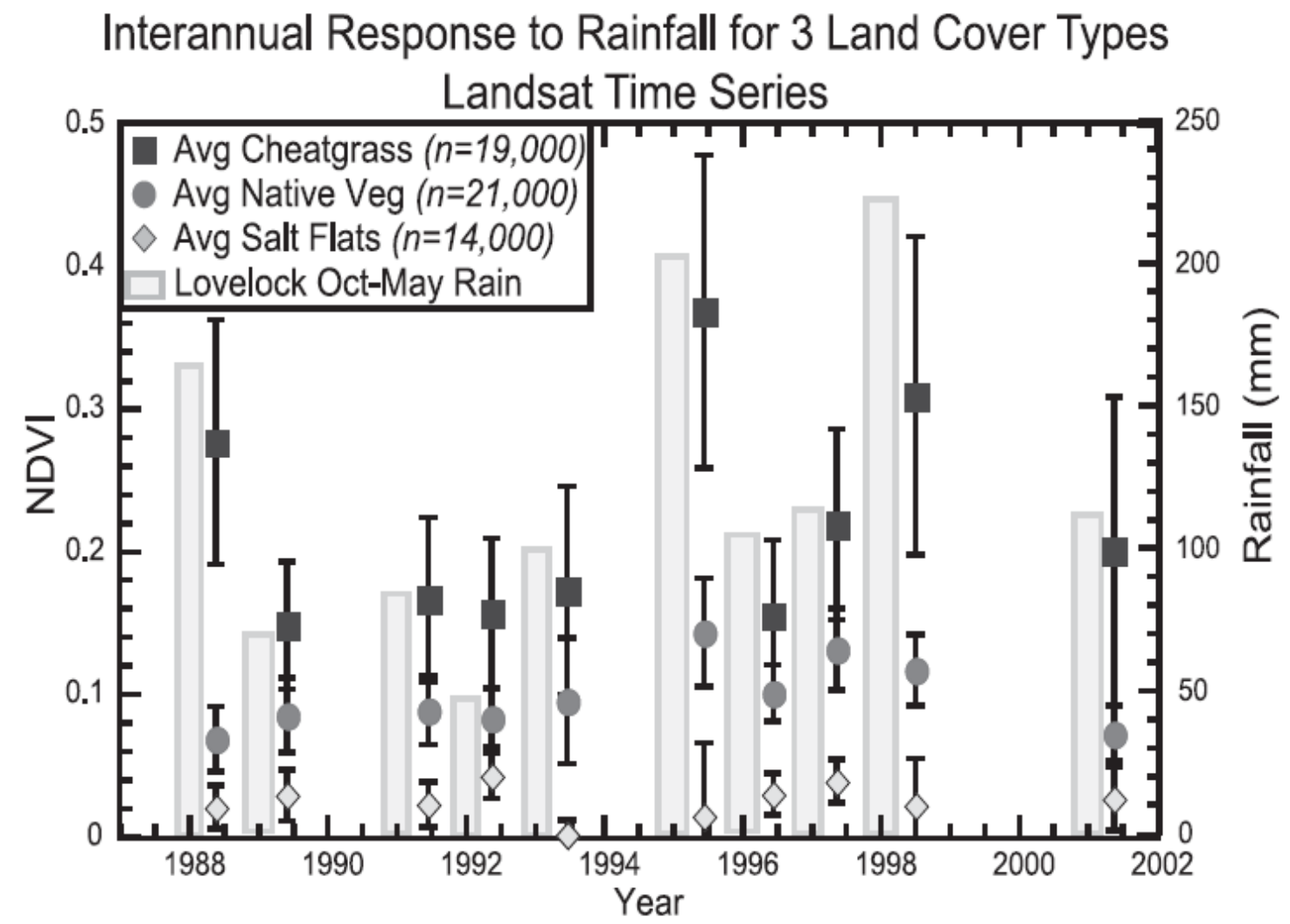

Figure 5-1: Vegetation Index Classification Values (Bradley and Mustard, 2005)

NDVI2004

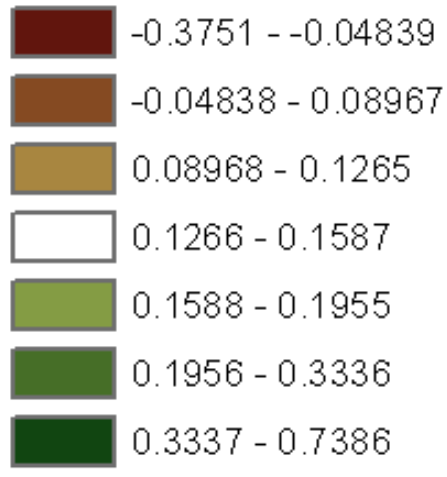

Figure 5-2: 2004 NDVI Legend

Bradley and Mustard (2005) found that the average dNDVI value for cheatgrass in their study fell between 0.14 and 0.26 (see Figure 5-3). This range of values was used as the annual brome range of vegetation for this project. The dNDVI and dSAVI were manually classified with five classes with a brown to green color ramp (see Figure 5-4). 


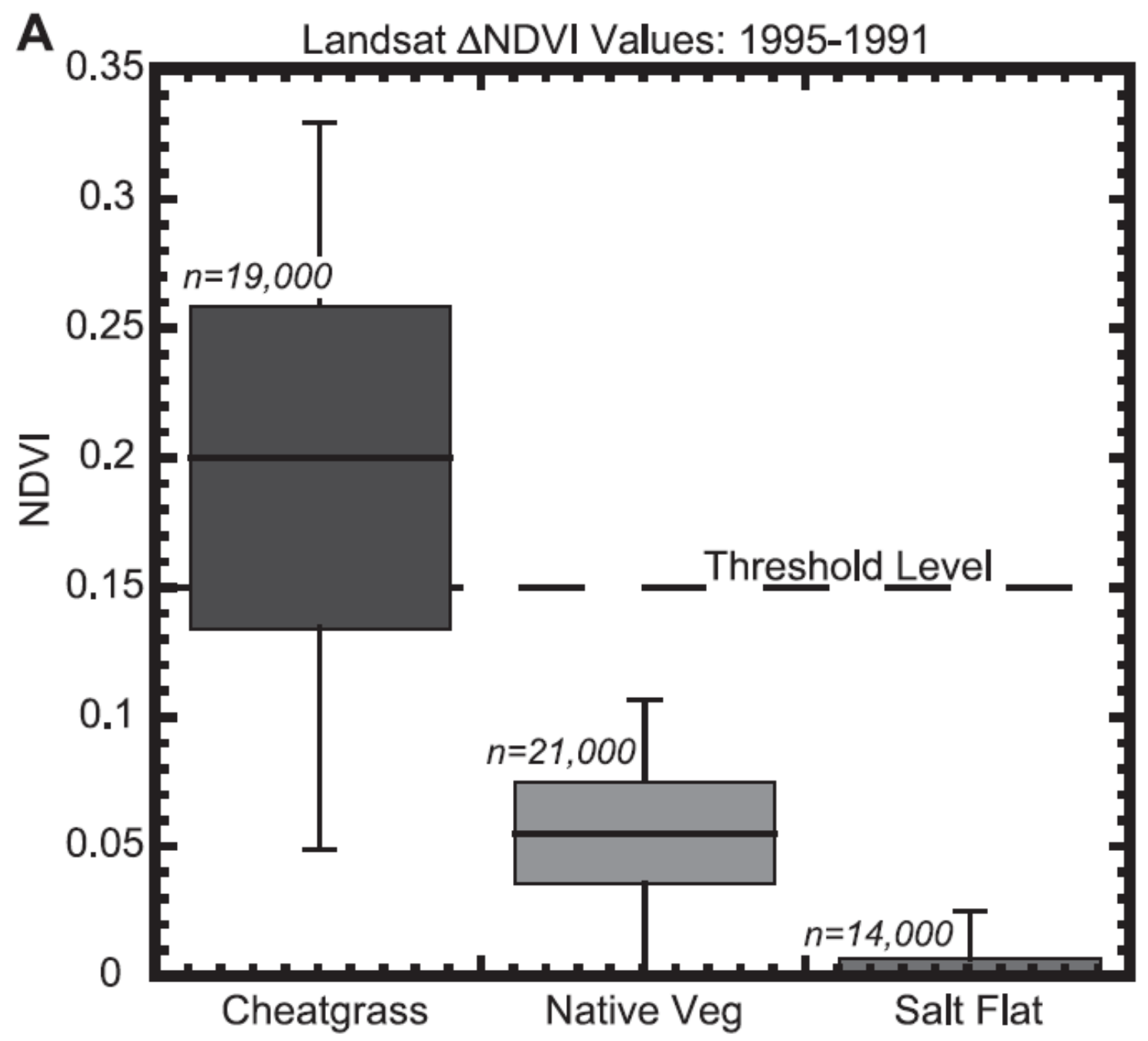

Figure 5-3: Difference in Vegetation Index Classification Values (Bradley and Mustard, 2005)

\section{dNDVI90s}

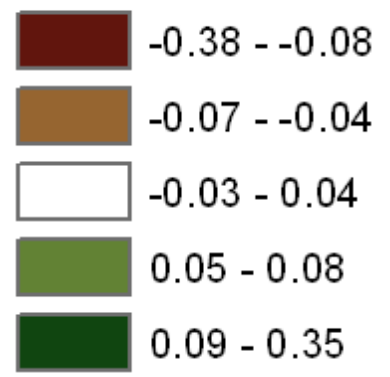

Figure 5-4: 1990s dNDVI Legend 


\subsection{Annual Brome Presence}

The feature class provided by JTNP indicating annual brome presence contained attribute data for both cheatgrass and red brome. For each point in the dataset, its attribute data specified if there was cheatgrass presence, red brome presence, or both cheatgrass and red brome presence. Three instances of the dataset were added to the ArcMap interface and a definition query was performed on each instance to create the cheatgrass, red brome, and annual brome layers.

\subsection{Historic Fire Classification and Display}

The historic fire feature classes provided by JTNP included a fire classification scheme within their attribute data. Developed by the United States Fish and Wildlife Service, the scheme classifies each fire within the dataset according to its size (see Table 3). These classes were used to symbolize the fire data within the map interface (see Figure 5-5 and Figure 5-6). Because the majority of fire data within the interface is point data, using a graduated scale to symbolize the data allows the user to better visualize the size of each fire. The polygon fire data was symbolized using a custom polygon fill symbol created specifically for the feature class (see Figure 5-7).

Table 3. Wildfire Classification Scheme

\begin{tabular}{|c|c|}
\hline Class of Fire & Acres Burned \\
\hline A & $\leq 0.25$ \\
\hline B & $.25-10$ \\
\hline C & $10-100$ \\
\hline D & $100-300$ \\
\hline E & $300-1000$ \\
\hline F & $1000-5000$ \\
\hline G & $\geq 5000$ \\
\hline
\end{tabular}

\section{classab}

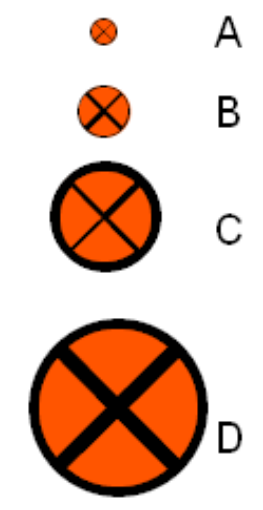

Figure 5-5: Wildfire Point Data Legend 


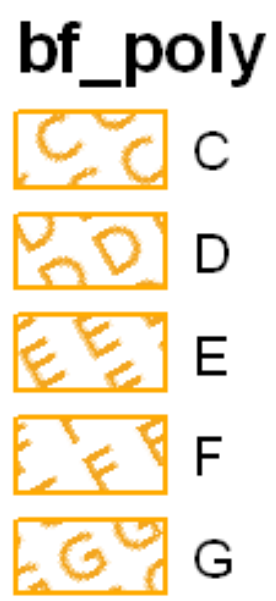

Figure 5-6: Wildfire Polygon Data Legend, Custom Fill Symbol

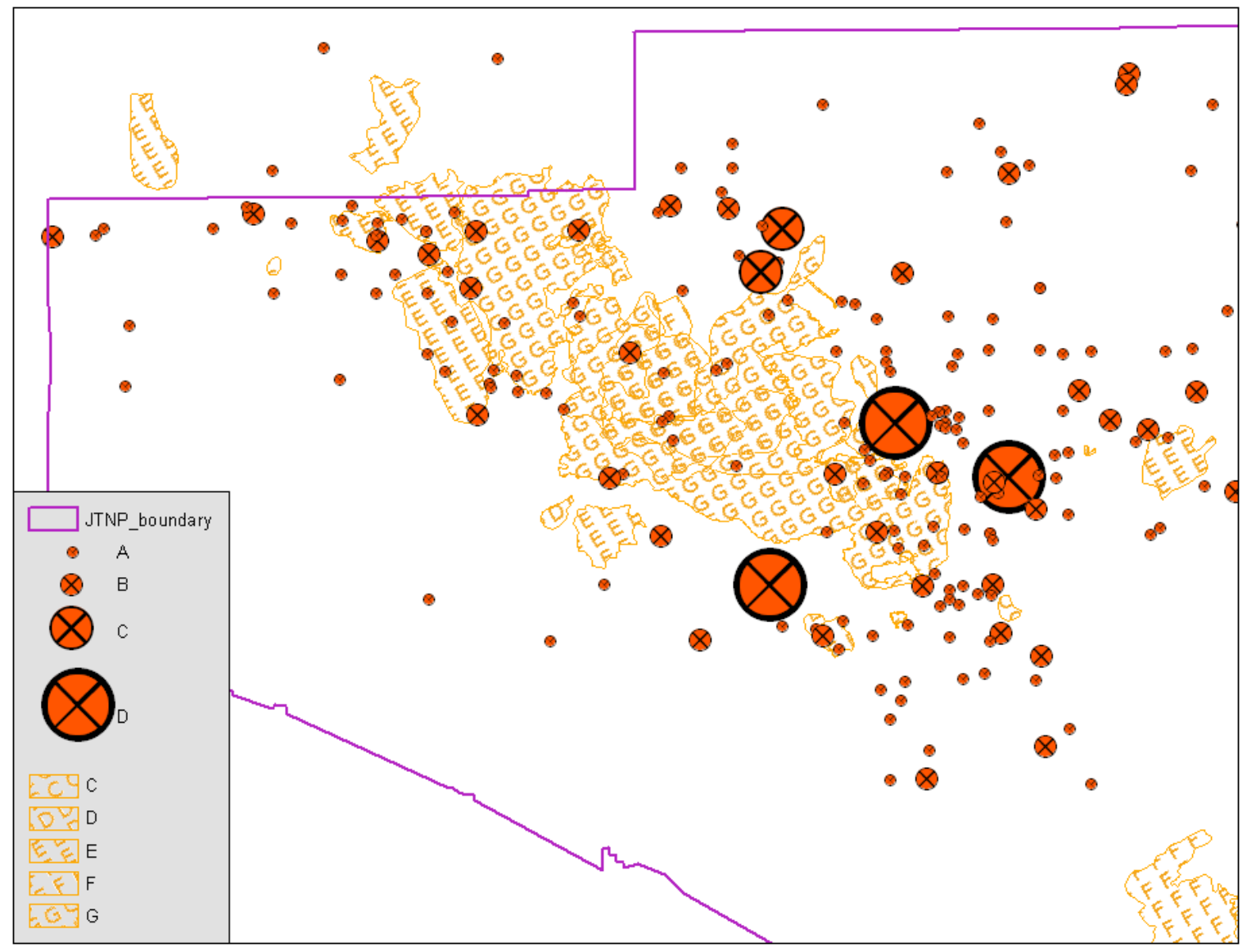

Figure 5-7: Symbolization of Fire Dataset in Map Interface

In addition to classification, the historic wildfire data were organized by the year each fire occurred using definition queries. Within each decade, the fires were broken into groups based on whether they occurred before, between, or after the wet and dry years that were being analyzed. Figure 5-8 illustrates a sample arrangement of the data layers for one decade. This grouping of fire display allows the user to perform a visual 
analysis of how historic fire may have affected the vegetation indices. For example, for the 1980s decade, the user can navigate the interface to investigate the following sequence: fires that occurred before 1984, vegetation indices for 1984, an overlay of the fires that occurred in 1984 on the vegetation indices for 1984, fires that occurred between 1984 and 1987, vegetation indices for 1987, an overlay of the fires that occurred in 1987 on the vegetation indices for 1987, the difference in vegetation indices for the 1980s, and finally, an overlay of all the fires that occurred in the 1980s on the difference in vegetation indices for the 1980s.

$\square \quad 1980$ s
$+\square$ 1980sFire
$+\square$ dSAVI80s
$+\square$ dNDVI80s
$+\square$ Fire=1987
$+\square$ SAVI1987
$+\square$ NDVI1987
$+\square$ Fire $<1987$
$+\square$ Fire=1984
$+\square$ SAVI1984
$+\square$ NDVI1984
$+\square$ Fire $<1984$

Figure 5-8: Sample Arrangement of Data Layers

\subsection{Symbolizing Human Disturbance}

The Disturbance dataset was added to the interface as a group layer. As discussed in Chapter 3, the Disturbance dataset consists of roads, trails and campsites. The addition of areas of human disturbance to the ArcMap interface gives the user more information about potential areas of annual brome growth, allowing for a more thorough visual analysis.

\subsection{Summary}

This chapter provided an illustration of the ArcMap interface developed for this project. The overall design of the interface was introduced and the steps taken to organize the contents were outlined. The chapter discussed the importance of symbolization and classification and how the user benefitted from the careful interface design. With the implementation of the solution completely described, the following chapter discusses the results of the project. 


\section{Chapter 6 - Results and Analysis}

This chapter presents the results of the project and discusses the analysis completed to determine annual brome presence. First, the results of the vegetation indices are explored and discussed. Next, the process of determining annual brome presence is described in detail. This process included analyzing the impacts of known locations of brome presence, historic fire boundaries, and areas of human disturbance on the current annual brome extent, and how these factors are used to determine that extent.

\subsection{Vegetation Index Results}

The following sub-sections describe the results obtained from calculating the vegetation indices and the differences in vegetation indices for the 1980s, 1990s, and 2000s.

\subsubsection{NDVI and SAVI}

The Normalized Difference Vegetation Index (NDVI) and the Soil Adjusted Vegetation Index (SAVI) were successfully calculated for each Landsat TM image obtained for analysis. With the exception of the 2007 image, each NDVI and SAVI calculation returned valid results, values between -1 and 1 . The 2007 Landsat TM image obtained from the USGS Earth Explorer website contained some NO DATA pixel values (see Figure 6-1). Despite the NO DATA values, this image was included in the analysis because the image quality within the study area boundary was acceptable, the image had $0 \%$ cloud cover, and the image capture date was the closest to May $15^{\text {th }}$ out of the available imagery. The NDVI and SAVI values in the study area were not affected by the image error and the invalid results; values below -1 or above 1 were excluded from analysis (see Figure 6-2 and Figure 6-3). 


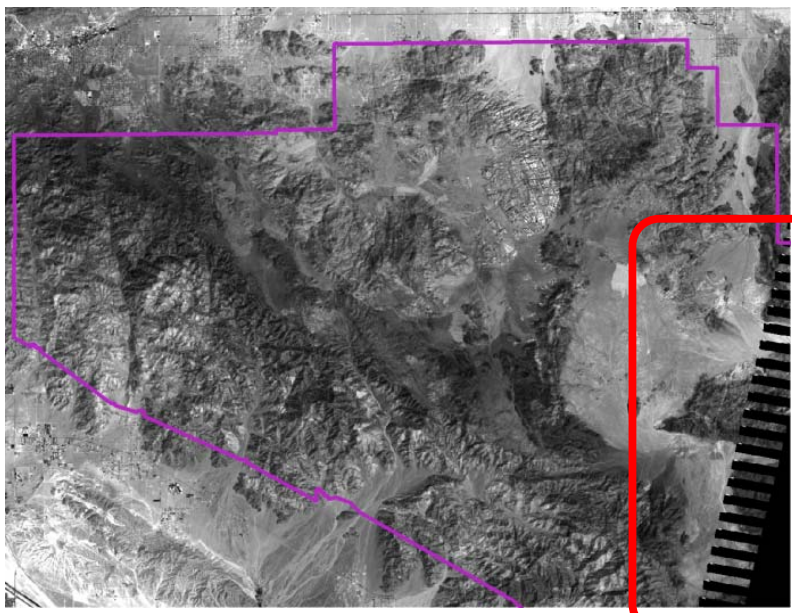

Figure 6-1: Band 3 of the 2007 Landsat TM Image

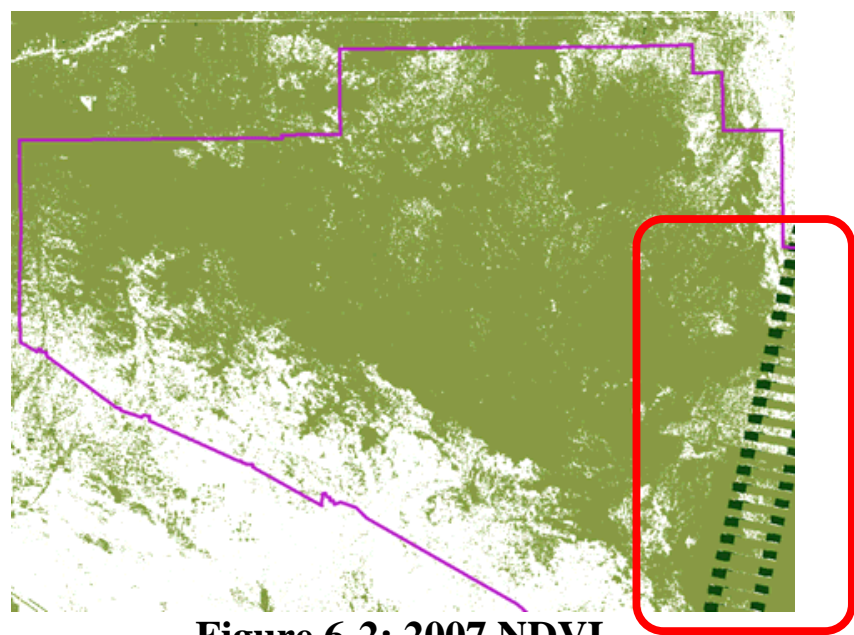

Figure 6-2: 2007 NDVI

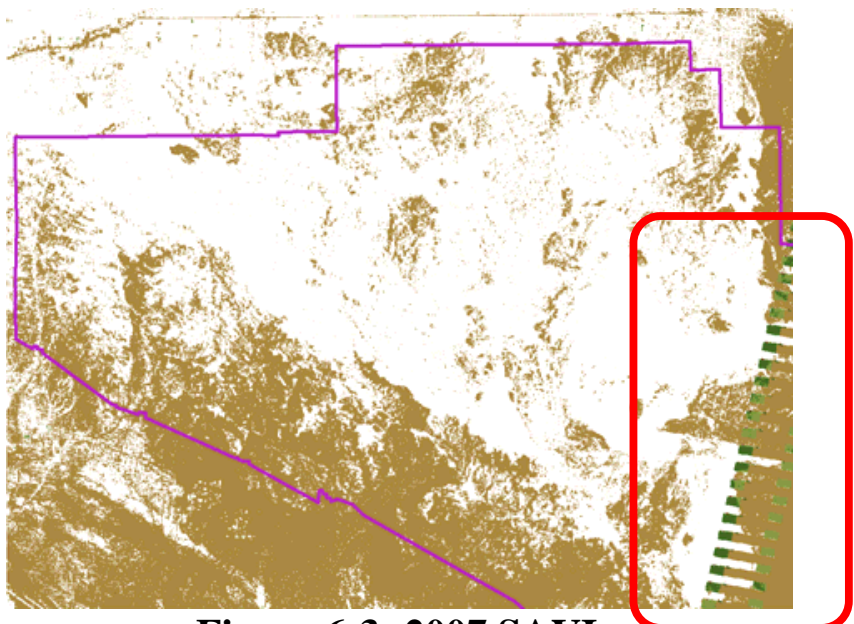

Figure 6-3: 2007 SAVI 
The first attempts to symbolize the NDVI and SAVI according to the methodology of Bradley and Mustard (2005) were not successful. These images were manually classified with five classes and a brown to green color map. The classes were: minimum value to $0,0.01$ to $0.15,0.16$ to $0.30,0.31$ to 0.45 , and .0 .46 to 1 . The images produced by this classification scheme were not informative because the large class sizes led to the image being dominated by one color, since most values fell between 0 and 0.15 (see Figure 6-4 and Figure 6-5).

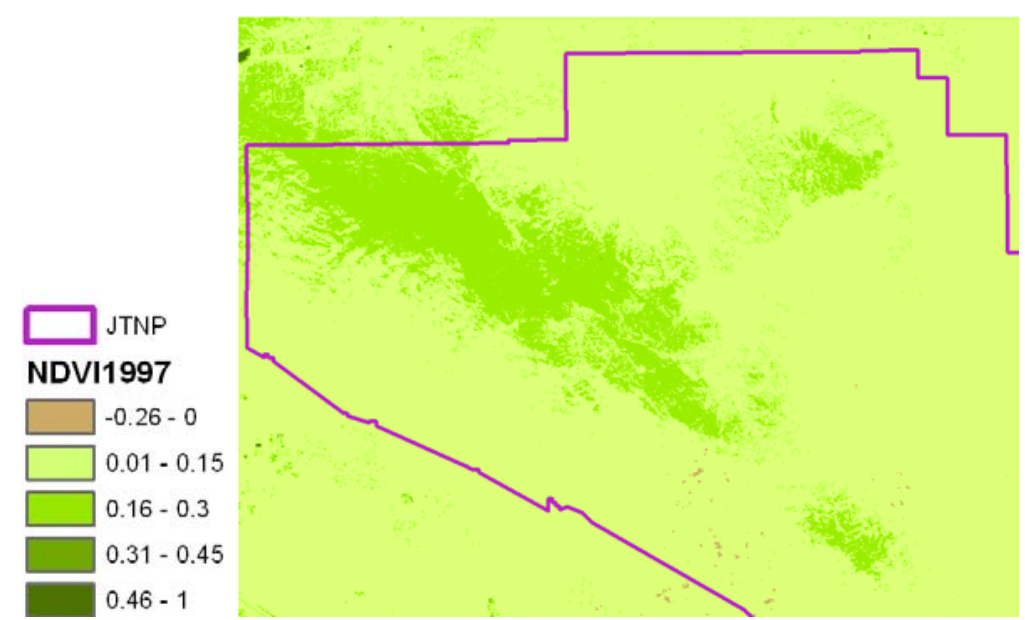

Figure 6-4: 1997 NDVI Manual Classification

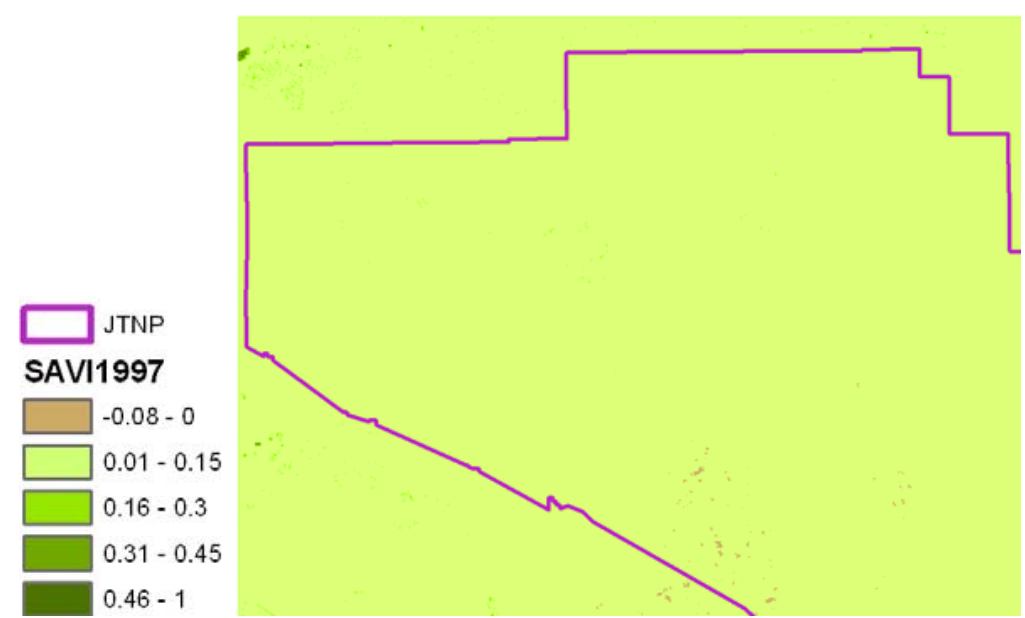

Figure 6-5: 1997 SAVI Manual Classification

Lee's (2009) method of symbolizing the SAVI using Natural Breaks was adopted and this provided more informative results (see Figure 6-6 and Figure 6-7). As Lee (2009) noted, the class breaks created by Natural Breaks emphasizes groupings that occur naturally within the data. As discussed in Chapter 5, each NDVI and SAVI was classified using Natural Breaks (Jenks) with seven classes and a brown to green color ramp. Brown represents areas of rock or bare soil, green represents healthy vegetation, and white represents areas with less healthy vegetation. 


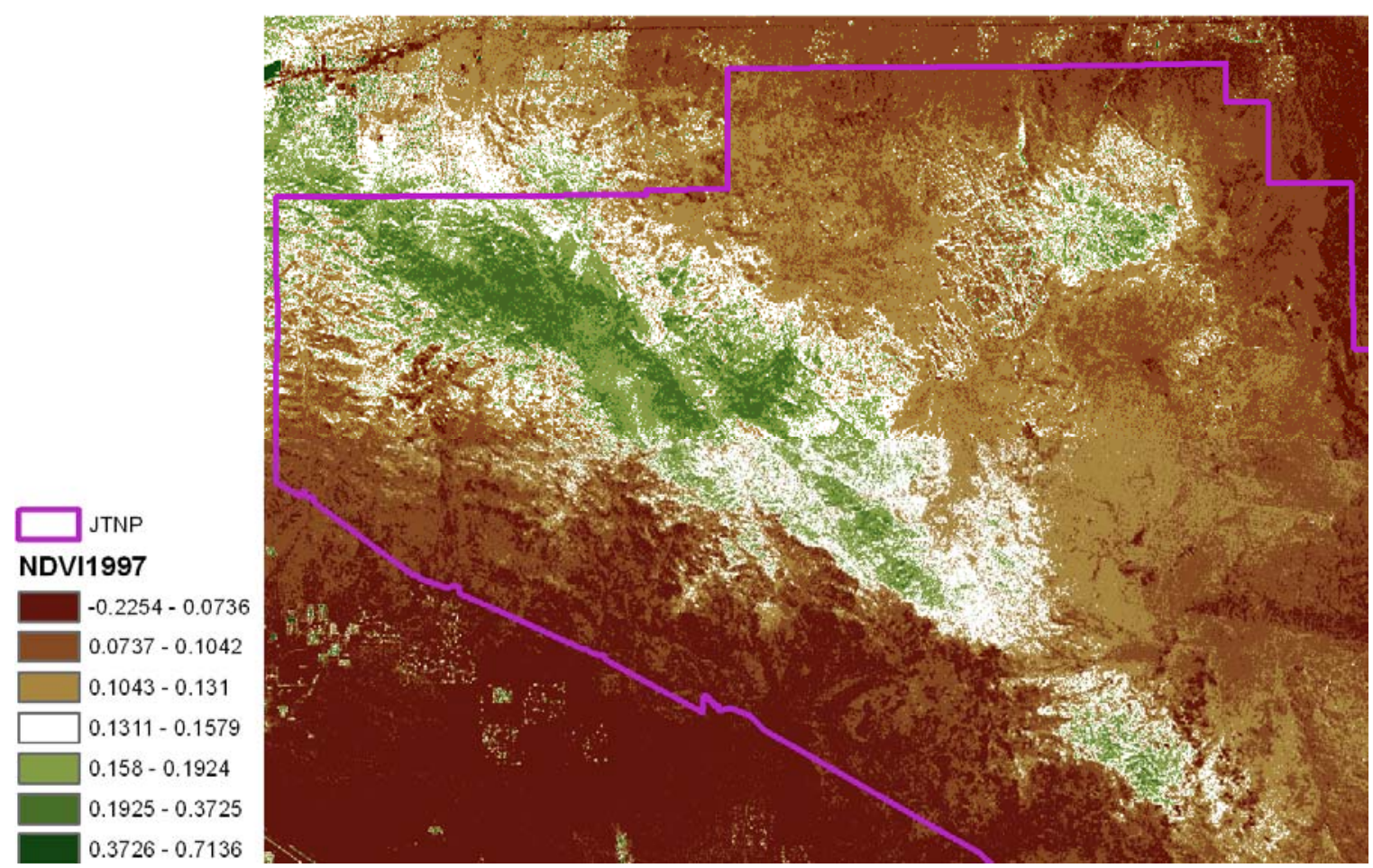

Figure 6-6: 1997 NDVI Natural Breaks (Jenks) Classification

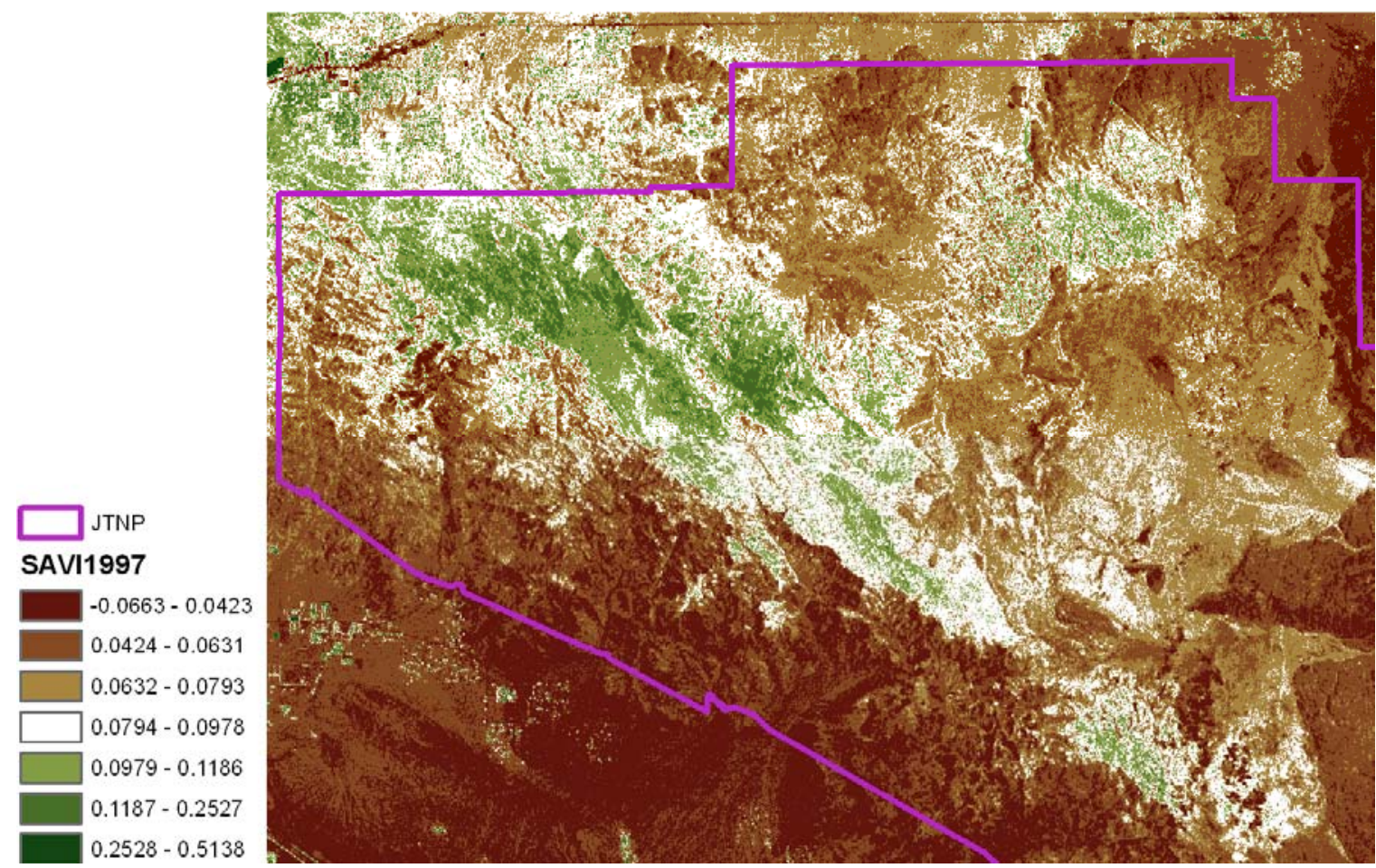

Figure 6-7: 1997 SAVI Natural Breaks (Jenks) Classification

The Natural Breaks classification was a better choice than manual classification, but in some cases it led to misrepresentation of the vegetation index. Figure 6-6 is an example of the Natural Breaks classification symbolizing healthy vegetation as bare soil. 
Values between 0.1 and 0.6 are widely accepted as values indicating healthy vegetation. In Figure 6-6, values between 0.1 and 0.16 are symbolized as brown or white, indicating to the user these areas have no vegetation. This is most likely explained by the fact that the NDVI is influenced by soil background and is not as accurate as the SAVI for detecting vegetation in desert habitats. Figure 6-7 supports this idea, with all values between 0.1 and 0.6 being symbolized as healthy vegetation in the SAVI image.

Despite issues with symbolizing the NDVI values, Natural Breaks was chosen as the preferred classification method for vegetation indices in the delivered map user interface. However, the interface gives the user freedom to choose a different classification scheme if necessary.

\subsection{2 dNDVI and dSAVI}

The change in NDVI and SAVI was successfully calculated for each decade. With the exception of the 2000s images, each calculation returned valid results, with all values between -1 and 1 . The errors in the 2007 Landsat TM images discussed in the previous section also negatively impacted the difference in vegetation index calculation, producing values below -1 and above 1 for the dNDVI00s image (see Figure 6-8). These invalid results were excluded from analysis.

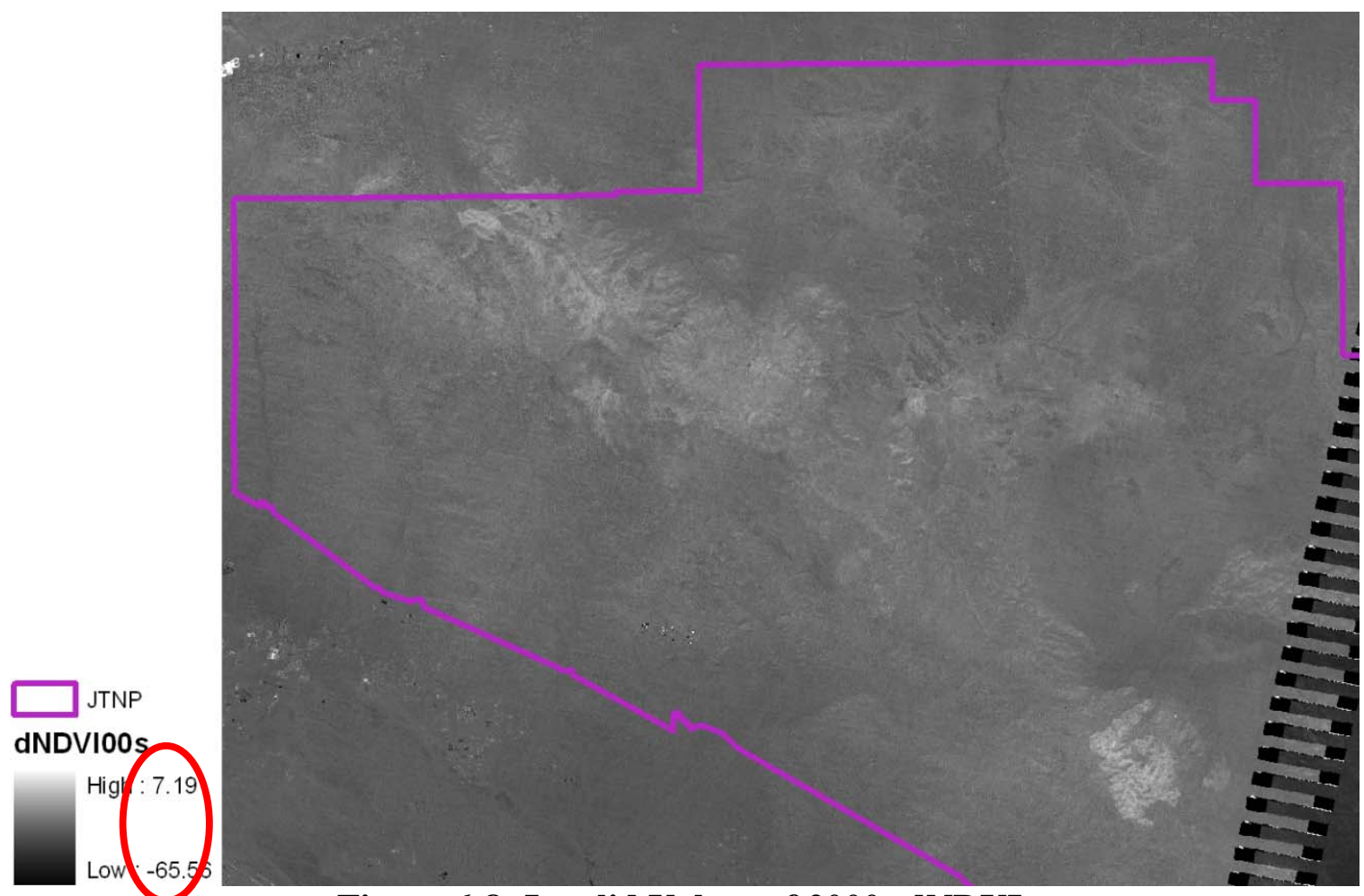

Figure 6-8: Invalid Values of 2000s dNDVI

Initial attempts to symbolize the dNDVI and dSAVI according to the methodology of Bradley and Mustard (2005) were not successful. The images were manually classified with five classes and a brown to green color map. The classes were: minimum value to $-0.14,-0.13$ to $0,0.01$ to $0.14,0.15$ to 0.26 , and 0.27 to maximum value. The 
images produced by this classification scheme were not informative because the class breaks led to the image being dominated by one color (see Figure 6-9 and Figure 6-10).

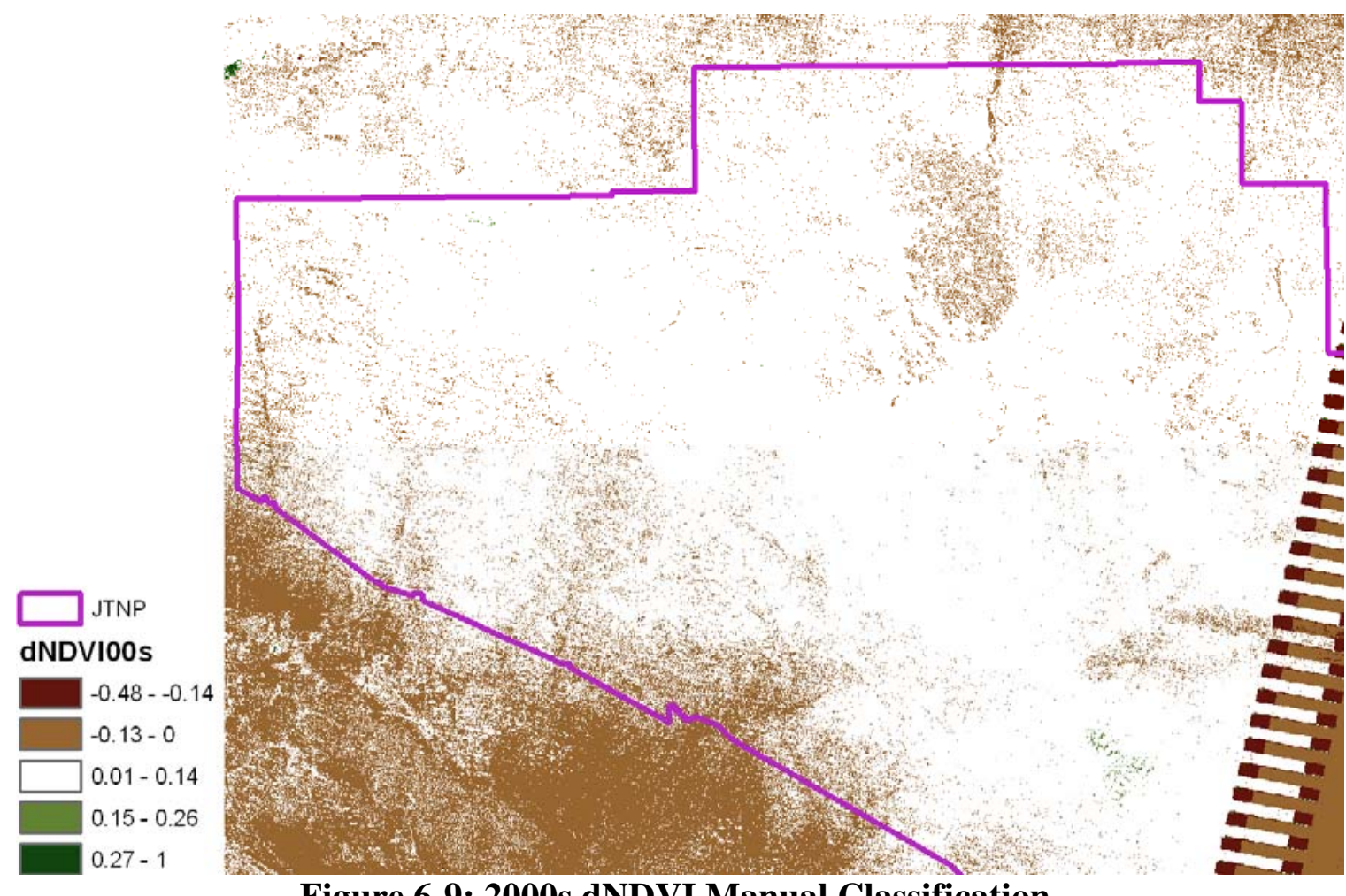

Figure 6-9: 2000s dNDVI Manual Classification

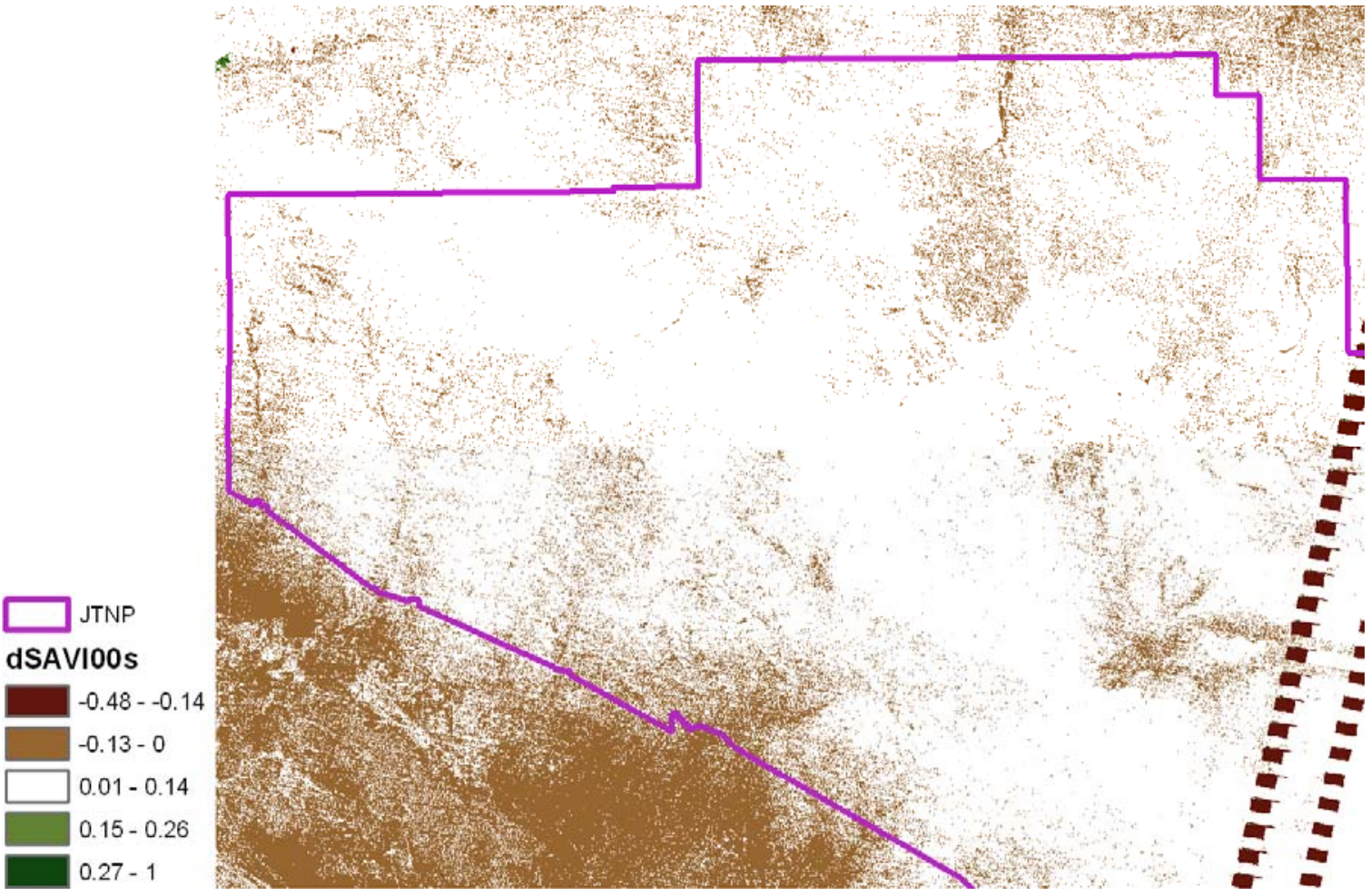

Figure 6-10: 2000s dSAVI Manual Classification 
A better method of manually classifying the dNDVI and dSAVI was developed and this method provided more informative results (see Figure 6-11 and Figure 6-12). As discussed in Chapter 5, each dNDVI and dSAVI was manually classified using 5 classes and a brown to green color ramp. The classes were: minimum value to $-0.08,-0.07$ to $0.04,-0.03$ to $0.04,0.05$ to 0.08 , and 0.09 to maximum value. The color brown symbolizes vegetation areas that lost health from the dry year to the wet year, with darker brown representing a more drastic loss in health. The color green symbolizes vegetation areas that gained health from the dry year to the wet year, thus representing the vegetation's amplified response to rainfall, with darker green representing areas with greater response.

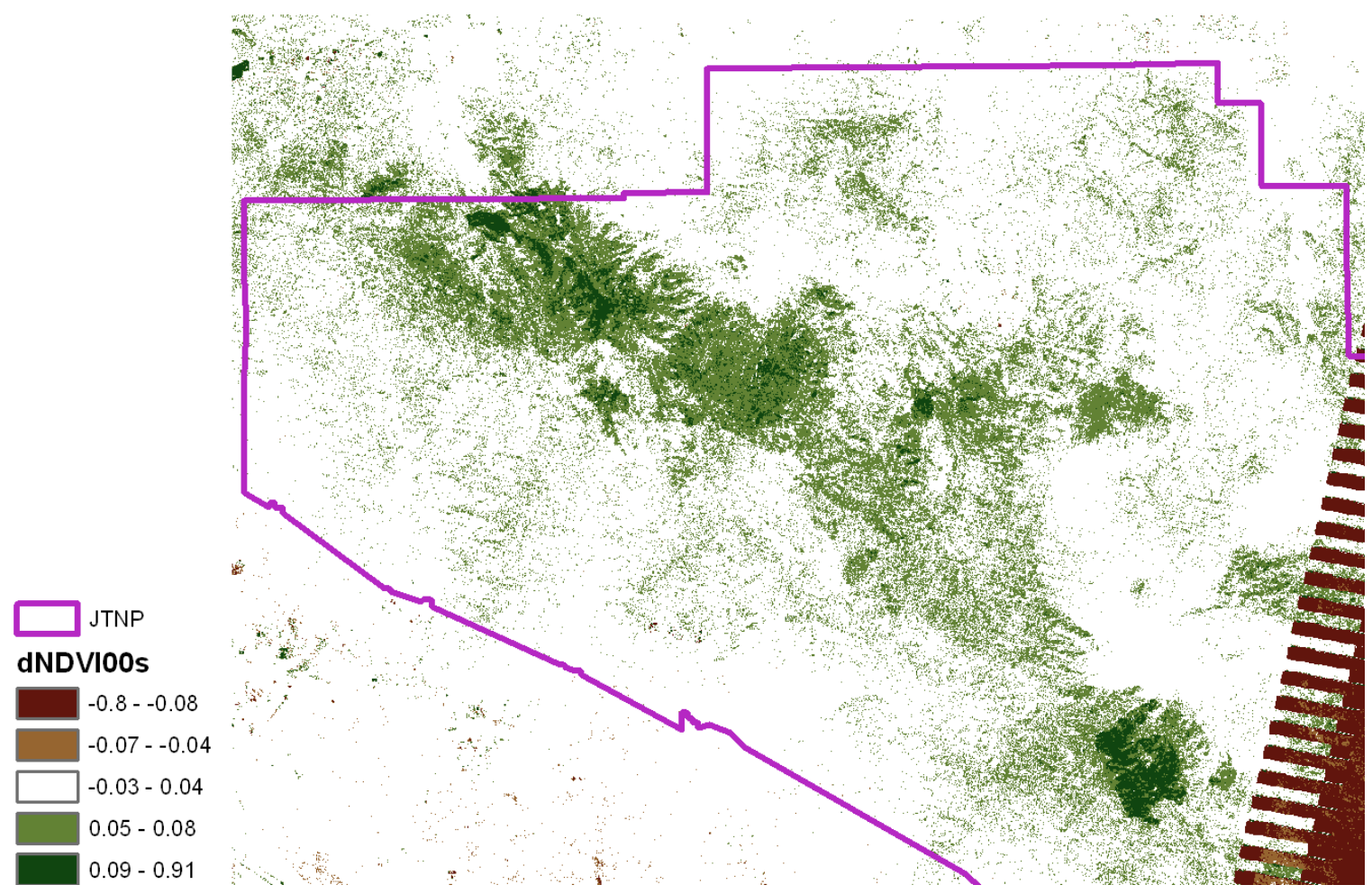

Figure 6-11: Improved 2000s dNDVI Manual Classification 


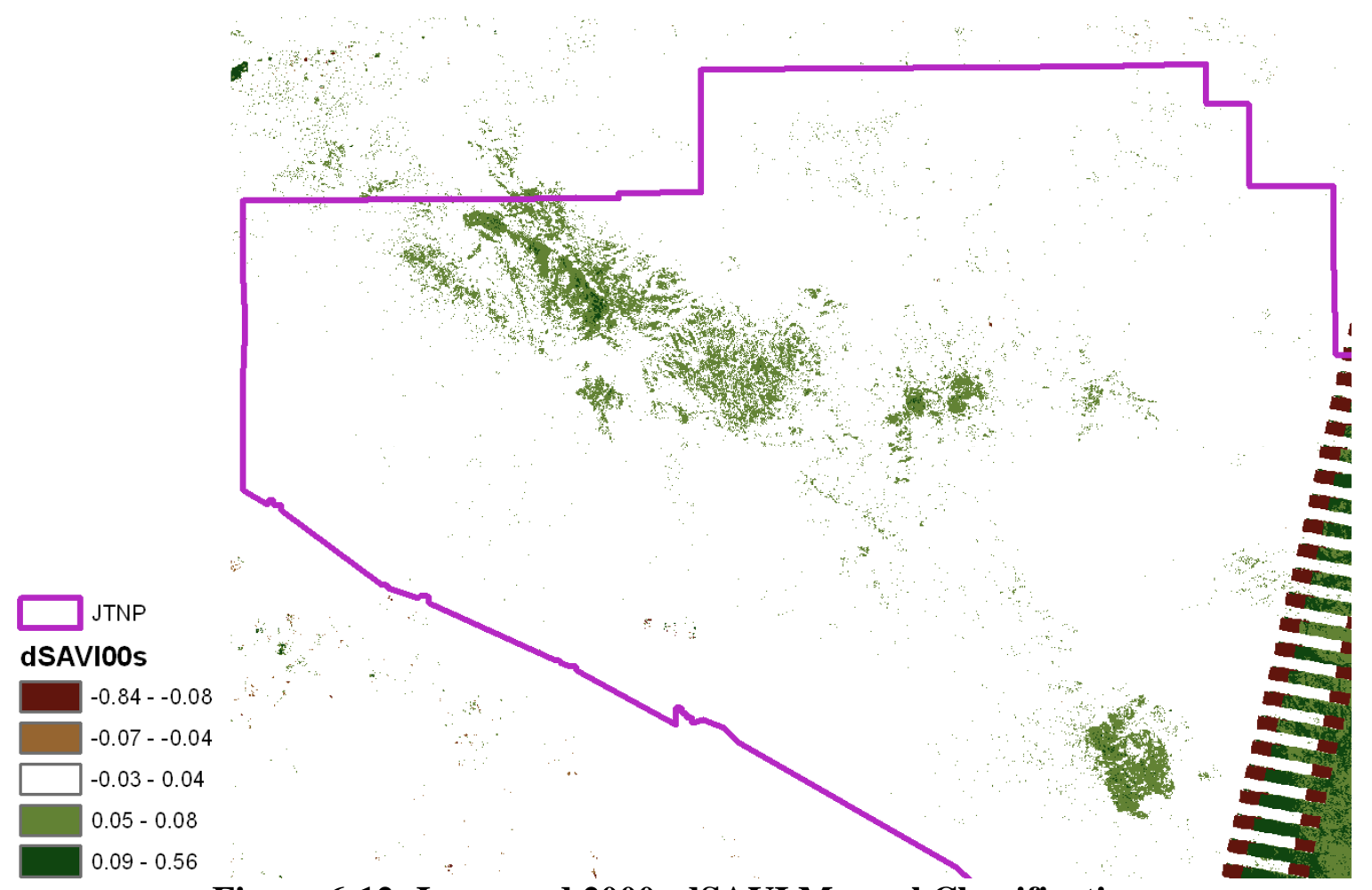

Figure 6-12: Improved 2000s dSAVI Manual Classification

This improved manual classification allows the user to clearly identify areas of vegetation with an amplified response to rainfall, areas where vegetation has lost health, and areas where no change in vegetation occurred between the wet and dry years. By using the same class breaks for each vegetation index, the user can compare and contrast the indices without error. The user can observe change because the class breaks are standardized across the decades. The five classes also allow the user to observe areas with drastic change and areas with moderate change. Symbolizing the zero value class with the color white gives the user a clear understanding that this neutral class represents areas of insignificant change. Although this is the preferred classification for the difference vegetation indices in the delivered map user interface, the user is free to modify the symbolization.

\subsection{Determining Annual Brome Presence}

As discussed in previous chapters, this project uses the methodology of Bradley and Mustard (2005) to determine the current extent of annual brome within Joshua Tree National Park. Bradley and Mustard (2005) observed the amplified response of annual brome to precipitation and used this response to map its extent. By calculating the difference in NDVI and SAVI for the study area, this amplified response can be observed in JTNP. The following subsections analyze the observed difference in vegetation indices for the study area and the attempts to validate these observations with known annual brome locations and locations where annual brome is mostly likely to grow. 


\subsubsection{Using Vegetation Indices}

Following the methods of Bradley and Mustard (2005), the amplified response of vegetation to rainfall observed in the difference vegetation indices is assumed to be an indication of annual brome presence. Specifically, areas with a dNDVI or dSAVI value of 0.09 or greater are assumed to be areas of annual brome infestation. Due to errors in the 2000s images and the existence of urban areas in the north and the southwest corner of the study area, some pixels with 0.09 or greater values were excluded from the visual analysis (see Figure 6-13). Figures 15 through 17 identify areas of possible annual brome infestation. Figure 6-14 is the legend to be used for each of the Figures 15 through 17.

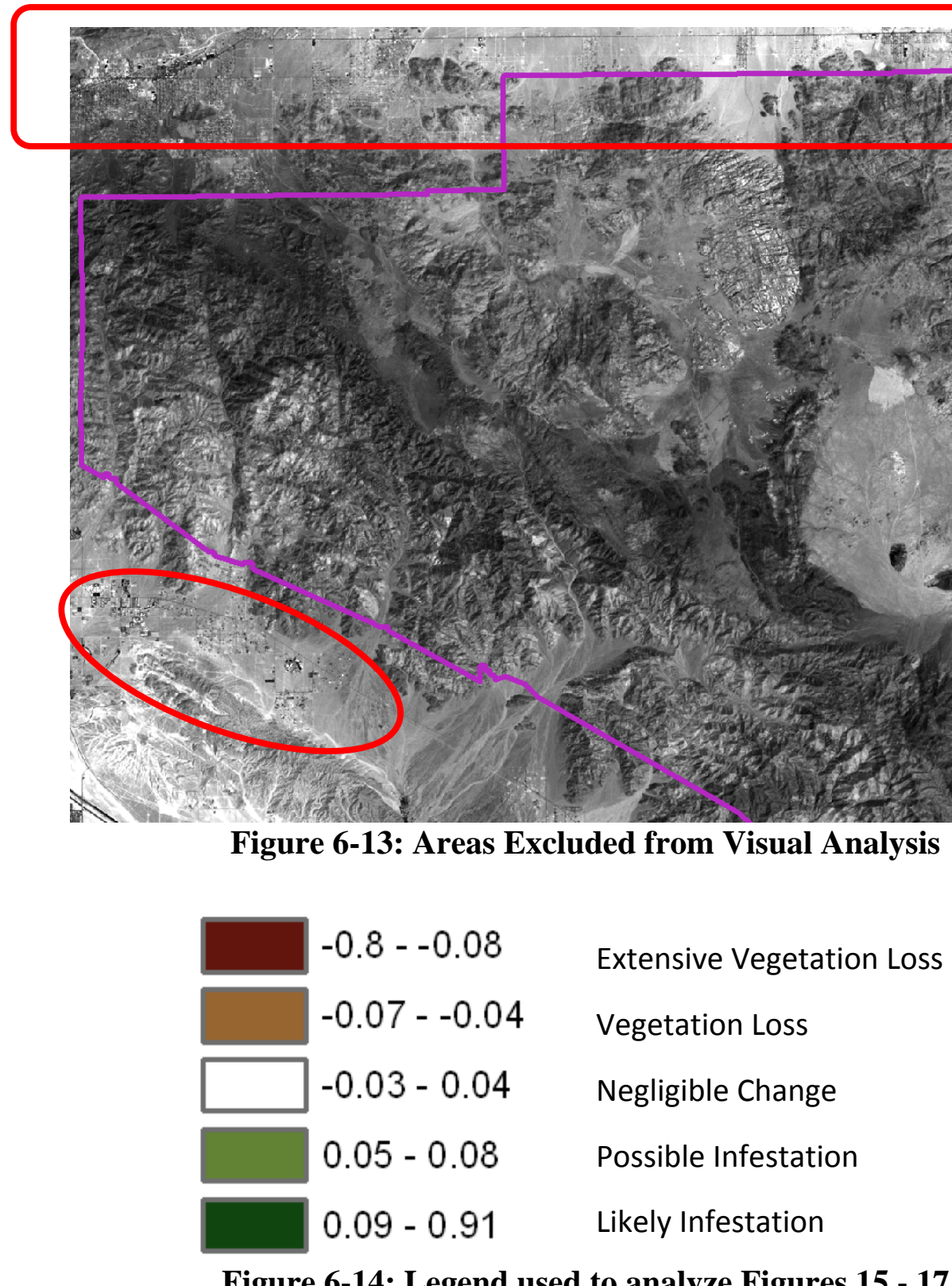

Figure 6-14: Legend used to analyze Figures 15 - 17 

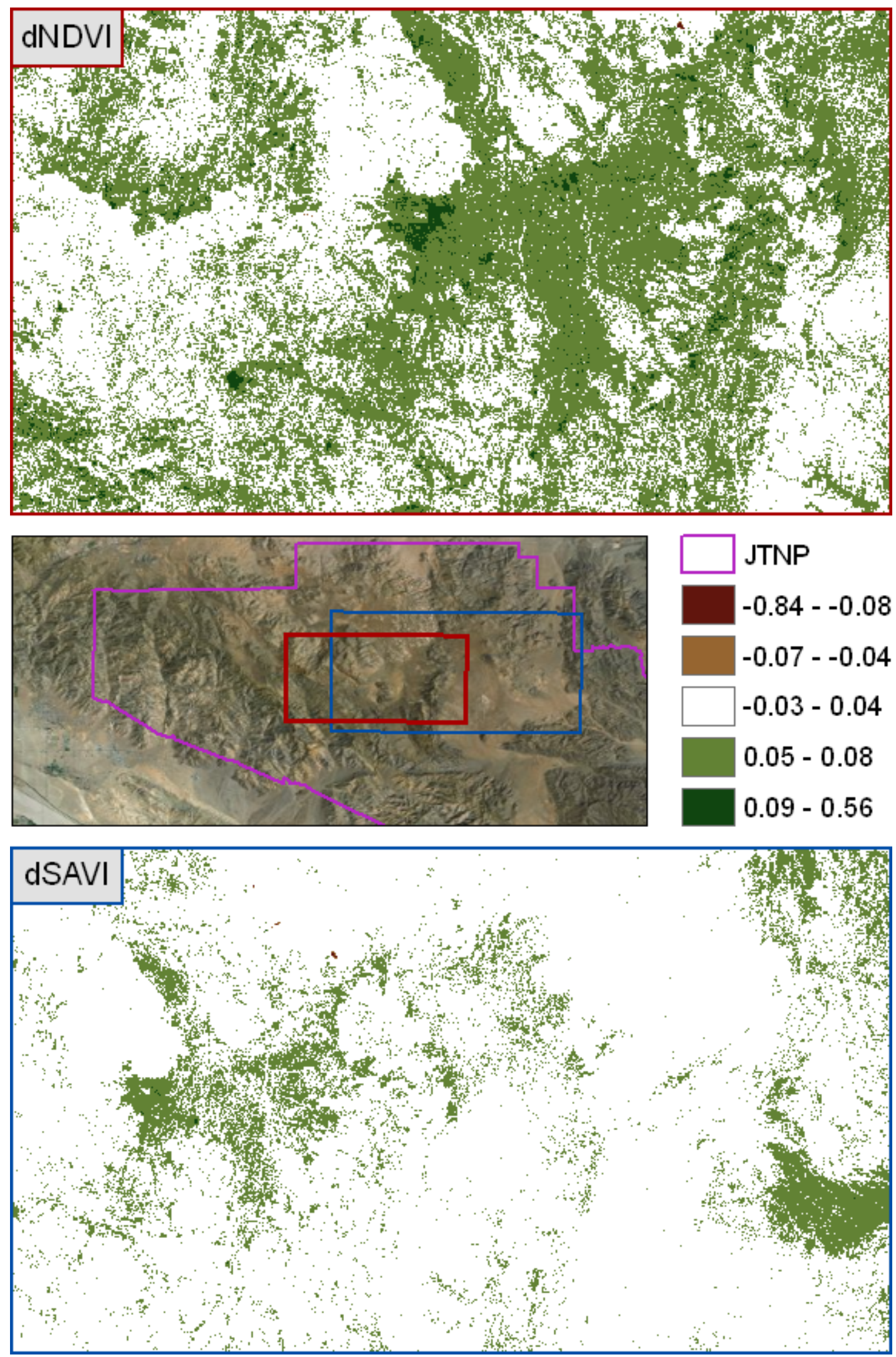

Figure 6-15: 1980s dNDVI and dSAVI Showing Possible Brome Infestation 


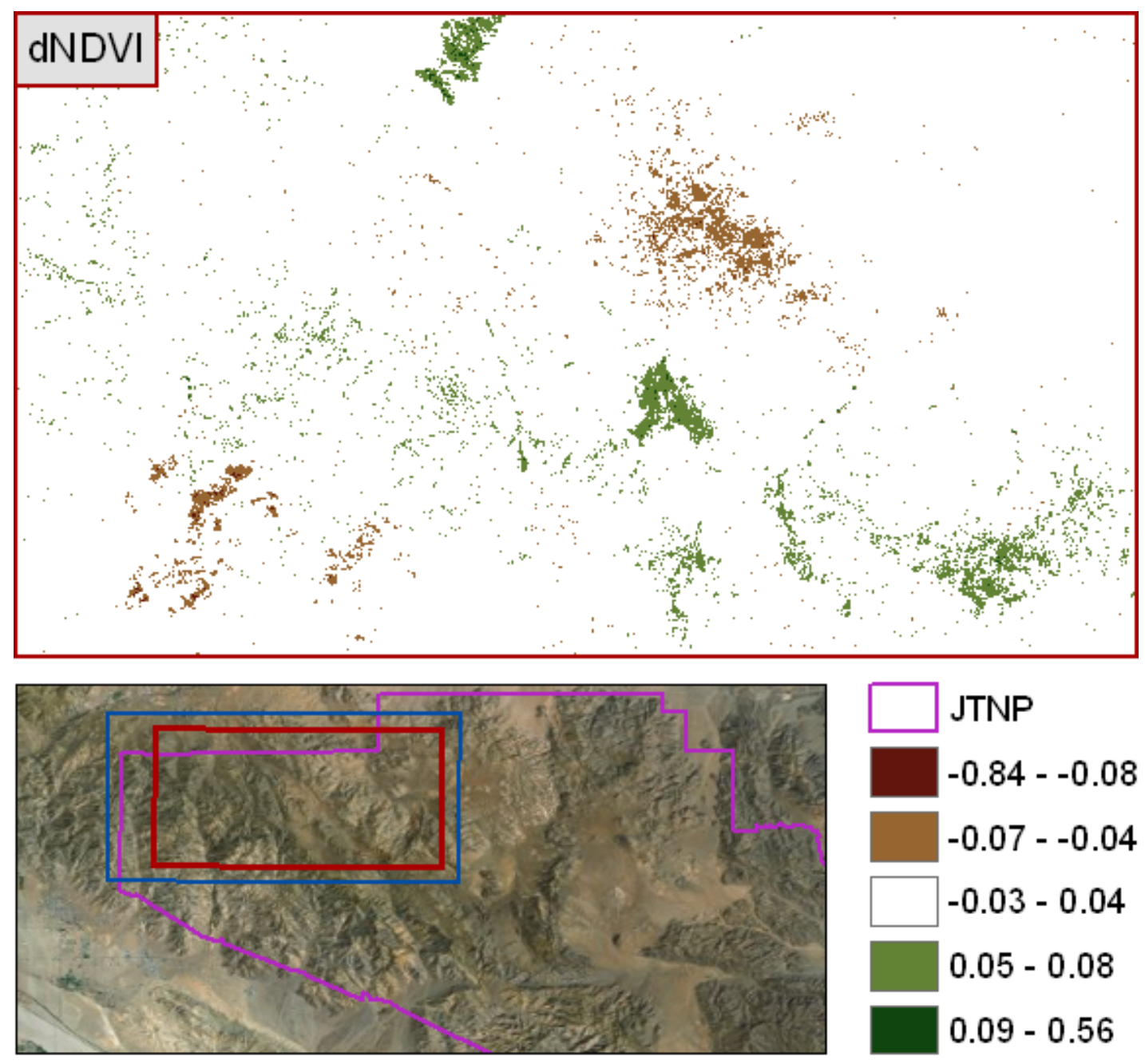

\section{dSAVI}

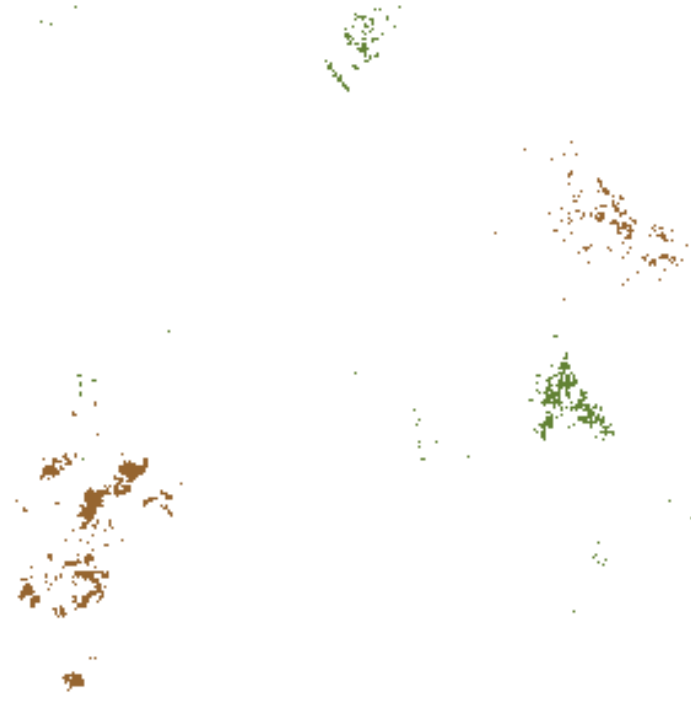

Figure 6-16: 1990s dNDVI and dSAVI Showing Possible Brome Infestation 

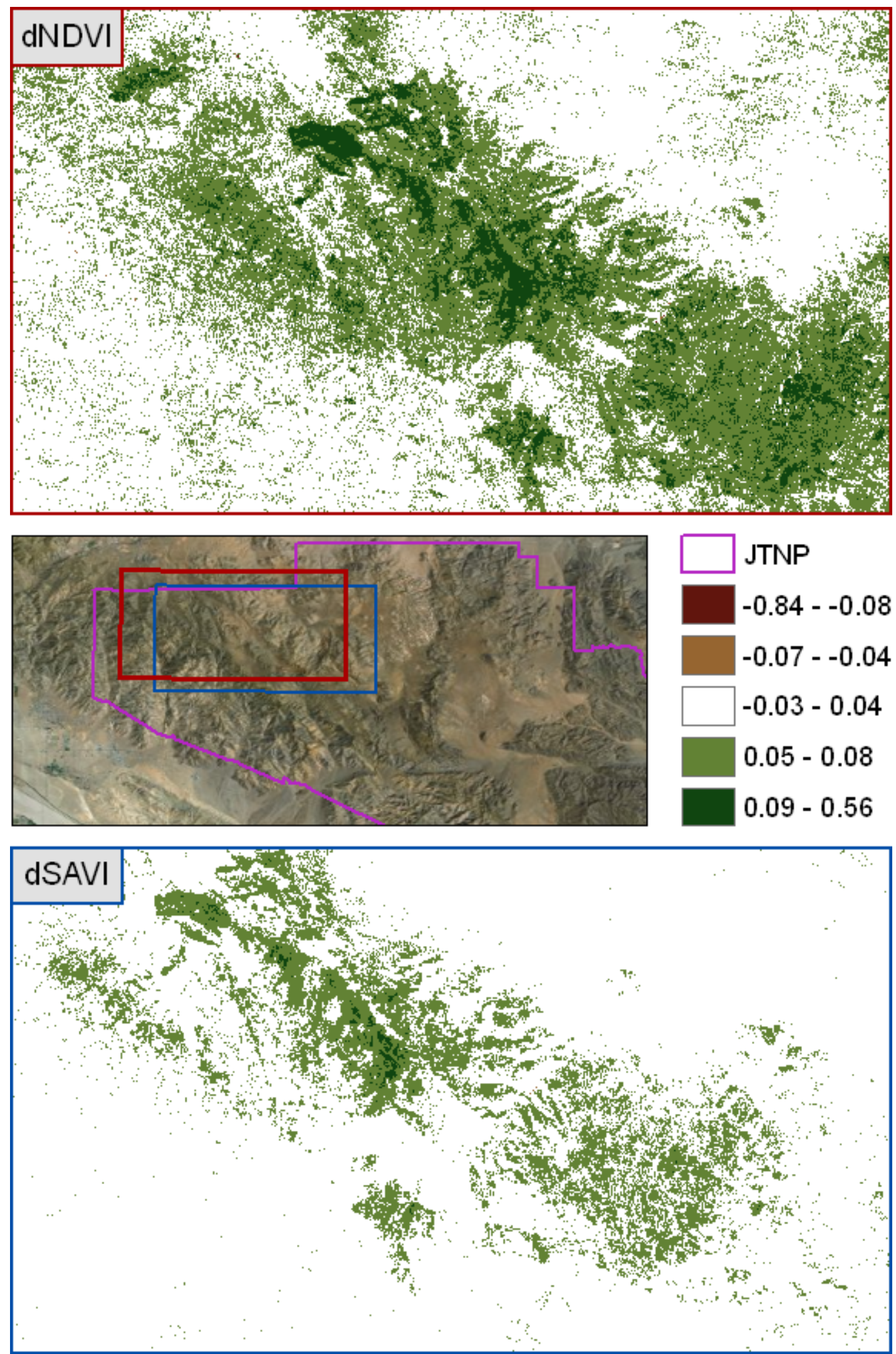

Figure 6-17: 2000s dNDVI and dSAVI Showing Possible Brome Infestation 


\subsubsection{Using Known Locations of Brome}

The scope of this project did not include the extensive field observation process that Bradley and Mustard (2005) underwent to verify their findings. This project used annual brome presence data to verify the analysis discussed in the previous section. Joshua Tree National Park provided the point feature class described in Chapter 3 for this purpose. The feature class did not cover the entire study area, the sample points were not randomly distributed, and each point represented a 10x10 meter vegetation plot located near popular boulders within the park. Despite the feature class's shortcomings, the data were accurate points of known annual brome existence. If these points matched up to the areas of amplified response to rainfall, the vegetation index analysis could be considered viable.

Because the brome presence data were collected in 2008 and 2009, the points were compared to the 2000s vegetation indices first. One would expect high difference in vegetation index values at the brome presence points for the vegetation index analysis to be verified. For the dNDVI, most of the brome points fell on areas of amplified response, but there were very few that occurred in areas of a large difference in NDVI (see Figure 6-18). For the dSAVI, there were a few points of amplified response but the majority of brome points fell on no-change areas (see Figure 6-18). This visual analysis did not support the assumption that amplified response to rainfall indicates the presence of annual brome. 

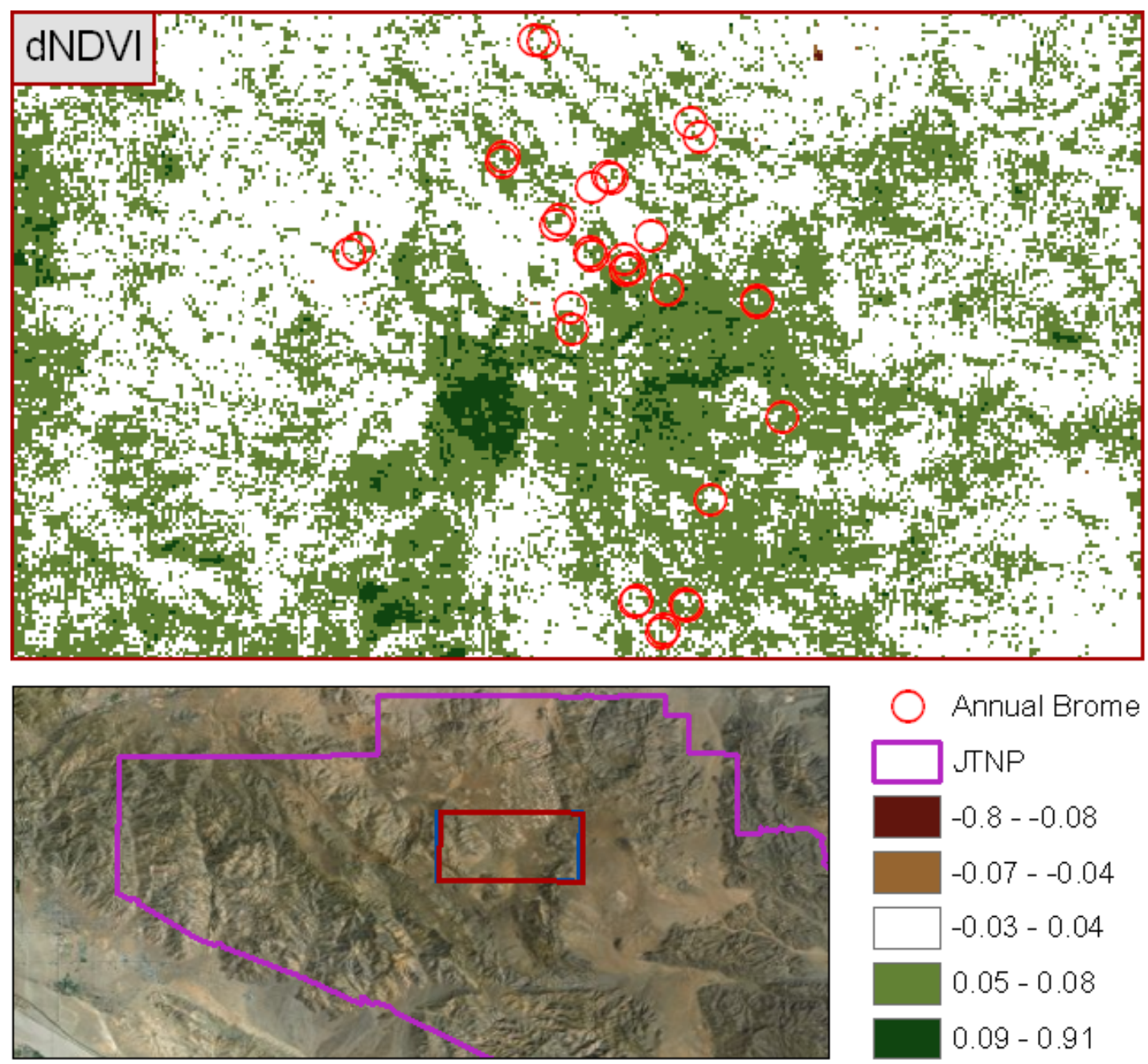

Annual Brome

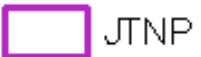

$-0.8--0.08$

$-0.07--0.04$

$\square-0.03-0.04$

$0.05-0.08$

$0.09-0.91$

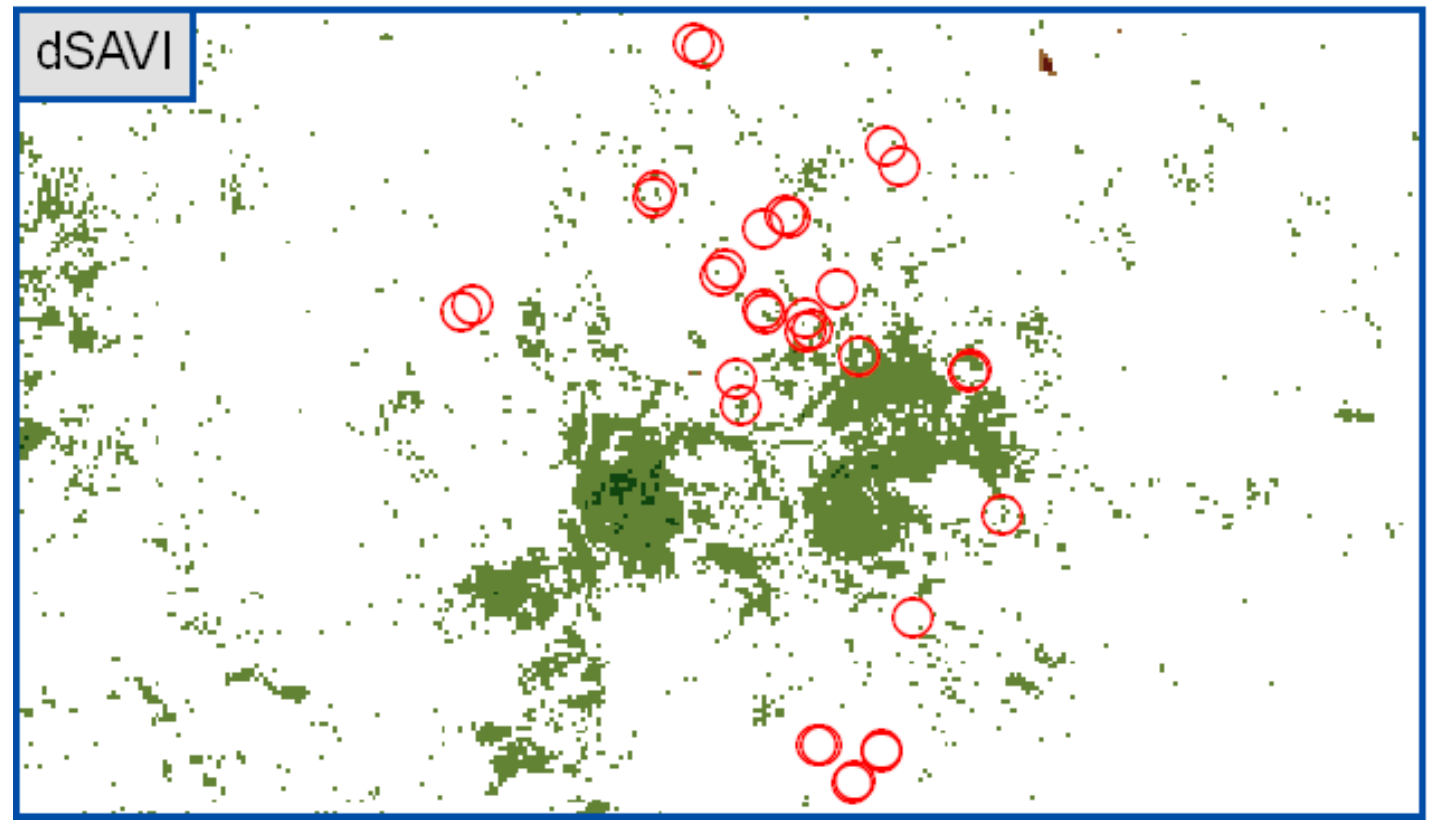

Figure 6-18: 2000s dNDVI and dSAVI with Annual Brome Presence Points 
According to Bradley and Mustard (2006), if annual brome exists in an area currently, it is likely that it existed in the same area previously. The 1990s and 1980s vegetation indices were compared to the brome presence points for this reason. The visual analyses of these vegetations indices confirmed the results of the 2000s analysis. A positive difference between wet and dry year vegetation indices is not a strong enough indicator of annual brome presence. Field observation and sampling is necessary to produce viable results using the methodology of Bradley and Mustard (2005).

\subsubsection{Using Historic Fire Boundaries}

As discussed in Chapter 2, wildfires are known to promote the invasion of annual brome. A visual analysis was completed to detect patterns between historic wildfire boundaries and annual brome presence. The map interface allows the user to view fire boundaries by decade the fire burned, thus allowing a time-series analysis of fire and annual brome spread.

Two of the largest fires that occurred in JTNP were the Covington fire in 1995 and the Juniper Complex fire in 1999. Using the interface to explore fire data from the 1990s and the 2000s vegetation indices, it was determined that the fire boundaries and the increase in vegetation health occurred in the same area (see Figure 6-19). There were no brome presence points to verify this observation, but the fact that devastating wildfires promote annual brome growth supports the possibility that, in this case, the difference in vegetation indices may indicate annual brome infestation. 

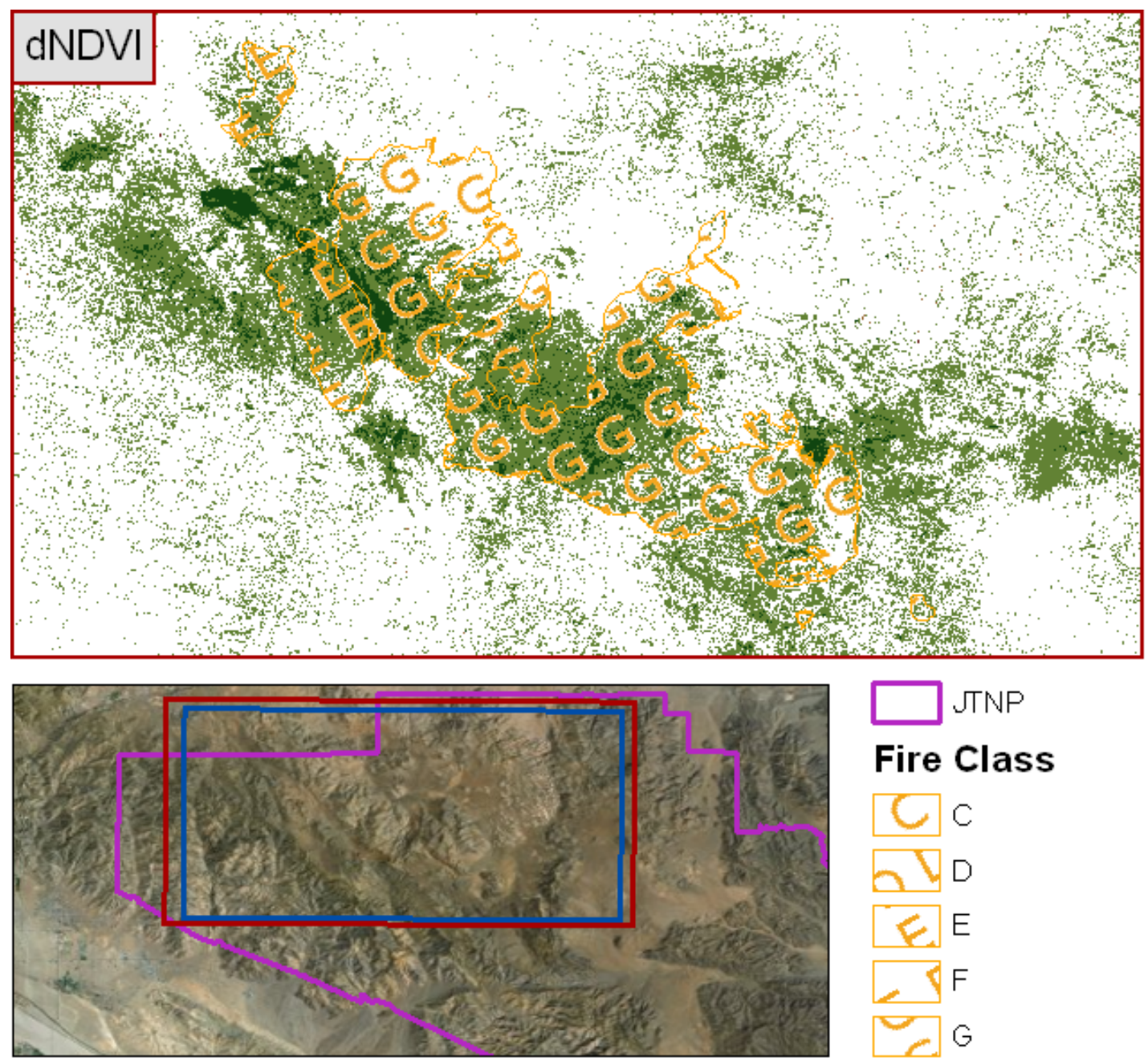

$\square$ JNP

Fire Class
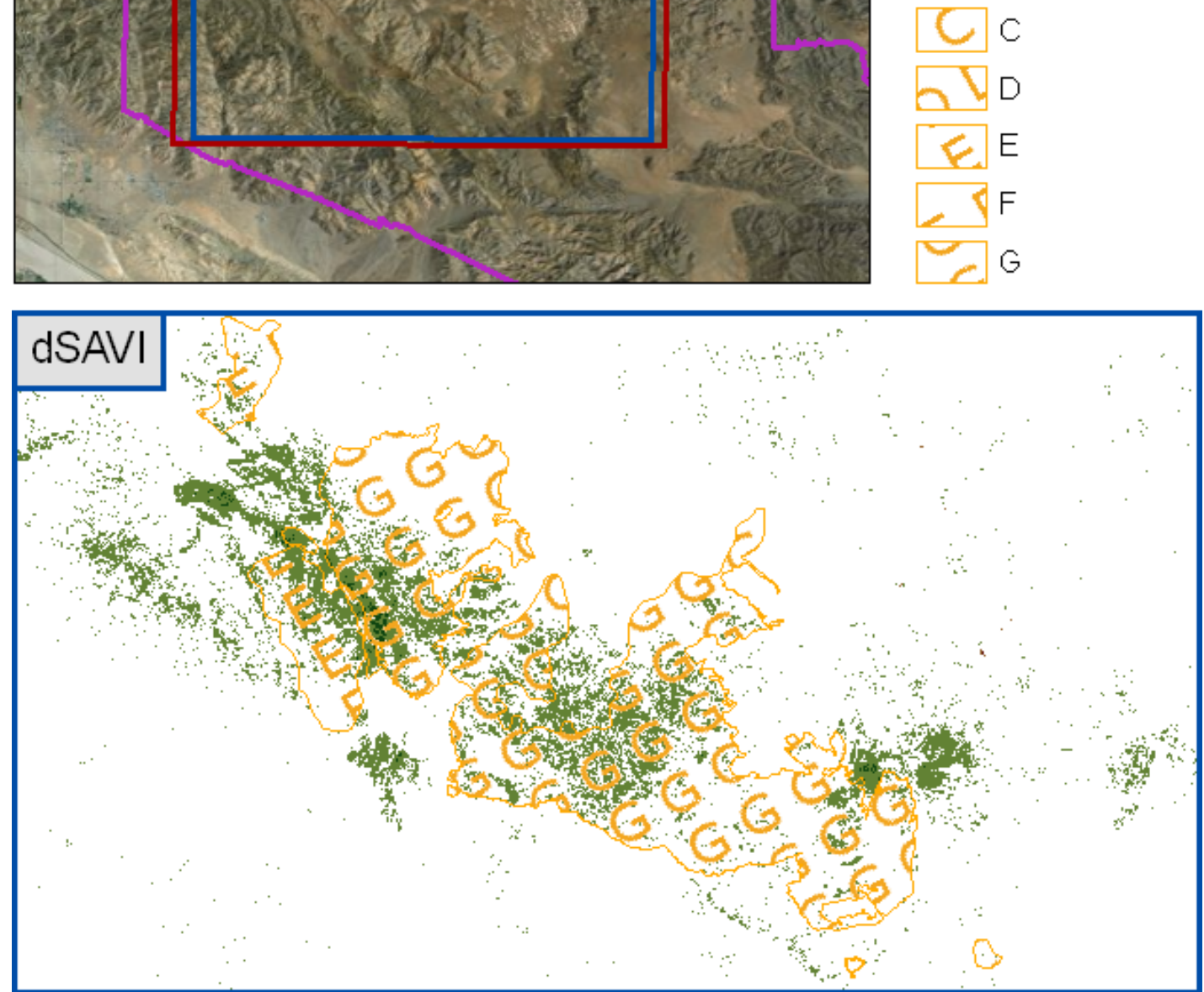

Figure 6-19: 1990s Fire and 2000s dNDVI and dSAVI 


\subsubsection{Using Areas of Human Disturbance}

The influence of human disturbance on the spread of annual brome was discussed in Chapter 2. Seeds get caught in tire treads and spread along roads. They also get caught in human clothing and spread along trails and throughout campsites. A visual analysis was completed to detect patterns between areas of human disturbance and areas of annual brome presence. The map interface allows the user to explore human disturbance dataroads, trails, campgrounds - and compare these data with the difference in vegetation indices and the brome presence points. The visual analysis of the human disturbance data produced interesting, but inconclusive results. There were some examples supporting the claims that human disturbance promotes annual brome infestation, but in the majority of cases, the visual analysis results were not strong enough to definitively map the extent of annual brome.

Figure 6-20 provides an example of increased vegetation along roads and trails. This area has also been burned by wildfires, which may also produce increased growth of annual brome. Given the uncertainty of the type of vegetation, and the cause of its increase, this example does not provide an extent of annual brome. However, it is interesting to see such high SAVI differences in areas where one would expect annual brome infestation. 

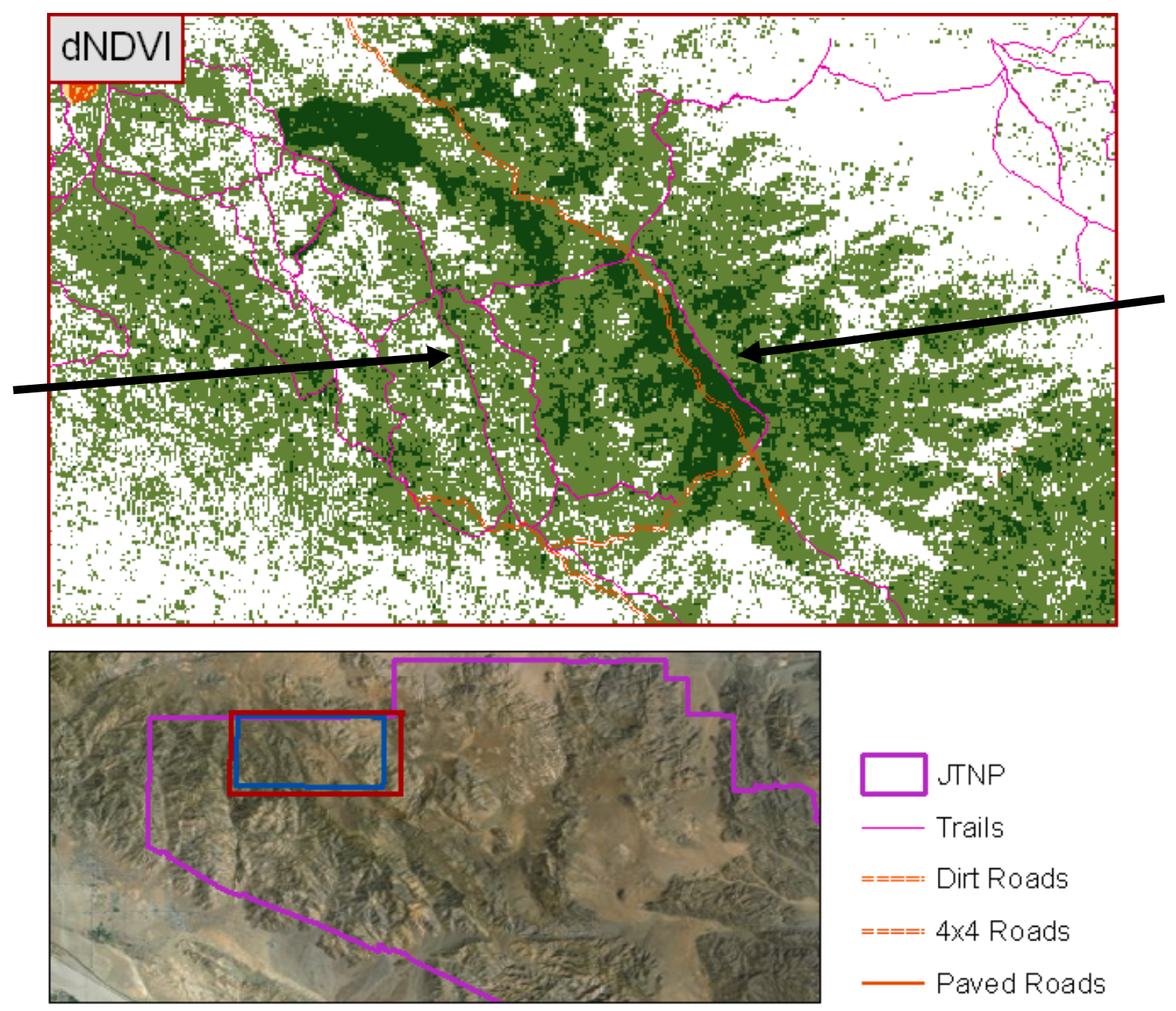

$====$ Dirt Roads

$====: 4 \times 4$ Roads

- Paved Roads

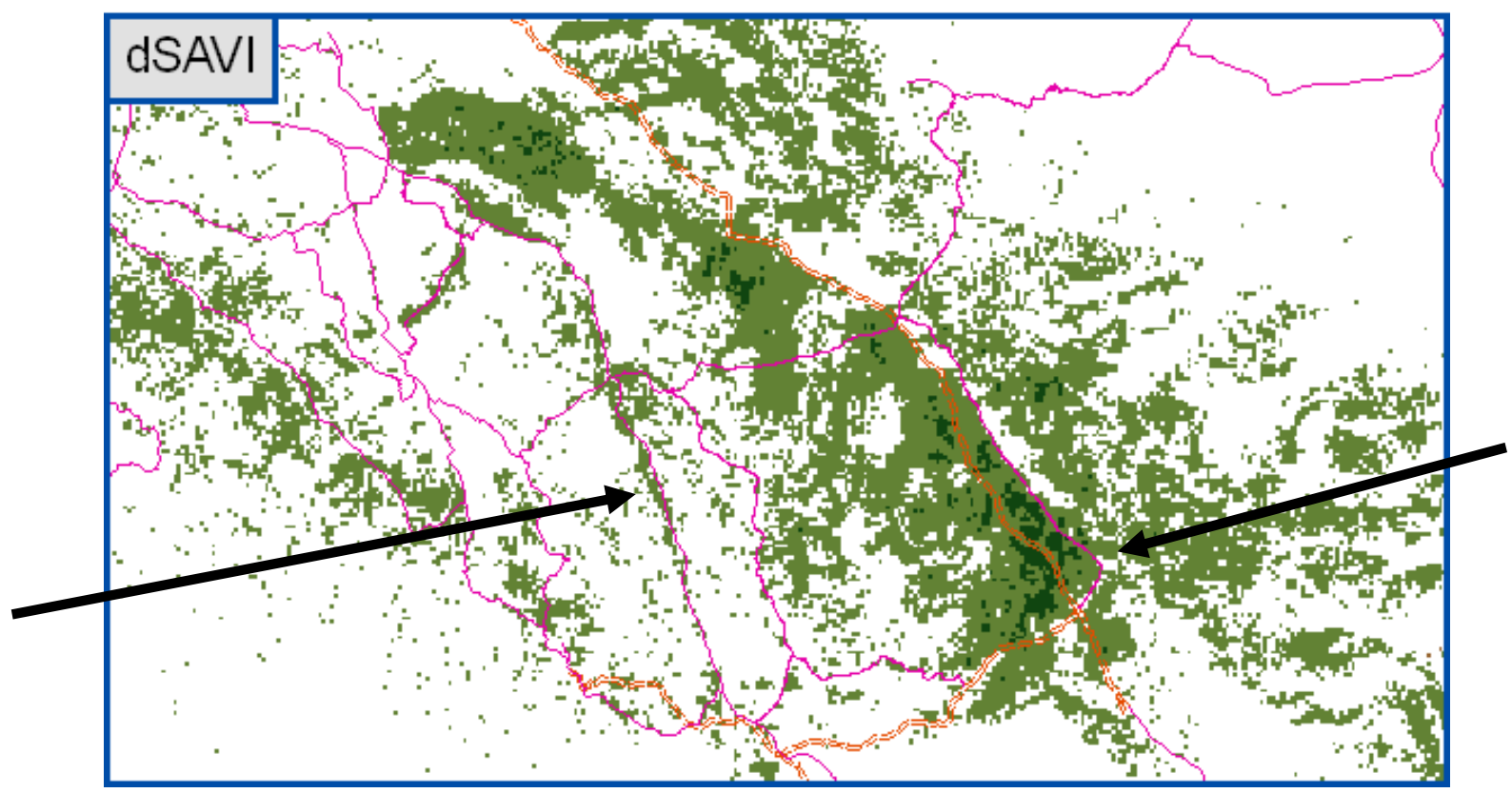

Figure 6-20: 2000s dNDVI and dSAVI, Roads, and Trails 
Figure 6-21 combines difference in SAVI results with areas of human disturbance and brome presence points. Although few of the brome presence points fall on areas of increased vegetation, most of the points are along roads and trails or near campgrounds. This fact gives strong support to the claim that human disturbance promotes annual brome growth, but does not support the use of vegetation indices to map brome extents.

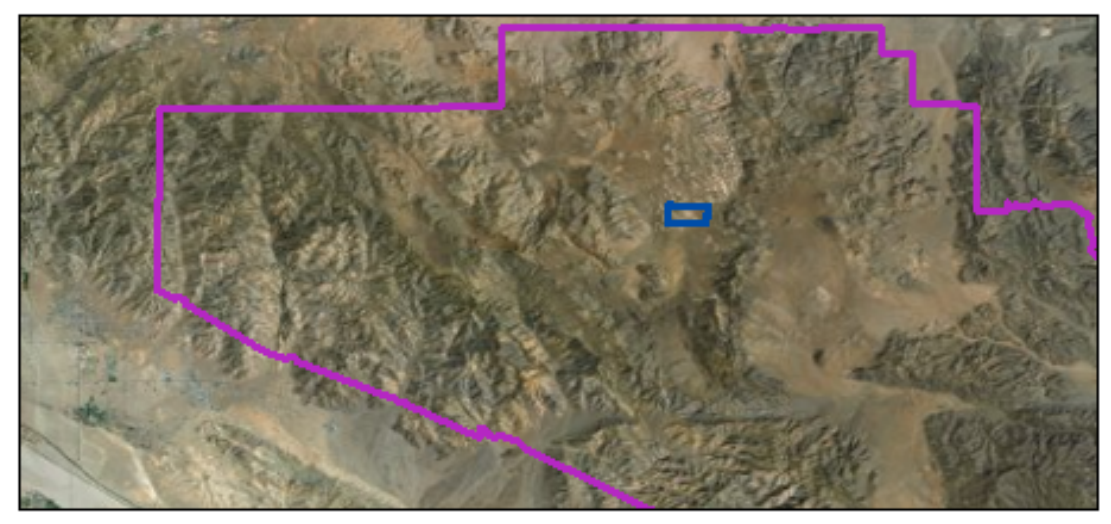

Annual Brome

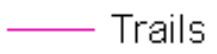

$====$ Dirt Roads

$====: 4 \times 4$ Roads

- Paved Roads

Campgrounds

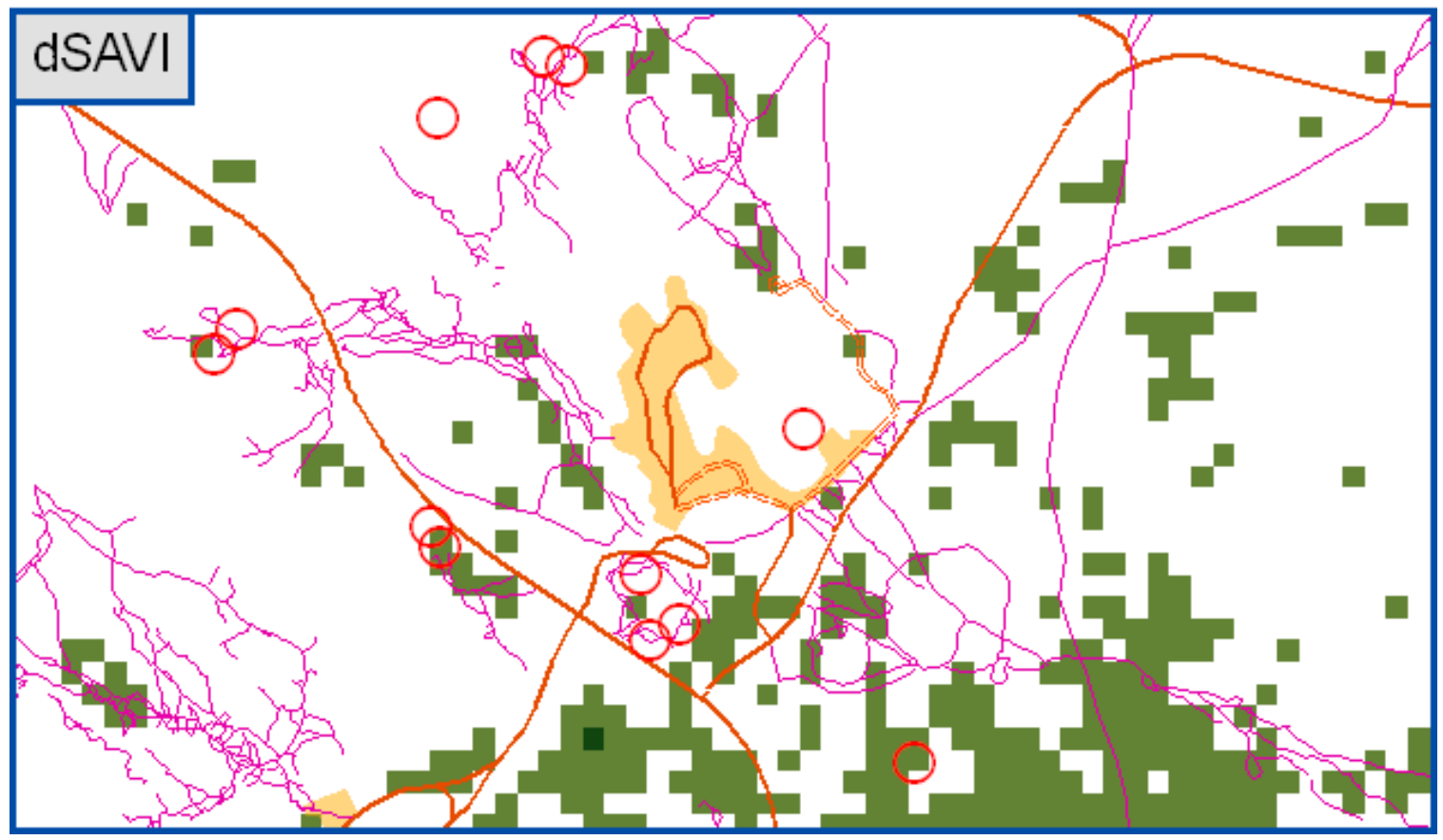

Figure 6-21: 2000s dSAVI, Human Disturbance, Brome Presence Points

Figure 6-22 contradicts the previous example. This figure shows an area with several roads and trails leading to and from a large campground. One would expect to see high difference in vegetation index values or several brome presence points in the area, like Figure 6-21, but this is not the case. There are no brome presence points in the area, and very few pixels with large dSAVI values that suggest increased vegetation. Originally, wildfire was thought to be the difference between the two areas, but upon further analysis it was discovered that neither area had suffered severe wildfire. Field observations and vegetation sampling could help determine exactly what is going on in 
these two regions. Until then, these results cannot be used to accurately map annual brome extent.

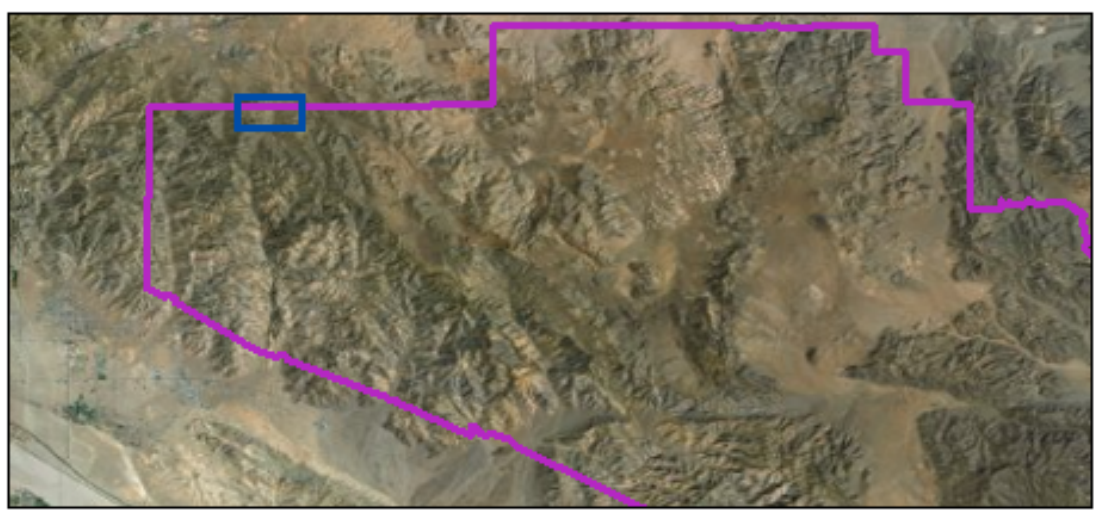

Annual Brome

- Trails

$====$ Dirt Roads

$====: 4 \times 4$ Roads

— Paved Roads

Campgrounds

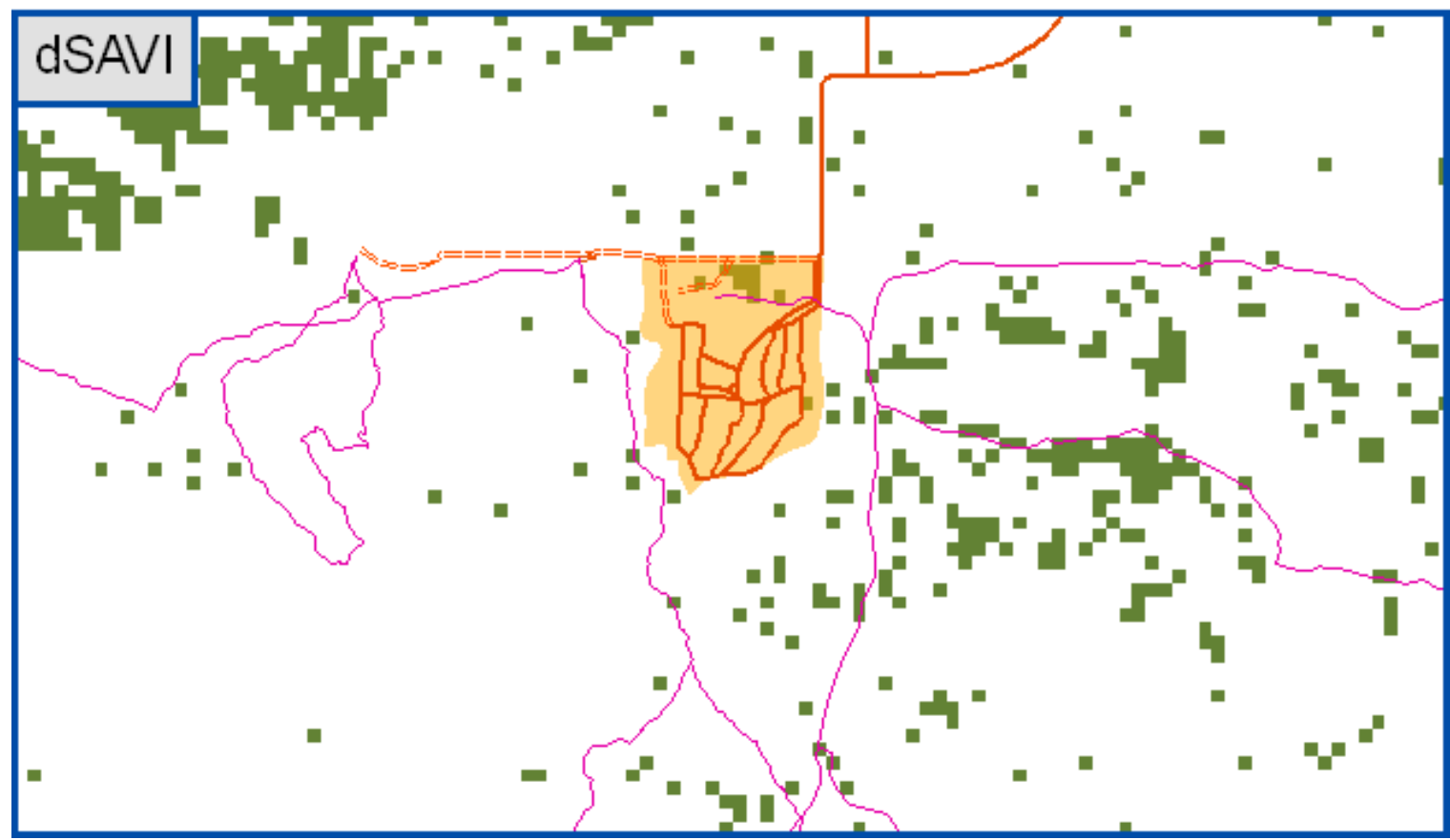

Figure 6-22: 2000s dSAVI and Human Disturbance

\subsection{Summary}

This chapter provided an explanation of the project's analysis and results. The vegetation index results and errors in the vegetation index results were discussed and illustrated. The analysis completed in order to map annual brome extent was also described and examples of key analyses and results were provided. The next chapter concludes the project report, providing suggestions for further research into annual brome at Joshua Tree National Park. 


\section{Chapter 7 - Conclusions and Future Work}

This chapter contains the closing remarks and end results of the project. The chapter describes the project's successes and also gives recommendations for continuing research into annual brome in Joshua Tree National Park.

\subsection{Conclusions}

The purpose of this project was to support land management and wildfire mitigation efforts in JTNP through an accurate mapping of the infestation of annual brome. The goal of the project was to build a GIS that would map the current extent of annual brome within the park, map past annual brome extents to be used to analyze the spread of annual brome, and map areas of human disturbance and historic fire disturbance to be used to analyze the effects of these data on annual brome growth within the park. The methods of Bradley and Mustard (2005) were used to create the GIS.

The GIS was successfully built and delivered in an ArcGIS Desktop map interface. The interface includes three decades of vegetation index data that were used in the annual brome extent analysis. The interface also provides a set of tools to calculate vegetation indices from Landsat TM imagery converted to reflectance values. These tools allow the user to further this research in JTNP or apply the project's methods to another study area. In addition to vegetation indices, the interface contains historic fire data with custom symbolization, human disturbance data, and point data representing known annual brome presence.

The project was successful in recreating the methods of Bradley and Musard (2005) for JTNP, and producing maps of potential annual brome growth within the park. These areas of potential growth need verification as the scope of this project did not include field observations or ground truthing. It was discovered that vegetation indices alone cannot be used to accurately map the extent of annual brome, field sampling is necessary. However, a visual analysis of the potential annual brome extents was successfully completed and discussed in Chapter 6. The project was successful in mapping areas of human disturbance and fire disturbance and these data were used in the visual analysis of annual brome extent. The interface gives the user the ability to explore the data, perform a visual analysis, and make conclusions and decisions based on these observations and the user's expertise. The user is also free to add other data to the interface to be used in analysis.

\subsection{Future Work}

While an accurate mapping of annual brome extent was not produced at the completion of this project, the continuation of this research in the future could meet that goal. With field observation, and a more representative sampling of vegetation within Joshua Tree National Park, analysis similar to Peterson (2003) and Bradley and Mustard (2006) could be completed to map the current extent of annual brome and predict its spread. One example of an appropriate sampling scheme can be found in Bradley and Mustard's (2005) methods. Before calculating vegetation indices, they made 16 field observations 
at three types of vegetation plots: locations with known cheatgrass infestation, areas controlled by native habitat, and salt flats with zero vegetation. These field observations provided a baseline for their research and proved invaluable for analysis. Bradley and Mustard validated their analysis results by repeating field observations at 659 locations that spanned the study area and were accessed by roads. This type of field observation and verification could be recreated at JTNP.

This project was the fourth in a series of projects completed with funding from BASF for annual brome research. Future work could include developing a decision support system similar to the work of Armstrong (2007) and Murphy (2008) using accurate annual brome extent data. A website could be created to deliver the decision support system over the Web.

BASF has also provided several recommendations to continue the work of previous projects. In personal correspondence from BASF biologists to Murphy in January, 2008, the following additions to the work of Esh (2006) and Armstrong (2007) were listed:

a) Addition of historic fire disturbance as infested site prediction

b) Addition of a default factor when no historic/current infested area data is available

c) Addition of a print option that incorporates a legend

d) Probability of fire based on factors of typical fire starting activities and location

e) Suggested fuel break locations, such as, along roadsides, under utility lines, around urban areas, interface between high fire damage areas (as indicated by Murphy's pine beetle research) and brome infested areas.

Some of these suggestions have already been addressed in this and previous projects, but there are opportunities for further research. This project incorporated historic fire disturbance into analysis, and the print option for web applications became standard functionality in ArcGIS 9.3. While a) and c) have been completed, recommendations b), d), and e) would be important additions to the current research.

\subsection{Summary}

BASF was looking to provide information to possible users of Plateau. This project successfully created a useful information product for land managers at Joshua Tree National Park. This map interface was developed using remote sensing techniques and geographic information systems (GIS). This project report provides helpful information for determining how to solve the problem of annual brome within national parks. While the project did not yield an accurate map of the extent of annual brome within Joshua Tree National Park, its map interface provides land managers the tools to continue the research and make informed fire management decisions. 


\section{Works Cited}

Armstrong, C. E. (2007). Annual Brome (Bromus tectorum) Wildfire Fuel Breaks: Webenabled GIS Wildfire Model Decision Support System. Unpublished Major Individual Project, University of Redlands, Redlands, CA.

BASF. (2009a). BASF The Chemical Company. Retrieved July 2, 2009, from BASF at a glance: http://www.basf.com/group/corporate/en/about-basf/profile/index

BASF. (2009b). Retrieved July 2, 2009, from Plateau Herbicide: http://www.vmanswers.com/products/plateau-herbicide.html

Bossard, C. C., Randall, J. M., \& Hoshovsky, M. C. (2000). Invasive Plants of California's Wildlands. Berkeley: University of California Press.

Bradley, B. A., \& Mustard, J. F. (2005). Identifying land cover variability distinct from land cover change: Cheatgrass in the Great Basin. Remote Sensing of Environment, 94, 204-213.

Bradley, B. A., \& Mustard, J. F. (2006). Characterizing the landscape dynamics of an invasive plant and risk of invasion using remote sensing. Ecological Applications, 16(3), 1132-1147.

Brooks, M. L. (2000). Bromus madritensis ssp. rubens. In C. C. Bossard, J. M. Randall, \& M. C. Hoshovsky, Invasive Plants of California's Wildlands. Berkeley, CA: University of California Press.

Brooks, M. L., \& Matchett, J. R. (2006). Spatial and temporal patterns of wildfires in the Mojave, 1980-2004. Journal of Arid Environments, 67, 148-164.

Chander, G., Markham, B. L., \& Helder, D. L. (2009). Summary of current radiometric calibration coefficients for Landsat MSS, TM, ETM+,. Remote Sensing of Environment, 113, 893-903.

Eaker, D., \& Decker, C. (2009, September 08). Zion National Park Announces Limited Trail Closures and Road Delays for Aerial Herbicide Spraying and Seeding Project. Retrieved February 25, 2010, from Zion National Park: http://www.nps.gov/zion/parknews/zion-national-park-announces-limited-trailclosures-and-road-delays-for-aerial-herbicide-spraying-and-seeding-project.htm

Esh, H. (2006). The Wildland/Urban Interface: Cheatgrass, Fire Danger, and, Fuel Breaks. Unpublished Major Individual Project, University of Redlands, Redlands, CA.

Fuhrmann, K., Weber, K., \& Decker, C. (2009). Restoring burned areas at Zion National Park (Utah). Ecological Restoration, 27(2), 132-134.

Gillham, J. H. (2001). Invasive Species Inventory and Weed Susceptibility Prediction Model for Southwestern Wyoming. University of Wyoming, Laramie.

Huete, A. R., Liu, H. Q., Batchily, K., \& van Leeuwen, W. (1997). A comparison of vegetation indices over a gobal set of TM images for EOS-MODIS. Remote Sensing of Environment, 59, 440-451.

JTNP. (2006a, August 8). A Desert Park. Retrieved January 20, 2010, from Joshua Tree National Park: http://www.nps.gov/jotr/planyourvisit/desertpark.htm

JTNP. (2006b, August 3). Nonnative Species. Retrieved January 20, 2010, from Joshua Tree National Park: http://www.nps.gov/jotr/naturescience/nonnativespecies.htm

JTNP. (2009a, July 13). Park History. Retrieved January 25, 2010, from Joshua Tree National Park: http://www.nps.gov/jotr/historyculture/parkhistory.htm 
JTNP. (2009b, June 23). Fire Regime. Retrieved February 20, 2010, from Joshua Tree National Park: http://www.nps.gov/jotr/naturescience/fireregime.htm

Lee, J. K. (2009). Monitoring Trails and Disturbance in Joshua Tree National Park. Unpublished Major Individual Project, University of Redlands, Redlands, CA.

Mangi Environmental Group. (2005). Joshua Tree National Park Fire Management Plan Environmental Assessment.

Murphy, S. P. (2008). Integrating an Agent-based Model into a Web-Enabled Annual Brome Land Management System. Unpublished Major Individual Project, University of Redlands, Redlands, CA.

Peterson, E. B. (2005). Estimating cover of an invasive grass (Bromus tectorum) using tobit regression and phenology derived from two dates of Landsat ETM+ data. International Journal of Remote Sensing, 26(12), 2491-2507.

Peterson, E. B. (2003). Mapping Percent-Cover of the Invasive Species Bromus tectorum (Cheatgrass) over a Large Portion of Nevada from Satellite Imagery. Report for the U.S. Fish and Wildlife Service, Nevada State Office, Reno, by the Nevada Natural Heritage Program, Carson City.

Skinner, M., Ogle, D. G., St. John, L., Briggs, J., \& Neese, E. (2008, October 1). Plant Guide: Cheatgrass. Bromus tectorum L. Retrieved January 25, 2010, from United States Department of Agriculture Natural Resources Conservation Service PLANTS Database: http://plants.usda.gov/plantguide/pdf/pg_brte.pdf

Young, J. (2000). Bromus tectorum. In C. C. Bossard, J. M. Randall, \& M. C. Hoshovsky, Invasive Plants of California's Wildlands. Berkeley, CA: University of California Press. 


\section{Appendix A. Calculation of Wet/Dry Years}

Process completed to determine wet/dry years for analysis:

- Downloaded monthly precipitation totals from California Data Exchange website.

- Added these monthly totals to obtain yearly precipitation totals.

- Calculated the mean yearly precipitation for the entire time period.

- Calculated the difference between each year's total and the mean.

- Negative differences indicated relatively low precipitation and positive differences indicated relatively high precipitation. 
Table 4. Data Used to Select Wet and Dry Years

\begin{tabular}{|c|c|c|}
\hline Year & Precipitation (in) & Total - Average \\
\hline 1980 & 29.76 & 24.65787879 \\
\hline 1981 & 0 & -5.102121212 \\
\hline 1982 & 0 & -5.102121212 \\
\hline 1983 & 0 & -5.102121212 \\
\hline 1984 & 6.76 & 1.657878788 \\
\hline 1985 & 0 & -5.102121212 \\
\hline 1986 & 0 & -5.102121212 \\
\hline 1987 & 3.61 & -1.492121212 \\
\hline 1988 & 1.88 & -3.222121212 \\
\hline 1989 & 2.29 & -2.812121212 \\
\hline 1990 & 2.04 & -3.062121212 \\
\hline 1991 & 4.75 & -0.352121212 \\
\hline 1992 & 7.37 & 2.267878788 \\
\hline 1993 & 4.34 & -0.762121212 \\
\hline 1994 & 3.73 & -1.372121212 \\
\hline 1995 & 3.69 & -1.412121212 \\
\hline 1996 & 1.69 & -3.412121212 \\
\hline 1997 & 8.54 & 3.437878788 \\
\hline 1998 & 3.51 & -1.592121212 \\
\hline 1999 & 3.37 & -1.732121212 \\
\hline 2000 & 3.29 & -1.812121212 \\
\hline 2001 & 3.55 & -1.552121212 \\
\hline 2002 & 0.58 & -4.522121212 \\
\hline 2003 & 6.91 & 1.807878788 \\
\hline 2004 & 7.16 & 2.057878788 \\
\hline 2005 & 9.88 & 4.777878788 \\
\hline 2006 & 0 & -5.102121212 \\
\hline 2007 & 3.55 & -1.552121212 \\
\hline 2008 & 4.29 & -0.812121212 \\
\hline 2009 & 0 & -5.102121212 \\
\hline 2010 & 0 & -5.102121212 \\
\hline
\end{tabular}




\section{Appendix B. DN to Radiance Conversion Equations}

$$
\begin{aligned}
& \text { RAD1984_B3 }=1.043976 * \text { FLOAT(TM5061984_B3) }-2.21 \\
& \text { RAD1984_B4 }=0.876024 * \text { FLOAT(TM5061984_B4) }-2.39 \\
& \text { RAD1987_B3 }=1.043976 * \text { FLOAT(TM5311987_B3) }-2.21 \\
& \text { RAD1987_B4 }=0.876024 * \text { FLOAT(TM5311987_B4) }-2.39 \\
& \text { RAD1997_B3 }=1.043976 * \text { FLOAT(TM5101997_B3) }-2.21 \\
& \text { RAD1997_B4 }=0.876024 * \text { FLOAT(TM5101997_B4) }-2.39 \\
& \text { RAD1999_B3 }=1.043976 * \text { FLOAT(TM5161999_B3) }-2.21 \\
& \text { RAD1999_B4 }=0.876024 * \text { FLOAT(TM5161999_B4) }-2.39 \\
& \text { RAD2004_B3 }=1.043976 * \text { FLOAT(TM5132004_B3) }-2.21 \\
& \text { RAD2004_B4 }=0.876024 * \text { FLOAT(TM5132004_B4) }-2.39 \\
& \text { RAD2007_B3 }=1.043976 * \text { FLOAT(TM5062007_B3) }-2.21 \\
& \text { RAD2007_B4 }=0.876024 * \text { FLOAT(TM5062007_B4) }-2.39
\end{aligned}
$$




\title{
Appendix C. Radiance to Reflectance Conversion Equations
}

\author{
REF1984_B3 $=\left(\mathrm{PI} * \mathrm{RAD} 1984 \_\mathrm{B} 3 * 1.00904\right) /(1536 * \operatorname{SIN}(58.91 * 0.01745))$ \\ REF1984_B4 $=(\mathrm{PI} *$ RAD1984_B4 * 1.00904) $/(1031 * \operatorname{SIN}(58.91 * 0.01745))$ \\ REF1987_B3 $=(\mathrm{PI} *$ RAD1987_B3 * 1.01387) $/(1536 * \operatorname{SIN}(61.17 * 0.01745))$ \\ REF1987_B4 $=(\mathrm{PI} *$ RAD1987_B4 *1.01387) $/(1031 * \operatorname{SIN}(61.17 * 0.01745))$ \\ REF1997_B3 $=(\mathrm{PI} *$ RAD1997_B3 *1.00975) $/(1536 * \operatorname{SIN}(59.77 * 0.01745))$ \\ REF1997_B4 $=(\mathrm{PI} *$ RAD1997_B4 * 1.00975) $/(1031 * \operatorname{SIN}(59.77 * 0.01745))$ \\ REF1999_B3 $=(\mathrm{PI} *$ RAD1999_B3 * 1.01108) $/(1536 * \operatorname{SIN}(62.42 * 0.01745))$ \\ REF1999_B4 $=(\mathrm{PI} *$ RAD1999_B4 * 1.01108) $/(1031 * \operatorname{SIN}(62.42 * 0.01745))$ \\ REF2004_B3 $=\left(\mathrm{PI} * \mathrm{RAD} 2004 \_\mathrm{B} 3 * 1.01065\right) /(1536 * \operatorname{SIN}(62.53 * 0.01745))$ \\ REF2004_B4 $=(\mathrm{PI} *$ RAD2004_B4 * 1.01065) $/(1031 * \operatorname{SIN}(62.53 * 0.01745))$ \\ REF2007_B3 $=(\mathrm{PI} *$ RAD2007_B3 *1.00880 $) /(1536 * \operatorname{SIN}(63.40 * 0.01745))$ \\ REF2007_B4 $=(\mathrm{PI} *$ RAD2007_B4 * 1.00880) $/(1031 * \operatorname{SIN}(63.40 * 0.01745))$
}

